\title{
A multi-year study of lower tropospheric aerosol variability and systematic relationships from four North American regions
}

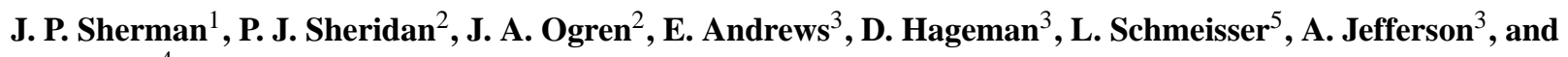 \\ S. Sharma ${ }^{4}$ \\ ${ }^{1}$ Dept. Physics and Astronomy, Appalachian State University, 525 Rivers St, \\ CAP Building, Room 231, Boone, NC 28608, USA \\ ${ }^{2}$ NOAA, Earth Systems Research Laboratory, Global Monitoring Division/GMD-1, \\ 325 Broadway, Boulder, CO 80305, USA \\ ${ }^{3}$ CIRES, University of Colorado, Boulder, CO, 80309, USA \\ ${ }^{4}$ Environment Canada, 4905 Dufferin St, Toronto, ON, M3H 5T4 Canada \\ ${ }^{5}$ Dept. Atmospheric Sciences, University of Washington, Seattle, WA 98195, USA
}

Correspondence to: J. P. Sherman (shermanjp@appstate.edu)

Received: 28 September 2014 - Published in Atmos. Chem. Phys. Discuss.: 28 October 2014

Revised: 16 October 2015 - Accepted: 23 October 2015 - Published: 10 November 2015

\begin{abstract}
Hourly averaged aerosol optical properties (AOPs) measured over the years 2010-2013 at four continental North American NOAA Earth System Research Laboratory (NOAA/ESRL) cooperative aerosol network sites - Southern Great Plains near Lamont, OK (SGP), Bondville, IL (BND), Appalachian State University in Boone, NC (APP), and Egbert, Ontario, Canada (EGB) are analyzed. Aerosol optical properties measured over 1996-2009 at BND and 19972009 at SGP are also presented. The aerosol sources and types in the four regions differ enough so as to collectively represent rural, anthropogenically perturbed air conditions over much of eastern continental North America. Temporal AOP variability on monthly, weekly, and diurnal timescales is presented for each site. Differences in annually averaged AOPs and those for individual months at the four sites are used to examine regional AOP variability. Temporal and regional variability are placed in the context of reported aerosol chemistry at the sites, meteorological measurements (wind direction, temperature), and reported regional mixing layer heights. Basic trend analysis is conducted for selected AOPs at the long-term sites (BND and SGP). Systematic relationships among AOPs are also presented.

Seasonal variability in $\mathrm{PM}_{1}$ (sub-1 $\mu \mathrm{m}$ particulate matter) scattering and absorption coefficients at $550 \mathrm{~nm}\left(\sigma_{\mathrm{sp}}\right.$ and $\sigma_{\mathrm{ap}}$, respectively) and most of the other $\mathrm{PM}_{1}$ AOPs is much larger than day of week and diurnal variability at all sites. All sites
\end{abstract}

demonstrate summer $\sigma_{\text {sp }}$ and $\sigma_{\text {ap }}$ peaks. Scattering coefficient decreases by a factor of 2-4 in September-October and coincides with minimum single-scattering albedo $\left(\omega_{0}\right)$ and maximum hemispheric backscatter fraction $(b)$. The covariation of $\omega_{0}$ and $b$ lead to insignificant annual cycles in top-of-atmosphere direct radiative forcing efficiency (DRFE) at APP and SGP. Much larger annual DRFE cycle amplitudes are observed at EGB $(\sim 40 \%)$ and BND $(\sim 25 \%)$, with least negative DRFE in September-October at both sites. Secondary winter peaks in $\sigma_{\mathrm{sp}}$ are observed at all sites except APP. Amplitudes of diurnal and weekly cycles in $\sigma_{\text {ap }}$ at the sites are larger for all seasons than those of $\sigma_{\mathrm{sp}}$, with the largest differences occurring in summer. The weekly and diurnal cycle amplitudes of most intensive AOPs (e.g., those derived from ratios of measured $\sigma_{\mathrm{sp}}$ and $\sigma_{\mathrm{ap}}$ ) are minimal in most cases, especially those related to parameterizations of aerosol size distribution.

Statistically significant trends in $\sigma_{\mathrm{sp}}$ (decreasing), $\mathrm{PM}_{1}$ scattering fraction (decreasing), and $b$ (increasing) are found at BND from 1996 to 2013 and at SGP from 1997 to 2013. A statistically significant decreasing trend in $\mathrm{PM}_{10}$ scattering Ångström exponent is also observed for SGP but not BND. Most systematic relationships among AOPs are similar for the four sites and are adequately described for individual seasons by annually averaged relationships, although 
relationships involving absorption Ångström exponent vary with site and season.

\section{Introduction}

Predictions of future climate change resulting from projected increases in carbon dioxide are limited by large uncertainties in the direct and indirect radiative forcing due to aerosols (Andreae et al., 2005). Measurement-based estimates of globally averaged aerosol direct radiative forcing (DRF) are 55-80\% greater than the model-based estimates (Yu et al., 2009). The measurement-model differences are even larger on regional scales and for the anthropogenic component (Yu et al., 2009). Such measurement-model discrepancies are the result of a combination of differences in aerosol amount, single-scattering albedo, surface albedo, and radiative transfer schemes (Yu et al., 2006). One of the high-priority tasks recommended to reduce the uncertainty in aerosol radiative effects is to "maintain, enhance, and expand the surface observation networks measuring aerosol optical properties for satellite retrieval validation, model evaluation, and climate change assessments" (Kahn et al., 2009).

Studies based on long-term measurements made by global surface-based aerosol monitoring networks such as NASA's Aerosol Robotic Network (AERONET) and NOAA's Earth System Research Laboratory (NOAA/ESRL) have contributed to improved understanding of mean values of aerosol optical properties (AOPs), spatial and temporal AOP variability, and relationships among some AOPs (Dubovik et al., 2005; Delene and Ogren, 2002; hereafter referred to as D\&O2002). The US-based Interagency Monitoring of Protected Visual Environments (IMPROVE) network (Malm et al., 2004) has conducted similar studies using speciated aerosol mass concentrations, aerosol light scattering coefficient (at some sites), and reconstructed aerosol light extinction coefficient measurements in remote areas of the US. Recent long-term trend studies based on data from surface networks indicated that aerosol optical depth ( $\mathrm{Li}$ et al., 2014; Yoon et al., 2012) and lower tropospheric aerosol light scattering coefficient (Collaud-Coen et al., 2013; hereafter referred to as CC2013) decreased at a majority of North American aerosol monitoring sites. Hand et al. (2014) reported large reductions of up to $50 \%$ in reconstructed aerosol visible light extinction for the $20 \%$ haziest days annually at IMPROVE sites in the US from 2002 to 2011, with the largest decreases in the eastern US. Through trend analysis of speciated aerosol mass concentrations and emissions inventories, Hand et al. (2014) showed that reductions in $\mathrm{US} \mathrm{SO}_{2}$ emissions have likely played a major role in the reduced aerosol light extinction, particularly in the eastern US. Murphy et al. (2011) applied trend analysis to data from IMPROVE sites across the US to show that elemental carbon aerosol mass concentrations decreased by over $25 \%$ between 1990 and 2004, with reductions during winter months close to $50 \%$. Region- and season-dependent changes in emissions of aerosols and precursor gases may result in changes in mean values and variability of aerosol optical and microphysical properties. However, few long-term studies of aerosol intensive properties (e.g., properties that are independent of aerosol loading, such as single scattering albedo, asymmetry parameter, and direct radiative forcing efficiency) have been conducted in or over multiple North American regions.

Surface-based networks employing in situ measurements of aerosol optical properties, such as the WMO Global Atmosphere Watch (GAW) and NOAA/ESRL aerosol networks are particularly well-suited for studies of aerosol variability on a variety of temporal scales under both clear and cloudy conditions. An additional advantage of the in situ measurements is the ability to derive single-scattering albedo under low aerosol loading conditions. Column-averaged single scattering albedo derived from sky radiance measurements made by Cimel sun/sky radiometers as part of AERONET possess high uncertainties at the lower aerosol optical depths (AOD) typical of most rural North American sites (Dubovik et al., 2000). A weakness of many in situ surface aerosol measurement systems is the inability to determine the hygroscopic dependence of aerosol light scattering. Many aerosol monitoring stations in the NOAA/ESRL and GAW networks follow similar sampling protocols where the aerosols are dried to decouple the aerosol properties from local variations in relative humidity $(\mathrm{RH})$. Another concern is the uncertainty as to when and under what conditions the near-surface measurements are representative of the atmospheric column at each site. The first problem can be addressed through the use of humidified light scattering measurements (e.g., Sheridan et al., 2001), which are or have been made at a few ESRL network sites, including three of the four sites reported in this paper. The second issue has been investigated through multiyear aircraft measurement programs over instrumented surface sites. At the Southern Great Plains (near Lamont, OK) and Bondville, IL sites respectively, Andrews et al. (2004) and Sheridan et al. (2012) reported that median values of key low-RH intensive AOPs exhibited little statistical variability up to $\sim 2 \mathrm{~km}$ altitude and that long-term median values could be well-approximated by the near-surface values. Instantaneous measurements of the near-surface properties were often poorly correlated with those of the column at these sites. (Andrews et al., 2004; Sheridan et al., 2012).

D\&O2002 reported multi-year measurements of AOPs at four North American sites that were used to (1) highlight the need to quantify both aerosol extensive properties (e.g., properties that depend on aerosol amount) and aerosol intensive properties on regional scales over at least a 1-year period; and (2) conclude that global AOD measurements made daily by satellites, combined with in situ measurements of regionally representative intensive AOPs, are likely sufficient to determine aerosol DRF with a relatively small amount of uncertainty. One limitation of their study was the then lack of 
NOAA/ ESRL network sites in the more populous eastern continental North America. D\&O2002 also studied systematic relationships between aerosol loading (using scattering coefficient as a proxy) and other AOPs. D\&O2002 argued the importance of such relationships for applications including inversion of remote sensing data, whereby a dynamic model could be used to specify the constraining AOPs as a function of aerosol loading.

The study described here utilizes 4 years (2010-2013) of continuous measurements of aerosol light absorption, scattering, and hemispheric backscattering coefficients made at four continental North American sites (Fig. 1; Table 1) in the NOAA/ESRL cooperative aerosol network: (i) the Appalachian Atmospheric Interdisciplinary Research facility at Appalachian State University (APP) in Boone, NC, located in the southern Appalachian mountain region of the southeastern US; (ii) the Bondville Environmental and Atmospheric Research Site (BND), located in the agricultural midwestern US near Champaign, IL; (iii) the Environment Canada monitoring station at Egbert, Ontario (EGB), located in the agricultural and forested rural region N/NW of Toronto; and (iv) the Southern Great Plains Central Facility (SGP) of the US Department of Energy Atmospheric Radiation Measurement program (DOE ARM), located in the southern plains of the US in rural Oklahoma. We use these measurements to calculate several key AOPs relevant to aerosol radiative forcing (Table 2). Hourly averaged AOPs are binned by month, day of week, and hour of day to study annual, weekly, and diurnal AOP cycles at each site. AOPs are also binned by wind sector for each season to study the role of known regional aerosol sources on AOPs and their variability at each site. Published aerosol chemistry for each site and its seasonal variability are used along with published mixing layer heights for each region and monthly median temperatures at the sites to help explain the AOP cycles at each site and differences among sites. Basic trend analysis is conducted for selected AOPs at the long-term sites (BND and SGP). Systematic relationships among AOPs are also presented. The objectives are to

1. provide an explanation of temporal and regional AOP variability that is consistent with meteorology, regional aerosol sources, and reported aerosol chemistry at the sites;

2. identify possible AOP trends at the long-term sites (SGP and BND);

3. determine whether systematic relationships exist for key aerosol properties relevant to aerosol DRF calculations.

In addition to our use of meteorology and published aerosol chemistry to interpret the AOP variability, this study differs from the D\&O2002 paper in three respects.

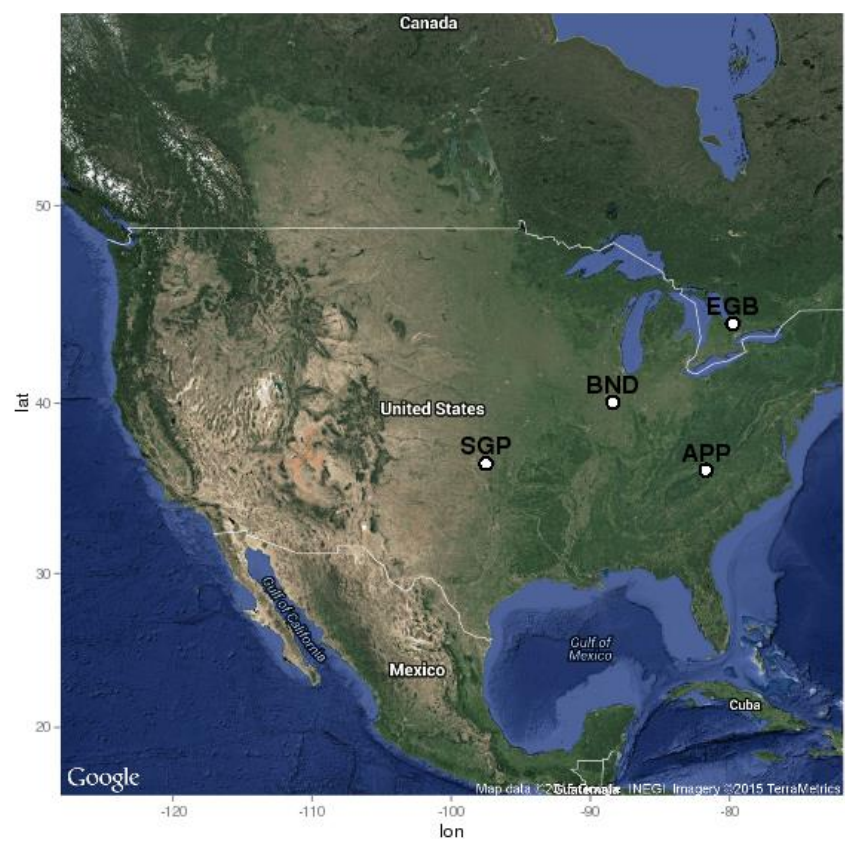

Figure 1. Locations of the four NOAA-ESRL sites in this study: Southern Great Plains, OK, (SGP); Bondville, IL (BND); Appalachian State (APP) in Boone, NC; and Egbert, Ontario, Canada (EGB).

1. The time period of the study is different, which allows us to compare (at least for BND and SGP) how the AOPs have changed in the intervening years.

2. This paper has a focus on continental sites, whereas D\&O2002's four sites included an Arctic site and a marine site.

3. We report the following for individual seasons: (a) diurnal and weekly AOP variability, and (b) some systematic relationships involving aerosol absorption Ångström exponent. D\&O2002 reported select AOPs for full years.

\section{Methodology}

\subsection{Air sampling infrastructure at the sites}

The APP, BND, EGB, and SGP sites are all designed with similar inlet systems following established NOAA/ESRL and GAW aerosol sampling protocols (e.g., Sheridan et al., 2001; WMO, 2003). To minimize contamination from local activities around the stations, ambient aerosols are sampled from the top of sampling stacks that are well above the surrounding terrain. The top of the stack is $10 \mathrm{~m}$ above the ground at BND, EGB, and SGP. The sampling inlet at APP is located at the top of a $34 \mathrm{~m}$ tall tower in order to sample aerosols at a height $>5 \mathrm{~m}$ above the surrounding tree canopy. 
Table 1. Sites, instruments and data period included in the study, listed from west to east. Aerosol sampling size cuts and the instrument used to measure absorption are also included. All sites use a TSI 3563 3- $\lambda$ nephelometer ${ }^{\mathrm{a}}$ to measure total scattering and hemispheric backscattering.

\begin{tabular}{|c|c|c|c|c|c|c|}
\hline Site & $\begin{array}{l}\text { Lat/Long } \\
\text { (deg.) }\end{array}$ & $\begin{array}{r}\text { Elev. } \\
\text { (ma.s.1.) }\end{array}$ & $\begin{array}{r}\text { Years data } \\
\text { used }\end{array}$ & $\begin{array}{l}\text { \# hours used } \\
\text { 2010-2013 }\end{array}$ & $\begin{array}{r}\text { Size cut } \\
\qquad(\mu \mathrm{m})\end{array}$ & $\begin{array}{l}\text { Absorption instrument } \\
\text { (dates used mm/yy) }\end{array}$ \\
\hline SGP & $36.6 \mathrm{~N}, 97.5 \mathrm{~W}$ & 315 & $1997-2013^{\mathrm{e}}$ & $\begin{array}{l}32971\left(\sigma_{\mathrm{sp}}\right) \\
25140\left(\sigma_{\mathrm{ap}}\right)\end{array}$ & 1.10 & $3-\lambda \operatorname{PSAP}^{\mathrm{c}}(01 / 10-12 / 13)$ \\
\hline BND & $40.0 \mathrm{~N}, 88.4 \mathrm{~W}$ & 230 & 1996-2013 & $\begin{array}{l}33449\left(\sigma_{\mathrm{sp}}\right) \\
32040\left(\sigma_{\mathrm{ap}}\right)\end{array}$ & 1.10 & $\begin{array}{l}1-\lambda \operatorname{PSAP}^{\mathrm{b}}(09 / 96-02 / 06) \\
3-\lambda \operatorname{PSAP}^{(03 / 06-02 / 12)} \\
3-\lambda \operatorname{CLAP}^{\mathrm{d}}(03 / 12-12 / 13)\end{array}$ \\
\hline EGB & $44.2 \mathrm{~N}, 79.8 \mathrm{~W}$ & 253 & 2010-2013 & $\begin{array}{l}32448\left(\sigma_{\mathrm{sp}}\right) \\
26304\left(\sigma_{\mathrm{ap}}\right)\end{array}$ & & $1-\lambda$ PSAP $(01 / 10-12 / 13$ \\
\hline APP & $36.2 \mathrm{~N}, 81.7 \mathrm{~W}$ & 1080 & 2010-2013 & $\begin{array}{l}34220\left(\sigma_{\mathrm{sp}}\right) \\
34178\left(\sigma_{\mathrm{ap}}\right)\end{array}$ & 1.10 & $3-\lambda$ PSAP $(01 / 10-12 / 13)$ \\
\hline
\end{tabular}

a $3-\lambda$ TSI nephelometer measures at $\lambda=450,550,700 \mathrm{~nm} ;{ }^{b} 1-\lambda$ PSAP measures at $565 \mathrm{~nm}$, adjusted to $550 \mathrm{~nm}$ using Bond et al. (1999) correction; ${ }^{\mathrm{c}} 3-\lambda$ PSAP measures at $467,530,660 \mathrm{~nm} ;{ }^{\mathrm{d}} 3-\lambda$ CLAP measures at $467,529,653 \mathrm{~nm}$; ${ }^{\mathrm{e}}$ SGP aerosol light scattering data from 1997 to 2013 are used, but absorption data are only used from 2010 to 2013.

Table 2. Parameters and equations used to calculate aerosol optical properties. Constants and parameters used in the formula to calculate globally averaged top-of-atmosphere direct radiative forcing (DRFE) for each site are also included and are denoted with **.

\begin{tabular}{ll}
\hline Parameter & Equation (or value) \\
\hline Extinction coefficient & $\sigma_{\mathrm{ep}}=\sigma_{\mathrm{sp}}+\sigma_{\mathrm{ap}}$ \\
Single-scattering albedo & $\omega_{0}=\sigma_{\mathrm{sp}} / \sigma_{\mathrm{ep}}=\sigma_{\mathrm{sp}} /\left(\sigma_{\mathrm{sp}}+\sigma_{\mathrm{ap}}\right)$ \\
Hemispheric backscatter fraction & $b=\sigma_{\mathrm{bsp}} / \sigma_{\mathrm{sp}}$ \\
Scattering Ångström exponent & $\alpha_{\mathrm{sp}}=-\log \left(\sigma_{\mathrm{sp}}\left(\lambda_{1}\right) / \sigma_{\mathrm{sp}}\left(\lambda_{2}\right)\right) / \log \left(\lambda_{1} / \lambda_{2}\right)$ \\
Absorption Ångström exponent & $\alpha_{\mathrm{ap}}=-\log \left(\sigma_{\mathrm{ap}}\left(\lambda_{1}\right) / \sigma_{\mathrm{ap}}\left(\lambda_{2}\right)\right) / \log \left(\lambda_{1} / \lambda_{2}\right)$ \\
Sub-micron scattering fraction & $R_{\mathrm{sp}}=\sigma_{\mathrm{sp}, 1} / \sigma_{\mathrm{sp}, 10}$ \\
Sub-micron absorption fraction & $R_{\mathrm{ap}}=\sigma_{\mathrm{ap}, 1} / \sigma_{\mathrm{ap}, 10}$ \\
Direct radiative forcing efficiency & $\mathrm{DRFE}=\mathrm{DRF} / \mathrm{AOD}=-D S_{0} T_{\mathrm{atm}}^{2}\left(1-A_{\mathrm{c}}\right) \beta \omega_{0} \times\left[\left(1-R_{\mathrm{S}}\right)^{2}-\left(2 R_{\mathrm{S}} / \omega_{0} \beta\right)\left(1-\omega_{0}\right)\right]$ \\
Upscatter fraction** & $\beta=0.0817+1.8495 \times b-2.9682 \times b^{2}$ \\
Fractional day length** & $D=0.50(\mathrm{globally}$ averaged) \\
Solar constant** & $S_{0}=1370 \mathrm{~W}$ m \\
Atmospheric transmission** & $T_{\mathrm{atm}}=0.76(\mathrm{globally}$ averaged) \\
Cloud fraction** & $A_{\mathrm{c}}=0.60(\mathrm{globally}$ averaged) \\
Spectrally averaged surface albedo** & $R_{\mathrm{s}}=0.15($ globally averaged) \\
\hline
\end{tabular}

To reduce the confounding effects of relative humidity $(\mathrm{RH})$ on the aerosol measurements, the sample air is gently heated when needed at all sites except EGB to achieve sample line and instrument $\mathrm{RH} \leq 40 \%$ (Sheridan et al., 2001). Nephelometer instrument RH at EGB exceeds $40 \%$ for a majority of hours in July-September, but the moderately elevated instrument RH during these months is not believed to have any substantial impact on the results presented in this paper (Sect. S3 of the Supplement).

All of the sites except EGB use a switched impactor system (e.g., Sheridan et al., 2001) to alternate between sub$10 \mu \mathrm{m}\left(D_{p}<10 \mu \mathrm{m}\right)$ and sub-1 $\mu \mathrm{m}\left(D_{p}<1 \mu \mathrm{m}\right)$ aerodynamic diameter particle size ranges. We refer to the sub-10 $\mu \mathrm{m}$ and sub-1 $\mu \mathrm{m}$ particle size cut ranges using the common convention $\mathrm{PM}_{10}$ and $\mathrm{PM}_{1}$, respectively, where $\mathrm{PM}$ is the acronym for particulate matter. APP and SGP size-cut switching oc- curs every 15 and $30 \mathrm{~min}$, respectively, in order to facilitate ramping of the $\mathrm{RH}$ in the humidograph system that is used to measure the hygroscopic dependence of light scattering (Sheridan et al., 2001). Humidograph data are not reported in this study. Size-cut switching at BND, where there is currently no humidograph system, occurs every 6 minutes. Aerosol concentrations and optical properties typically demonstrate little change on timescales less than $1 \mathrm{~h}$ at APP, BND, and SGP so it is assumed that the same aerosols are sampled for both size cuts at these switching rates over a large majority of hours. The EGB system uses a $1 \mu \mathrm{m}$ cyclone to achieve a fixed $D_{p}<1 \mu \mathrm{m}$ particle size cut so $\mathrm{PM}_{10}$ aerosol properties are not available for EGB. Descriptions of the basic inlet design and sampling strategy, including flow rates, tubing sizes and estimated aerosol losses are provided elsewhere (Sheridan et al., 2001; D\&O2002). 


\subsection{Measurements and instruments}

This study reports on several primary aerosol measurements, including aerosol light scattering $\left(\sigma_{\mathrm{sp}}\right)$, hemispheric backscattering $\left(\sigma_{\mathrm{bsp}}\right)$, and absorption $\left(\sigma_{\mathrm{ap}}\right)$ coefficients (Table 2). Each of these parameters is measured for both the $\mathrm{PM}_{10}$ and $\mathrm{PM}_{1}$ size ranges (only $\mathrm{PM}_{1}$ for EGB) and used to calculate the radiative effects of sub- $1 \mu \mathrm{m}$ particles $\left(\mathrm{PM}_{1}\right)$. Variability of AOPs measured at the APP, BND, and SGP sites over the 2010-2013 time period is similar for the $\mathrm{PM}_{10}$ and $\mathrm{PM}_{1}$ size cuts so this paper focuses primarily on $\mathrm{PM}_{1}$ AOPs (Sect. 2.5) for consistency with EGB measurements. Annually averaged $\mathrm{PM}_{10}$ AOPs and their annual cycles are included in the Supplement that accompanies this paper (Table S5 and Fig. S8).

A three-wavelength (3- $\lambda$ ) integrating nephelometer (Model 3563, TSI Inc., St. Paul, MN) is used at all sites for measurement of $\sigma_{\mathrm{sp}}$ (angular range of $7-170^{\circ}$ ) and $\sigma_{\text {bsp }}$ (angular range of $90-170^{\circ}$ ). Aerosol light absorption coefficients are determined by filter-based instruments that make measurements at wavelengths close to those of the TSI nephelometer (Table 1). A 3- $\lambda$ particle soot absorption photometer (PSAP, Radiance Research, Seattle, WA) is used at APP and SGP for the entire data set and at BND for a majority of the study period. A single wavelength $(1-\lambda)$ PSAP is used at EGB. The PSAPs are modified by placing a small $(\sim 5 \mathrm{~W})$ heater on their internal inlet lines at the connection with the optical block. The temperature of the metal optical block is kept a few degrees higher than the incoming sample air temperature so the $\mathrm{RH}$ of the air stream at the sample and reference filters remains relatively low. The heater is not actively controlled to maintain a specific RH, but RH variability at low RH is not believed to influence the measurements as strongly as RH variability at high RH (Anderson et al., 2003). Laboratory tests indicate that the heater keeps the $\mathrm{RH}$ at the filters below $40 \%$ most of the time. An RH of $50 \%$ at the filter is exceeded only during sampling of very humid air (Sheridan et al., 2012). A new light absorption instrument (Continuous Light Absorption Photometer, CLAP) was recently developed by NOAA/ESRL to eventually replace the PSAP at all stations in the NOAA/ESRL network (Ogren et al., 2013). The CLAP is similar to the PSAP in that particles are collected on a filter of the same material as used in the PSAP and light transmission through the filter is monitored continuously. A major difference between CLAP and PSAP is that instead of a single sample spot, the CLAP has eight sample spots. CLAP filter spots are selected by solenoids that switch to the next sample spot once the filter transmittance drops below a desired limit (typically 0.7). Thus, the CLAP can run 8 times as long as the PSAP before requiring a filter change. The similarity in the CLAP and PSAP instrument designs facilitate the same corrections to the measured $\sigma_{\mathrm{ap}}$. The CLAP replaced the PSAP at BND in March 2012, after a 13-month instrument inter-comparison period. The
PSAP/CLAP comparisons made during the overlap period at BND indicate that the CLAP-measured $\sigma_{\text {ap }}$, when adjusted to common wavelengths, is approximately $2 \%$ lower than PSAP-measured $\sigma_{\text {ap }}$ for each of the three measurement wavelengths (Table 1). The CLAP comes with a small heater built into the optics block and is controlled to a set temperature, typically $39^{\circ} \mathrm{C}$ to minimize $\mathrm{RH}$ effects during sampling.

\subsection{Data processing, quality assurance, and calculated AOPs}

Software developed at NOAA is used to log the data at the sites, automatically transmit the data to NOAA, and ingest the data into the NOAA database. The database is accessible to the individual site mentors via virtual machine software. The virtual machine software includes a graphical user interface for reviewing and editing data as well as tools for extracting the data in a variety of formats and for desired averaging times. The data acquisition, processing and virtual machine software, along with documentation, are opensource and freely available from NOAA (http://www.esrl. noaa.gov/gmd/aero/sw.html). Quality-assured data products for each site in the NOAA/ESRL network are uploaded to the World Data Centre for Aerosols and made available at http://ebas.nilu.no/Default.aspx. The data products available include hourly averaged aerosol number concentrations (not presented in this paper), $\sigma_{\mathrm{sp}}, \sigma_{\mathrm{bsp}}$, and $\sigma_{\mathrm{ap}}$ for the $\mathrm{PM}_{10}$ and $\mathrm{PM}_{1}$ size cuts.

Data quality assurance review for each site is typically performed by the site mentor on a weekly basis. Data during periods of instrument or sampling problems and during times of instrument maintenance are invalidated. Absorption data are flagged for periods when the PSAP or CLAP filter transmission drops to less than 0.7 and invalidated when the filter transmission drops below 0.5 because high filter loading increases the $\sigma_{\text {ap }}$ measurement uncertainty (Bond et al., 1999). The lack of PSAP filter changes on weekends at SGP leads to an under-representation of quality-assured Sunday (all day) and Monday (early morning) $\sigma_{\text {ap }}$ hours over the period of this study. Quality-assured $\sigma_{\text {ap }}$ data at SGP are only available for $38 \%$ of Sunday through Monday morning hours during 2010-2013, vs. $70-80 \%$ of the hours for the rest of the week. Weekend days with low $\sigma_{\text {ap }}$ are thus well-represented at SGP, while weekend days with high $\sigma_{\text {ap }}$ (leading to overloaded PSAP filters) are under-represented. PSAP filters are changed on weekends at the other sites.

Light absorption coefficient measurements at SGP are particularly sensitive to ambient RH fluctuations due to air conditioning cycles, particularly during hot, humid summers. CC2013 did not use SGP $\sigma_{\text {ap }}$ data in their trend analysis for this reason. Excessively high temperatures during the summer months of June-August (and the early part of September) 2010-2012 resulted in high daytime dew points that often were as high as 20 to $22^{\circ} \mathrm{C}$ during the late afternoon. The 
high sample humidity coincided with unusually high noise in the PSAP. The hours with noisy $\sigma_{\text {ap }}$ data were removed. On average this resulted in a $15 \%$ loss or $3.6 \mathrm{~h}$ per day in the data. Since this time, effort was made to lower the sample RH through insulation of the optics block, use of a Nafion drier on the instrument inlet and rerouting the trailer ventilation. Despite the data loss, the SGP summertime $\sigma_{\text {ap }}$ data do not exhibit a remarkable difference compared to the other sites nor does the 2010-2012 time period vary significantly from 2013, when the noise was not as apparent. We include the SGP $\sigma_{\text {ap }}$ data in this paper for the 2010-2013 seasonal, weekly and diurnal cycle studies and the systematic relationships among AOPs. We do not include $\sigma_{\text {ap }}$ or AOPs calculated using $\sigma_{\mathrm{ap}}$ as part of the long term trend analysis.

The four NOAA-ESRL network sites discussed in this paper are located such that there are no major local aerosol sources in the predominant upwind directions, although there are some aerosol sources that are typically downwind that may occasionally be sampled. Brief spikes in aerosol number concentrations, $\sigma_{\mathrm{sp}}, \sigma_{\mathrm{bsp}}$, and/or $\sigma_{\mathrm{ap}}$ are flagged as local contamination by the site mentor. These spikes are usually 15-20 min or less in duration and often coincide with vehicular traffic near the sites or times of peak morning commuter traffic. Broader aerosol peaks are typically retained, as they are characteristic of the sampling environment of the station. One example of a broader aerosol peak not marked as contaminated is elevated $\sigma_{\text {ap }}$ which often persists for hours during mornings with surface inversions or during periods with humid, stagnant air masses.

Hourly averages of $\sigma_{\mathrm{sp}}, \sigma_{\mathrm{bsp}}$, and $\sigma_{\mathrm{ap}}$ are generated after the data have passed the quality assurance tests. The hourly averaged $\sigma_{\mathrm{sp}}$ and $\sigma_{\mathrm{bsp}}$ are adjusted to conditions of standard temperature and pressure ( $T=273.15 \mathrm{~K}, P=1013.25 \mathrm{hPa})$ to facilitate $\sigma_{\mathrm{sp}}$ and $\sigma_{\mathrm{bsp}}$ comparisons among the sites. TSI nephelometer measurements are corrected for nephelometer angular non-idealities including truncation effects (Anderson and Ogren, 1998). PSAP- and CLAP-measured $\sigma_{\text {ap }}$ values are corrected for sample area, flow rate, and non-idealities in the manufacturer's calibration as described in Bond et al. (1999) and Ogren (2010). Absorption Ångström exponent values are used to adjust the spectral $\sigma_{\text {ap }}$ values to those at the nephelometer wavelengths so that intensive AOPs involving both instruments (Table 2) can be calculated.

The primary measurements $\sigma_{\mathrm{sp}}, \sigma_{\mathrm{bsp}}$, and $\sigma_{\mathrm{ap}}$ are used to derive several aerosol properties (Table 2) used in radiative transfer calculations (Haywood and Shine, 1995). These properties have been described in many previous papers (e.g., Sheridan et al., 2001; D\&O2002) so only a brief discussion follows. The light extinction coefficient $\left(\sigma_{\mathrm{ep}}\right)$ is the sum of the scattering and absorption coefficients. The single-scattering albedo $\left(\omega_{0}\right)$ is the fraction of extinction due to scattering, with lower values of $\omega_{0}$ corresponding to stronger aerosol light absorption. The hemispheric backscatter fraction $(b)$ represents the fraction of light scattered into the backward hemisphere in the nephelometer and provides qualitative information on aerosol size, with larger values of $b$ corresponding to optically active particles with smaller diameters. The scattering and absorption Ångström exponents $\left(\alpha_{\mathrm{sp}}\right.$ and $\left.\alpha_{\mathrm{ap}}\right)$ describe the wavelength dependence of light scattering and absorption, respectively. The scattering Ångström exponent (typically in the range $0 \leq \alpha_{\mathrm{sp}} \leq 3$ ) provides semi-quantitative information about the aerosol size distribution, with larger values of $\alpha_{\mathrm{sp}}$ corresponding to size distributions dominated by smaller particles (van de Hulst, 1957). The absorption Ångström exponent can provide information on aerosol type for certain aerosols (e.g., Cazorla et al., 2013; Bergstrom et al., 2007). For example, dust and some types of organic carbon (OC) absorb light strongly in the near-UV and blue-violet regions of the electromagnetic spectrum (the so-called "brown carbon"), corresponding to $\alpha_{\text {ap }}>1$ (Cazorla et al., 2013; Costabile et al., 2013). Absorption by black carbon (BC) decreases as $\lambda^{-1}$ in the near-UV through near-IR, corresponding to $\alpha_{\text {ap }}=1$ (Bergstrom et al., 2002). The sub- $1 \mu \mathrm{m}$ scattering and absorption fractions $R_{\mathrm{sp}}$ and $R_{\text {ap }}$, respectively, indicate the fractions of $\mathrm{PM}_{10}$ light scattering and absorption due to $\mathrm{PM}_{1}$ particles and serve as a rough proxy for the "fine-mode" fraction of scattering and absorption coefficients.

Haywood and Shine (1995) presented simple equations (Table 2) for calculating top-of-atmosphere (TOA) aerosol DRF and direct radiative forcing efficiency (DRFE) for an optically thin, partially absorbing atmosphere. DRFE represents the DRF per unit AOD and is to first-order independent of AOD. If globally averaged values for all nonaerosol parameters are used (Table 2), the simple equation for DRFE provides a means for comparing the intrinsic forcing efficiency of the aerosols measured at different sites and times through DRFE dependence on $\omega_{0}$ and on up-scatter fraction $\beta$. The DRFE values themselves are only approximations when globally averaged values are used. Up-scatter fraction represents the fraction of incoming solar radiation that is scattered by atmospheric aerosols back to space. Upscatter fraction has been related to $b$ by the approximation of Wiscombe and Grams (1976). A second-order curve fit of the points in their Fig. 3 as reported in Sheridan and Ogren (1999) provides the parameterization shown in Table 2 .

\subsection{Measurement uncertainties}

Detailed measurement uncertainty calculations and discussions are provided in Sect. S1 of the Supplement and are briefly summarized here. The major sources of uncertainty in $\sigma_{\mathrm{sp}}$ and $\sigma_{\mathrm{bsp}}$ measured by the TSI 3563 nephelometer are the following: (1) instrumental noise; (2) uncertainty in the nephelometer calibration using filtered air and $\mathrm{CO}_{2}$ gases; (3) nephelometer calibration variability; (4) uncertainties in the correction for nephelometer angular non-idealities, which result in under-estimation (e.g., truncation) of light scattered in the near-forward direction; (5) uncertainty in 
Table 3. Total and precision fractional uncertainties (\%) of measured aerosol optical properties (AOPs) $\sigma_{\mathrm{sp}}, \sigma_{\mathrm{bsp}}$, and $\sigma_{\mathrm{ap}}$ and calculated AOPs (e.g., the intensive AOPs) for $1 \mathrm{~h}$ averaging time. Uncertainties are expressed as $95 \%$ confidence intervals. All calculated uncertainties are for $\lambda=550 \mathrm{~nm}$ except for $\alpha_{\mathrm{sp}}$ and $\alpha_{\mathrm{ap}}$, which are calculated for the 450/700 nm wavelength pair. All AOPs are PM $\mathrm{PMcept} \mathrm{for} \mathrm{PM}_{10} \alpha_{\mathrm{sp}}$ and the $\mathrm{PM}_{1}$ scattering and absorption fractions ( $R_{\mathrm{sp}}$ and $R_{\mathrm{ap}}$, respectively). The uncertainties in columns 3 and 4 differ only by inclusion of the PSAP unit-to-unit variability term (Eq. S3) in column 3. All uncertainties except $\Delta \sigma_{\mathrm{sp}}, \Delta \sigma_{\mathrm{bsp}}$, and $\Delta \sigma_{\mathrm{ap}}$ depend nonlinearly on the measured value, and cannot rigorously be represented as a percentage* . For these intensive AOP uncertainties, we use approximate annualmean values $\sigma_{\mathrm{sp}, 10}=30 \mathrm{Mm}^{-1}, \sigma_{\mathrm{ap}, 10}=3.0 \mathrm{Mm}^{-1}, R_{\mathrm{sp}}=, 0.80, R_{\mathrm{ap}}=0.88, b=0.14, \omega_{0}=0.91, \alpha_{\mathrm{sp}}=2.0$, and $\alpha_{\mathrm{ap}}=1.0$ to calculate fractional uncertainties. The intensive AOP fractional uncertainties apply for the average conditions listed above, and the equations in the Supplement should be used to calculate uncertainties at different sites or for different conditions.

\begin{tabular}{lrrr}
\hline & Total uncertainty $\%$ & $\begin{array}{r}\text { Precision uncertainty } \% \\
\text { for comparisons among sites }\end{array}$ & $\begin{array}{r}\text { Precision uncertainty } \% \\
\text { for comparisons at single site }\end{array}$ \\
\hline$\Delta \sigma_{\mathrm{sp}}$ & 8.0 & 3.8 & 3.8 \\
$\Delta \sigma_{\mathrm{bsp}}$ & 8.1 & 4.0 & 4.0 \\
$\Delta \sigma_{\mathrm{ap}}$ & 20 & 20 & 12 \\
$\Delta R_{\mathrm{sp}}$ & 2.7 & 1.1 & 1.1 \\
$\Delta R_{\mathrm{ap}}$ & 4.2 & 4.2 & 2.5 \\
$\Delta b$ & 2.3 & 1.1 & 1.1 \\
$\Delta \omega_{0}$ & 1.5 & 1.7 & 0.9 \\
$\Delta \alpha_{\mathrm{sp}}\left(\mathrm{PM}_{10}\right)$ & 1.8 & 1.4 & 1.4 \\
$\Delta \alpha_{\mathrm{ap}}$ & 17 & 17 & 10 \\
$\Delta \mathrm{DRFE}$ & 4.8 & 5.2 & 4.8 \\
\hline
\end{tabular}

* The uncertainties $\Delta \sigma_{\mathrm{sp}}, \Delta \sigma_{\mathrm{bsp}}$, and $\Delta \sigma_{\mathrm{ap}}$ depend very weakly on measured values through the noise term. This term represents a negligible contribution to the uncertainty for averaging times of $1 \mathrm{~h}$ or more.

correcting $\sigma_{\mathrm{sp}}$ and $\sigma_{\mathrm{bsp}}$ to standard temperature and pressure (STP) conditions; and (6) uncertainties in correcting $\sigma_{\text {sp }}$ and $\sigma_{\text {bsp }}$ to $40 \% \mathrm{RH}$ during humid conditions. Detailed accounts of uncertainty sources (1)-(5) are given in Anderson and Ogren (1998), Anderson et al. (1999), and Sheridan et al. (2002). The major sources of uncertainty in $\sigma_{\text {ap }}$ measured by the PSAP are the following: (1) instrumental noise; (2) unit-to-unit instrumental variability; and (3) uncertainty in the calibration of PSAP-measured $\sigma_{\mathrm{ap}}$, using extinction minus scattering as a reference method (Bond et al., 1999). Uncertainties in the PSAP spot size and flow rate corrections are often incorporated into the unit-to-unit variability term (Müller et al., 2011; Anderson et al., 1999). The total measurement uncertainties $\Delta \sigma_{\mathrm{sp}}, \Delta \sigma_{\mathrm{bsp}}$, and $\Delta \sigma_{\mathrm{ap}}$ are calculated by adding the major source contributions in quadrature (Anderson and Ogren, 1998). Standard error propagation techniques are applied (Sect. S1 of the Supplement) to calculate uncertainties in intensive AOPs, once $\Delta \sigma_{\mathrm{sp}}, \Delta \sigma_{\mathrm{bsp}}$, and $\Delta \sigma_{\mathrm{ap}}$ are estimated and adjustments made for correlations among $\sigma_{\mathrm{sp}}, \sigma_{\mathrm{bsp}}$, and $\sigma_{\text {ap }}$ (Tables $3, \mathrm{~S} 1, \mathrm{~S} 2$ ). Our reported uncertainties are $95 \%$ confidence intervals.

Identical nephelometers, PSAPs, calibration and correction methods are used at the four sites reported in this paper, with the exception of the late replacement of PSAP with the nearly identical CLAP at BND. As a result, some contributions to the measurement uncertainties approximately cancel when comparing AOPs between different sites and times, as noted by Anderson et al. (1999). Examples include the nephelometer calibration and STP correction uncertainties. The nephelometer truncation correction uncer- tainties are also nearly the same, due to the fact that the scattering Ångström exponent used to correct for nephelometer truncation of forward-scattered light (Anderson and Ogren, 1998) exhibits little temporal variability at each of the four sites and is of similar magnitude for each site (Fig. $2 \mathrm{~g}$ ). The PSAP unit-to-unit variability term can be neglected when comparing measurements made at the same site but cannot be neglected when comparing measurements made at different sites. The other uncertainty sources described above must be considered both for intra-site and inter-site AOP comparisons. We follow a similar methodology to that employed by Anderson et al. (1999). We consider the combined effect of all uncertainty sources which would not be expected to cancel or nearly cancel when comparing AOPs measured at different sites or times. We refer to their combined effect as measurement precision uncertainty, using the same notation as Anderson et al. (1999). We note that Anderson et al. (1999) did not include the nephelometer RH correction uncertainty nor the PSAP calibration uncertainty in their reported measurement precision uncertainties so our reported measurement precision uncertainties may represent upper bounds. We use the measurement precision uncertainties(Table 3) for comparing AOPs measured at different sites and times. Differences in AOPs between sites/seasons are assessed by comparison with the measurement precision uncertainty ranges (Sect. 2.5). The uncertainties are reported for $1 \mathrm{~h}$ averages, but the values differ negligibly for averaging times larger than this (Sect. S1 of the Supplement). 
(a)

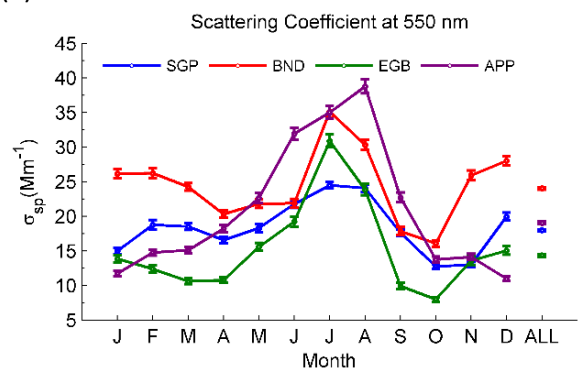

(c)

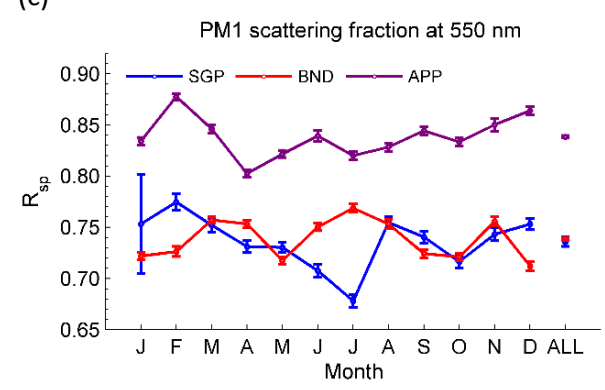

(e)

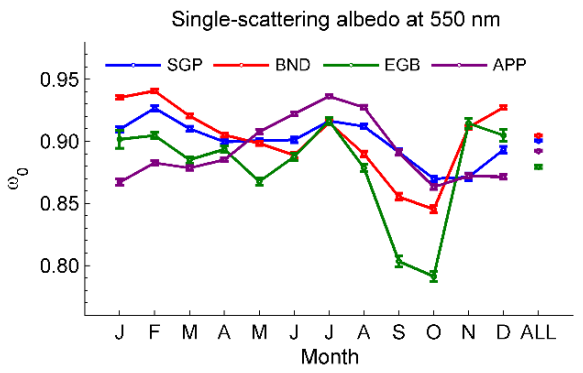

(g)

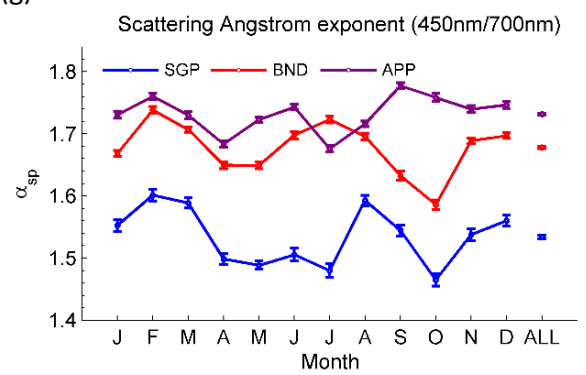

(b)

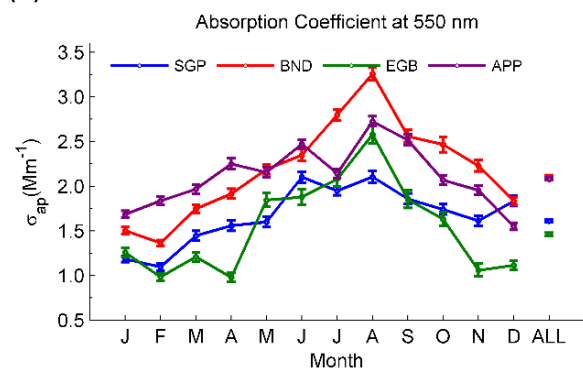

(d)

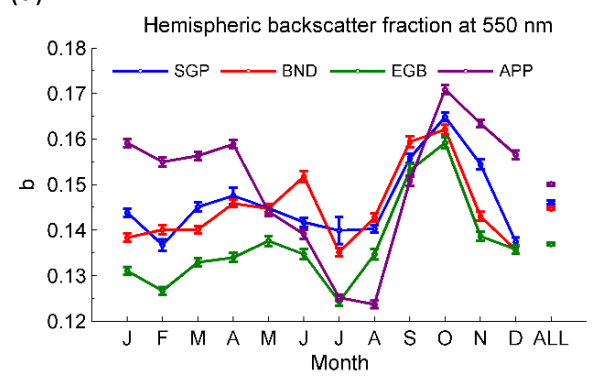

(f)

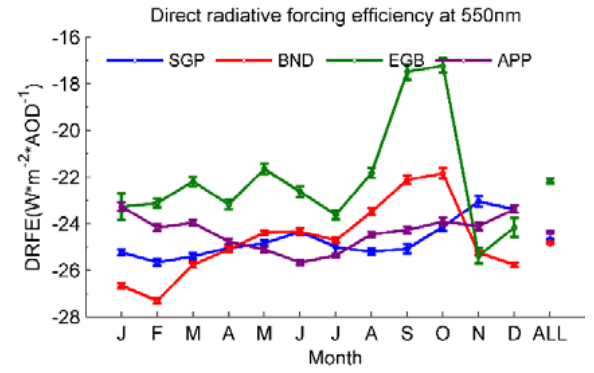

(h)

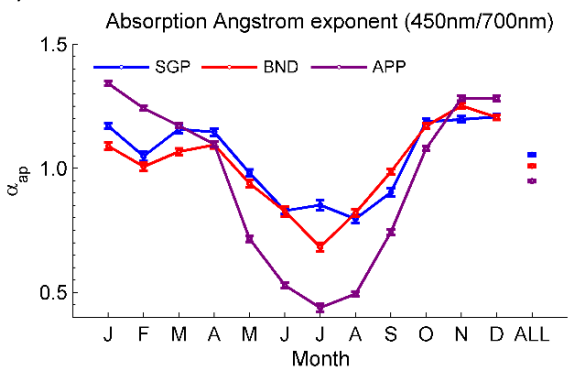

Figure 2. Annual cycle of (a) geometric mean $\mathrm{PM}_{1} \sigma_{\mathrm{sp}}$; (b) geometric mean $\mathrm{PM}_{1} \sigma_{\mathrm{ap}}$; (c) mean $R_{\mathrm{sp}} ;(\mathbf{d})$ mean $\mathrm{PM}_{1} b$; (e) mean $\mathrm{PM}_{1}$ $\omega_{0}$; (f) mean PM 1 DRFE; (g) mean $\mathrm{PM}_{10} \alpha_{\mathrm{sp}}(450 / 700 \mathrm{~nm})$; and (h) mean PM $\left.1 \alpha_{\mathrm{sp}} 450 / 700 \mathrm{~nm}\right)$ at APP, BND, EGB, and SGP over the 2010-2013 period. The values corresponding to "ALL" are geometric mean or mean values for the entire 2010-2013 period (all months). Error bars represent $95 \%$ confidence intervals of the mean values.

\subsection{Data analysis methods}

All statistics reported in this paper are based on hourly averaged, quality-assured $\sigma_{\mathrm{sp}}, \sigma_{\mathrm{bsp}}$, and $\sigma_{\mathrm{ap}}$ measurements made continuously or near-continuously at APP, BND, EGB, and SGP over the 2010-2013 period. We report only the results for the $\mathrm{PM}_{1}$ size cut at APP, BND, and SGP so as to min- imize redundancy and to simplify comparisons with $\mathrm{PM}_{1}$ AOPs measured at EGB. The only exceptions are the use of the more-relevant $\mathrm{PM}_{10}$ scattering Ångström exponent and the sub-1 $\mu \mathrm{m}$ scattering and absorption fractions $\left(R_{\mathrm{sp}}\right.$ and $R_{\text {ap }}$ ), calculated as the ratios of $\mathrm{PM}_{1} / \mathrm{PM}_{10} \sigma_{\mathrm{sp}}$ and $\sigma_{\mathrm{ap}}$, respectively (Table 2). $\mathrm{PM}_{10}$ AOP variability at APP, BND, 
and SGP is reported in the Supplement (Fig. S8 and Table S5). The intensive AOPs (Table 2) are calculated for each hour, using the hourly averaged $\sigma_{\mathrm{sp}}, \sigma_{\mathrm{bsp}}$, and $\sigma_{\mathrm{ap}}$ values. For brevity, only AOPs at $550 \mathrm{~nm}$ are presented with the exception of the wavelength dependent $\alpha_{\mathrm{sp}}$ and $\alpha_{\mathrm{ap}}$. Scattering and absorption Ångström exponents are calculated based on the $450 \mathrm{~nm}$ and $700 \mathrm{~nm}$ wavelength. We follow a similar approach to that taken by D\&02002 and Andrews et al. (2011) and only use hours for which $\mathrm{PM}_{1} \sigma_{\mathrm{sp}}$ at $550 \mathrm{~nm}$ is at least $1.0 \mathrm{Mm}^{-1}$ to calculate the intensive AOP statistics, so as to reduce noise resulting from taking ratios of two small quantities (Table 2). Filtering the intensive AOPs for low- $\sigma_{\mathrm{sp}}$ hours discards $1.4 \%$ of the hours at APP, $0.1 \%$ at BND, $1.8 \%$ at EGB, and $0.5 \%$ at SGP. These percentages are uniform across seasons, except for slightly higher percentages during fall at EGB and SGP (Table S3). We use all hours in calculating $\sigma_{\mathrm{ap}}, \sigma_{\mathrm{sp}}$ and $\sigma_{\mathrm{bsp}}$ statistics, to avoid a bias toward 'less clean' conditions. Lack of $\mathrm{PM}_{10}$ measurements and use of a single-wavelength PSAP preclude calculation of $R_{\mathrm{sp}}, R_{\mathrm{ap}}$, and $\alpha_{\text {ap }}$ at EGB.

\subsubsection{Temporal cycle analysis}

Hourly averaged and quality-assured AOPs are binned by month, day of week, and hour of day to study their annual, weekly, and diurnal cycles, respectively (Sect. 4.1). Geometric means and $95 \%$ confidence intervals of the geometric means are calculated for the binned $\sigma_{\mathrm{sp}}$ and $\sigma_{\mathrm{ap}}$, whose distributions are closer to log-normal than normal. Arithmetic means and $95 \%$ confidence intervals of the means are calculated for the binned intensive AOPs, whose distributions are suitably approximated as normal. Atmospheric variability for each month, day of week, or hour of day is quantified by the $95 \%$ confidence intervals of the mean value, which are represented as error bars on the plots. Differences in the mean AOPs are termed "significant" in this paper if they are larger than both (1) atmospheric variability (e.g., if the error bars do not overlap); and (2) twice the precision measurement uncertainty (Table 3). We define the magnitude of temporal variability on each of the timescales as the amplitude of the cycle of mean values (difference between maximum and minimum values). Cycle amplitudes are also expressed as percentages by dividing this difference by the midpoint between maximum and minimum values.

Aerosol optical properties at the four sites vary primarily on seasonal timescales. Day of week variability in AOPs can be used as a tool for distinguishing anthropogenic from natural aerosol sources, since natural sources would not be expected to have AOPs that vary on weekly scales (Murphy et al., 2008). Diurnal variability is used along with co-located meteorological data to infer the influence of local pollution sources and mixing layer height on measured AOPs. Due to the dependence of most AOPs on season, their weekly and diurnal cycles are reported for both full years and individual seasons.

\subsubsection{Meteorological analysis}

Data from co-located surface meteorological stations at the four sites are used to develop proxies to help explain some features of the AOP cycles at each station. Pollution-rose diagrams showing the dependence of $\sigma_{\mathrm{sp}}, \sigma_{\mathrm{ap}}$, and some calculated AOPs on wind direction are shown for individual seasons to examine the influences of wind sectors and known regional pollution sources on measured AOPs (Figs. 5-8 and S16-S22). We compare the temperature dependence of $\sigma_{\mathrm{sp}}$ (Figs. S5 and S7) with reported temperature dependence of biogenic secondary organic aerosol (SOA) (Leaitch et al., 2011; Goldstein et al., 2009) and ammonium nitrate partitioning (Parworth et al., 2015; Rupakheti et al., 2005). We also use temperature dependence of $\sigma_{\mathrm{sp}}$ along with monthly median temperatures at the sites (Fig. S23) and monthly averaged $\sigma_{\text {sp }}$ (Fig. 2a) to hypothesize the role of photochemistry on the seasonality of $\sigma_{\mathrm{sp}}$. Mixing layer height climatologies have been reported for locations at or within $\sim 170 \mathrm{~km}$ of the sites. We use the seasonal dependence of the reported mixing layer heights to assess the effect of convection (or lack thereof) on the annual and diurnal cycles of measured nearsurface $\sigma_{\mathrm{sp}}$ and $\sigma_{\mathrm{ap}}$ at the four sites.

\subsubsection{Significance and trend analysis}

Mean values of AOPs over the entire 2010-2013 period are calculated for each site and the differences in mean AOPs among the sites are used as a measure of regional variability (Sect. 4.2). Seasonal differences of most AOPs at individual sites are often much larger than the regional differences of annual-mean AOPs so the seasonality of regional AOP differences must also be taken into account. The differences in mean AOPs among the sites are termed "significant" if they satisfy the same two criteria stated in Sect. 2.5.1 for temporal differences. Of the four sites, only BND and SGP have long enough time series (> 10 years) to evaluate trends in AOPs (Sect. 4.3). Slopes and significance are obtained using the function "TheilSen" in the R package "openair" (Carslaw and Ropkins, 2012; Carslaw, 2015). Data are de-seasonalized and autocorrelation is accounted for using options supplied with the TheilSen function. Decadal slopes (\%/10 year) are calculated by multiplying the yearly slope by 10. Trends are not reported for SGP AOPs requiring absorption due to PSAP data quality issues over most of the 1997 2009 period. Absorption Ångström exponent trends are not calculated for BND because the available time series is less than 10 years.

\subsubsection{Systematic relationships}

Systematic relationships among intensive AOPs and aerosol loading are explored on an annual basis at the four North American sites for the 2010-2013 (Sect. 4.4). Relationships involving $\alpha_{\mathrm{ap}}$ vary with season at some sites, so 
these relationships are also presented for individual seasons. D\&O2002 suggested systematic relationships would be useful for constraining model parameterization of AOPs and for reducing uncertainties in satellite-based retrievals of AOD, which make assumptions regarding aerosol size distributions and $\omega_{0}$ (e.g., Levy et al., 2010). Systematic relationships can also provide information regarding aerosol source types and processes. Relationships between mean intensive AOPs and aerosol loading, represented by $\sigma_{\mathrm{sp}}$ at $550 \mathrm{~nm}$, are investigated for each season at each site by separating hourly averaged $\sigma_{\mathrm{sp}}$ values into bins of $10 \mathrm{Mm}^{-1}$ width and then calculating the mean AOPs for each $\sigma_{\mathrm{sp}}$ bin. The $x$ values for the data points on each plot correspond to the bin center. Only bins with a number of data points exceeding $0.1 \%$ of all data points are plotted. The relatively high $\omega_{0}$ values at all sites justifies the use of $\sigma_{\mathrm{sp}}$, rather than $\sigma_{\mathrm{ep}}$, as a proxy for loading. Relationships among a few select intensive AOPs are also included to provide more insight into aerosol sources and/or processes influencing the properties measured at the sites.

\section{Site descriptions}

All four sites in this study are mid-latitude $\left(35-45^{\circ} \mathrm{N}\right)$ locations in North America with elevations ranging from 230 to $1080 \mathrm{~m}$ above sea level (a.s.l.), placing them firmly in the boundary layer. These sites can be categorized as anthropogenically perturbed, rural continental locations. Published aerosol chemistry research at the sites (Link et al., 2015; Buzcu-Guven et al., 2007; Rupakheti,et al., 2005; Parworth et al., 2015) indicates that the sites are regionally influenced.

\subsection{Appalachian State University, Boone, North Carolina, USA (APP)}

The APP site is situated at the highest point on the Appalachian State University campus $(1080 \mathrm{~m})$, located in the southern Appalachian mountain town of Boone, NC (pop. $\sim 20000$ ). In situ aerosol measurements were initiated at APP in June 2009. APP is also home to a Cimel sun photometer as part of AERONET, a micro-pulse lidar, an aerosol mass spectrometer, a solar pyranometer as part of the NASA SolRad-Net, and a suite of meteorological and trace gas measurements. The region surrounding Boone is heavily forested in all directions. The APP site is not located near any major highways or major industry but is located $1-3 \mathrm{~km}$ from local commuter traffic sources during weekday mornings and late afternoons. The APP site is located $40-60 \mathrm{~km}$ from the following towns: (1) Lenoir/Hickory (population $\sim 60000$ ) to the SE; and (2) Wilkesboro (population 3500) to the east. The Charlotte metropolitan area (population 2.5 million) is located approximately $160 \mathrm{~km} \mathrm{SE}$ of APP and the Piedmont Triangle metropolitan area (population 1.6 million) is located 200-230 km ESE of APP. However, winds are from the SE only $\sim 5 \%$ of the time for all seasons (Fig. 5) so the influence of these towns/cities on the APP site is generally small.

Summer AOD in the warm, heavily forested SE US is influenced by highly temperature-dependent isoprene-derived SOA (Goldstein et al., 2009). The Appalachian mountain region is also home to some of the highest rural ammonium sulfate concentrations in the US, with maximum concentrations in summer and minimum concentrations in fall/winter (Hand et al., 2012b). Link et al. (2015) reported in the Supplement to their paper that non-refractory $\mathrm{PM}_{1}$ aerosol mass at APP during summers (winter) of 2012-2013 was 66\% (49\%) organic aerosol, $24 \%$ (31\%) sulfate, $7 \%(10 \%)$ ammonium, and $3 \%(10 \%)$ nitrate. Approximately $77 \%$ of the summer organic aerosol (OA) mass was comprised of low-volatility oxygenated SOA (LV-OOA) and isoprenederived SOA, while the winter OA was comprised of LVOOA and biomass-burning OA (Link et al., 2015). Woodburning stoves serve as the primary heating source for $6.2 \%$ of occupied housing units in Watauga County (US Census Bureau, 2010) and likely a larger percentage of housing units in the surrounding rural mountain communities. The highly oxidized, "aged" LV-OOA factor present in nearly equal concentrations during both summer and winter at APP suggests that it is representative of regional background SOA (Link et al., 2015).

Weather patterns affecting the southern Appalachian mountain region are highly diverse due to a variety of factors, including complex topography, mid-latitude location, and proximity to the Gulf of Mexico and Atlantic Ocean. Common weather regimes include winter storms, convective cells, dying tropical cyclones, and stagnant summertime episodes. Wind directions are predominately from the west for all seasons (Fig. 5). Wind speeds are highest in November-March and lowest in May-September. The annual temperature cycle in Boone, $\mathrm{NC}$ is relatively small, with average daily high temperatures of $\sim 24-26^{\circ} \mathrm{C}$ in JuneAugust and $\sim 5^{\circ} \mathrm{C}$ in January. The annual cycle in average monthly precipitation is also small, with a maximum in summer $(12-13 \mathrm{~cm})$ and minimum in October $(\sim 9 \mathrm{~cm})$. Relative humidity (RH) is highest during the summer at APP. Planetary boundary layer (PBL) heights calculated from vertical aerosol backscatter profiles measured with a micro-pulse lidar at APP from February 2013 to August 2014 reveal a relatively weak diurnal and seasonal dependence of PBL heights. Median afternoon (morning) PBL heights are $920 \mathrm{~m}(820 \mathrm{~m})$ in winter, $1200 \mathrm{~m}(880 \mathrm{~m})$ in spring, $1100 \mathrm{~m}(850 \mathrm{~m})$ in summer, and $1050 \mathrm{~m}(680 \mathrm{~m})$ in fall (unpublished result).

\subsection{Bondville, Illinois, USA (BND)}

The BND aerosol monitoring station is located on farmland at the Bondville Environmental and Atmospheric Research Site (BEARS) in rural east-central Illinois. In situ aerosol measurements at BND began in 1994. Additional measurements made at BND include a Cimel sun photometer 
as part of AERONET, a comprehensive set of meteorological measurements, an IMPROVE aerosol chemistry system, and a full suite of solar radiation measurements made by NOAA/ESRL. The BND station is situated approximately $6.5 \mathrm{~km}$ south of Bondville (population 450), $16 \mathrm{~km}$ southwest of Champaign-Urbana (population 230000), and is surrounded in all directions by corn, soybean and hay fields. A regional airport (Willard Airport) is situated approximately $10 \mathrm{~km}$ east of the BND site. The town of Decatur (population $\sim 75000$ ) lies $\sim 50 \mathrm{~km}$ to the SW, and three large metropoli$\tan$ areas are within $250 \mathrm{~km}$ of the site: (1) Chicago (population 9.6 million), located $\sim 240 \mathrm{~km}$ to the N/NE; (2) Indianapolis, IN (population 1.8 million), located $\sim 210 \mathrm{~km}$ to the east; and (3) St. Louis, MO (population $\sim 3.7$ million) is located $\sim 230 \mathrm{~km}$ to the SW. The area is crisscrossed by a network of interstate highways, including I-57 ( $~ 7 \mathrm{~km}$ to the east), I-72 ( 10 km north), I-74 ( $\sim 15 \mathrm{~km}$ northeast $)$, and I-70 ( 100 km south).

Buzcu-Guven et al. (2007) applied positive matrix factorization techniques to apportion the $\mathrm{PM}_{2.5}$ aerosol mass at BND into the following annually averaged factors: (1) secondary sulfate $(27 \%)$; (2) secondary nitrate (24\%); (3) mobile/SOA factor $(17 \%)$, largely due to gasoline and diesel vehicle emissions; (4) biomass-burning OA (12\%); (5) soil (6\%); (6) copper smelter (2\%); (7) chromium and nickel from metal plating (5\%); and (8) mixed industrial (7\%). The largest contributors to organic matter (OM) were biomass burning (38\% of OM) and mobile/SOA ( $24 \%$ of OM) factors, followed by factors associated with industrial sources ( $<20 \%$ of OM). Buzcu-Guven et al. (2007) could not resolve the mobile source aerosol factor into the two fuel combustion types (gasoline vehicle and diesel) because the BND site is affected by transported urban emissions rather than local emissions. They reported strong seasonality in secondary sulfate (maxima in summer) and nitrate (maxima in winter) at BND. Similar regional sulfate and nitrate seasonality was reported for the region by Hand et al. (2012b) and by Spak and Holloway (2009). The highest sulfate concentrations at BND were associated with transport from the Ohio River valley, western Ohio, and southern Illinois, where large numbers of coal-fired power plants are located (Buzcu-Guven et al., 2007). Winter ammonium nitrate concentrations in the Midwest US are among the highest in the country, due to significant sources of agricultural ammonia and combustiongenerated $\mathrm{NO}_{x}$ emissions, in addition to meteorological conditions (low temperature and high humidity) favorable for gas-to-particle partitioning (Hand et al., 2012b; Spak and Holloway, 2009).

Polluted air at BND is generally associated with southerly wind sectors (120-240 ${ }^{\circ}$ wind directions), and cleaner air is typically associated with NW wind sectors (Fig. 6). Winds reaching BND from the SW also pass over regions with high summer biogenic isoprene emissions (Fig. 3 of Parworth et al., 2015). Wind speeds are higher in November-May and lower in June-September (not shown). Higher wind speeds are more common for S/SW wind sectors for all seasons except winter, when higher wind speeds are more common for NW wind sectors. Lowest wind speeds are associated with easterly wind sectors. Average high temperatures are highest in July $\left(29.5^{\circ} \mathrm{C}\right)$ and lowest in January $\left(0.5^{\circ} \mathrm{C}\right)$. Average monthly precipitation is highest in May-July $(\sim 12 \mathrm{~cm})$ and lowest in January-February $(\sim 5 \mathrm{~cm})$. Holzworth (1964) used daily soundings at Joliet, IL (located $\sim 130 \mathrm{~km}$ N/NE of BND) to calculate monthly mean maximum mixing layer heights: DJF (480, 480, $480 \mathrm{~m})$; MAM (980, 950, $1040 \mathrm{~m})$; JJA $(1090,1380,1310 \mathrm{~m})$; SON (860, 790, $600 \mathrm{~m})$. Climatologies of surface aerosol optical properties observed at BND have been reported by Koloutsou-Vakakis et al. (2001) and D\&O2002. Sheridan et al. (2012) also reported BND surface aerosol properties for comparison with airborne aerosol measurements.

\subsection{Egbert, Ontario, Canada (EGB)}

The EGB station at the Centre for Atmospheric Research Experiments (CARE), is situated near the town of Egbert, in Ontario, Canada. In situ aerosol optical measurements at EGB began in 2009. The CARE facility is also home to complementary measurements of greenhouse gases such as $\mathrm{CO}_{2}$ and $\mathrm{CH}_{4}$, as well as meteorological instrumentation and measurements of aerosol chemistry and aerosol size distributions. Egbert is a rural location consisting of mixed deciduous/coniferous forest and agricultural land. The population of Egbert and the surrounding communities is approximately 20000 . Egbert is located $70 \mathrm{~km} \mathrm{~N} / \mathrm{NE}$ of Toronto, Ontario and the heavily populated southern Ontario region, with a population of approximately 8 million. A major highway (HWY 400) is located approximately $8 \mathrm{~km}$ to the east of the EGB site. The highway experiences commuter traffic during early morning and late afternoon. The town of Barrie (population $\sim 128000$ ) is located $\sim 25 \mathrm{~km} \mathrm{~N} / \mathrm{NE}$ of the EGB site, but the wind comes from this direction only $\sim 2-3 \%$ of the time for all seasons, and the associated air masses are relatively clean (Fig. 7). Forest density is highest to the north of EGB.

Southerly winds (120-240 ${ }^{\circ}$ wind directions) typically bring more polluted air masses (Fig. 7) associated with outflow from the heavily populated Toronto area, southern Ontario, and eastern US (Yang et al., 2011; Liggio et al., 2010). Southerly air masses contain higher levels of elemental carbon (EC), sulfates, nitrates, and OM and higher EC / OC ratios than cleaner air masses from the north (Chan et al., 2010; Rupakheti et al., 2005; Yang et al., 2011). Organic carbon (OC) and EC are highly correlated (poorly correlated) during cold (warm) months, implicating primary aerosol sources during cold months and a large influence of transported warm-season SOA from urban areas south of EGB (Yang et al., 2011). Northerly winds (300-60 wind directions) typically bring air masses from sparsely populated, heavily forested regions (Slowik et al., 2010), with 
high concentrations of temperature-dependent biogenic SOA during summer months (Leaitch et al., 2011; Slowik et al., 2010). Long-distance transport of smoke from the northwest is also observed during the summer forest fire season in northwest Canada. Wind speeds at EGB are higher in November-April and lowest in July-August. Average daily maximum temperatures are highest in July $\left(26^{\circ} \mathrm{C}\right)$ and lowest in January $\left(-3^{\circ} \mathrm{C}\right)$. Holzworth (1964) used daily soundings at Buffalo, NY (located $\sim 170 \mathrm{~km}$ SE of EGB) to calculate monthly mean maximum mixing layer heights: DJF $(510,480,530 \mathrm{~m})$; MAM $(780,600,810,1070 \mathrm{~m})$; JJA (1180, 1440, 1360 m); SON (1190, 530, $700 \mathrm{~m})$.

\subsection{Lamont, Oklahoma, USA (SGP)}

The DOE Southern Great Plains (SGP) Cloud, Aerosol and Radiation Testbed (CART) Central Facility site is located in north central Oklahoma near the town of Lamont (pop. 417) in a rural, agricultural region surrounded mostly by wheat, corn and hay fields. Measurements of in situ aerosol optical properties began in 1996. The site is also equipped with a Cimel sun photometer (as part of AERONET), cloud radars, lidars, meteorological instruments and many remote-sensing radiometers, making it the largest climate research facility in the world. The SGP site is situated $100-150 \mathrm{~km}$ from the following metropolitan areas: (1) Wichita, KS (population $\sim 638000$ ), located $112 \mathrm{~km}$ to the north; (2) Oklahoma City (population 1.3 million), located $136 \mathrm{~km}$ to the south; and (3) Tulsa, OK (population $\sim 400000$ ), located $\sim 150 \mathrm{~km}$ to the southeast. The SGP site experiences infrequent local traffic but is situated approximately $15 \mathrm{~km}$ to the west of an interstate highway (I-35). There are no major aerosol sources within several hundred $\mathrm{km}$ to the northwest, west or southwest of the site.

Parworth et al. (2015) reported an average total nonrefractory $\mathrm{PM}_{1}$ aerosol mass concentration at SGP (from November 2010-June 2012) of $7.0 \mu \mathrm{g} \mathrm{m}^{-3}$. Their reported total aerosol mass concentration was broken down into (1) OA (57\%); (2) nitrate (21\%); (3) sulfate (12\%); (4) ammonium ( $9.4 \%)$; and (5) chloride $(0.24 \%)$. Organic aerosol constituted a larger and nearly constant mass fraction ( $\sim 70 \%)$ from April to October. Sulfate mass fraction also exhibited little seasonality. Both OA and sulfate mass concentrations demonstrated fall minima, with mass concentrations $\sim 2-3$ times lower than during summer. Approximately $90 \%$ of the OA was highly oxidized aged aerosol, with biomass-burning OA comprising the remaining $\sim 10 \%$. The aged, oxidized OA peaked in June-July. Biomass-burning OA was highest in late winter and spring and was likely due to local agricultural burning in preparation for crop season (Parworth et al., 2015). Ammonium nitrate was the largest $\mathrm{PM}_{1}$ aerosol component in winter, followed by OA. Rural EC concentrations in northern Oklahoma are low and peak in autumn (Fig. 3 of Hand et al., 2013). The super-micron aerosol was primarily soil dust, which exhibits a summer maxima in the region (Hand et al., 2012b).

The typical annual weather cycle at SGP involves a cold, shallow inversion layer in the winter with relatively stagnant winds and a hot, humid summer with strong convection, high daytime boundary layer, and southerly winds. Prevailing winds at the SGP site are from the S/SE for all seasons except winter (Fig. 8). Average high temperatures are highest in July-August $\left(33-34^{\circ} \mathrm{C}\right)$ and lowest in January $\left(0.7^{\circ} \mathrm{C}\right)$. Average monthly precipitation is highest in MayJune $(\sim 11-12 \mathrm{~cm})$ and lowest in January-February $\left(\sim 3.0_{-}\right.$ $3.5 \mathrm{~cm})$. Median mixing layer heights are less than $100 \mathrm{~m}$ (above ground level) from 20:30 central standard time (CST) through 05:30CST for all seasons and median afternoon mixing layer heights are $752 \mathrm{~m}$ in winter, $1260 \mathrm{~m}$ in spring, $1640 \mathrm{~m}$ in summer, and $1390 \mathrm{~m}$ in fall (Delle Monache et al., 2004). The SW US and southern Great Plains experienced exceptionally hot and dry conditions during 2010-2012, coinciding with La Niña years. Extensive fires raged across the SW US during 2011-2012, particularly Texas, Arizona, Colorado, New Mexico and Oklahoma. The hot, dry conditions during 2010-2012 also created conditions favorable for airborne dust production and transport. Climatologies of surface and aerosol optical properties observed at SGP have been reported by Sheridan et al. (2001) and D\&O2002.

\section{Results and discussion}

Several broad features of AOP temporal variability are common to all or most of the four sites. For the sake of brevity, these features are first discussed collectively before moving on to a more detailed analysis of AOP variability at each site and then to comparisons among the sites. Much of the seasonal AOP variability at each site can be explained using the following: (1) published results of seasonally dependent aerosol chemistry at the sites; (2) pollution-rose diagrams, which simultaneously display percentage of hours with winds arriving from each wind sector and the distribution of AOP values for each sector; (3) known regional pollution sources; and (4) published seasonality of PBL height and monthly median temperature and relative humidity at the sites. Temperature dependence of $\sigma_{\mathrm{sp}}$ is also helpful. Diurnal and weekly cycles of select AOPs and the seasonal dependence of these cycles are used to estimate the relative influences of some local and regional sources (mainly traffic) and PBL heights. Regional variability in AOPs is discussed in the context of the annual AOP cycles and the above-listed sources of seasonal variability at each site. Trends in AOPs at BND and SGP are used to place results for the current period in a long-term context. Systematic relationships among select AOPs at each site are used to help interpret the temporal and regional AOP variability and to hypothesize aerosol sources or processes at the sites. Numerous pieces of supporting materials for the presented results are included as part of 
the Supplement. We reference those figures and tables with the letter "S" (e.g., Fig. S13, Table S2) to distinguish them from figures appearing in this paper.

\subsection{Temporal variability of aerosol optical properties}

\subsubsection{Temporal variability common to all sites}

The annual AOP cycle amplitudes are larger than the weekly and diurnal AOP cycle amplitudes at all sites. Nearly all annual AOP cycles are significant, with cycle amplitudes larger than the $95 \%$ confidence intervals of both the monthly mean AOPs (Fig. 2) and the measurement uncertainties (Table 3). July and/or August $\sigma_{\mathrm{sp}}$ maxima are observed at all sites (Fig. 2a), with steeper $\sigma_{\text {sp }}$ decreases from summer to fall than from summer to spring. Summer-to-spring and summer-tofall $\sigma_{\mathrm{sp}}$ decreases at EGB and APP are approximately twice the magnitude of those observed at BND and SGP. Scattering coefficient reaches a minimum during October at all sites except APP, where it is lowest in December. Absorption coefficient is highest in summer and lowest in winter at all sites (Fig. 2b), although the differences between summer $\sigma_{\text {ap }}$ maxima and the surrounding months are only significant at BND and EGB. Summer-to-autumn $\sigma_{\mathrm{sp}}$ decreases are larger than those of $\sigma_{\mathrm{ap}}$, leading to minimum $\omega_{0}$ in October at all sites (Fig. 2e). Hemispheric backscatter fraction is highest in October at all sites (Fig. 2d). The confluence of early autumn decreases in $\sigma_{\mathrm{sp}}$ and $\omega_{0}$ and increases in $b$ is indicative of less production and/or more efficient removal of large, highly scattering particles during early autumn, relative to summer. This effect is most noticeable at EGB and APP (Fig. 2) and also is seen in the summer-spring differences at APP. October $\omega_{0}$ minima contribute to DRFE maxima (least negative) at EGB and BND, but no significant autumn DRFE changes are seen at APP and SGP (Fig. 2f). Photochemistry likely influences the summer $\sigma_{\mathrm{sp}}$ maxima and $\sigma_{\mathrm{sp}}$ that are larger in spring than in fall at all sites. The temperature dependence of $\sigma_{\mathrm{sp}}$ (Fig. S5) and differences in monthly median temperatures (Fig. S23) combine to yield predicted differences in $\sigma_{\mathrm{sp}}$ that are of similar magnitude to the large observed summer-spring (July-April) $\sigma_{\mathrm{sp}}$ differences at EGB and APP and to the observed summer-autumn (July-October) $\sigma_{\mathrm{sp}}$ differences at EGB, BND, and SGP (Fig. 2a). The summerautumn $\sigma_{\mathrm{sp}}$ difference based on temperature considerations is less at APP than the observed $\sigma_{\mathrm{sp}}$ difference, leading us to hypothesize an additional contributor to the autumn $\sigma_{\mathrm{sp}}$ decrease. Cloud and fog scavenging of large, highly reflecting particles would be consistent with cooler September temperatures (Fig. S23a), higher RH (Fig. S23b), and cloud cover in September at APP. The inverse relationship between $\sigma_{\mathrm{sp}}$ and $b$ seen in the annual cycles at all sites (Fig. 2a and d) is indicative of the influence of particle growth (and possibly cloud or fog scavenging) on $\sigma_{\mathrm{sp}}$. Wet deposition likely impacts $\sigma_{\mathrm{sp}}$ most in summer and least in spring and fall, given the seasonality of precipitation at the sites. Secondary $\sigma_{\mathrm{sp}}$ maxima are observed during winter at all sites except APP (Fig. 2a). When combined with winter $\sigma_{\text {ap }}$ minima, the result is a winter $\omega_{0}$ maxima at these sites (Fig. 2e).

In contrast to $b$, the annual $R_{\mathrm{sp}}$ and $\mathrm{PM}_{10} \alpha_{\mathrm{sp}}$ cycles (Fig. 2c and g) at APP, BND, and SGP (the sites where these AOPs are calculated) do not demonstrate an obvious relationship with the annual $\sigma_{\mathrm{sp}}$ cycles. Collaud Coen et al. (2007) conducted simulations based on Mie theory to show that $b$ at $550 \mathrm{~nm}$ is most sensitive to particle size changes for diameters $\sim 100-300 \mathrm{~nm}$ (their Fig. 7 and accompanying discussion). Schuster et al. (2006) combined simulations based on Mie theory with volume size distributions and AOD from AERONET to show that extinction Ångström exponent is relatively insensitive to fine mode effective radius for bimodal aerosol size distributions and that extinction Ångström exponent may serve as a better indicator of fine-mode aerosol volume fraction than mean particle size. The stronger relationship between the annual $b$ and $\sigma_{\mathrm{sp}}$ cycles (relative to relationships between the cycles of $\sigma_{\mathrm{sp}}$ with either $\alpha_{\mathrm{sp}}$ or $R_{\mathrm{sp}}$ ) suggests that the major seasonal changes in the aerosol size distributions at APP, BND, and SGP may lie at the smaller end of the range of optically relevant accumulation mode particles (100-300 nm), with shifts toward larger particles in summer and smaller particles in fall. Photochemistry likely plays a role in the observed seasonal cycle of $b$, especially at APP and EGB. Gas-to-particle conversion onto existing particles is most efficient for the $100-500 \mathrm{~nm}$ diameter range, since this is where most of the aerosol surface area typically lies (Seinfeld and Pandis, 1998). Reduced gas to particle conversion in fall (when photochemistry and precursor levels are lower) would impact $b$ more than $\alpha_{\mathrm{sp}}$ and $R_{\mathrm{sp}}$.

Absorption Angström exponent is lowest during summer months and highest during winter months (Fig. 2h) at APP, BND and SGP (the three sites where $\alpha_{\text {ap }}$ can be calculated). The summer-to-winter difference in $\alpha_{\text {ap }}$ is clearly larger at APP $(\sim 0.9)$ than at BND and SGP $(\sim 0.5)$. Absorption Ångström exponent values near and below 1 during MaySeptember suggest that black carbon (BC) contributes most to $\sigma_{\text {ap }}$ during these months (Gyawali et al., 2009; Cazorla et al., 2013). Gyawali et al. (2009) performed simulations using Mie theory to show that $\alpha_{\text {ap }}$ values much less than 1 are possible (their Figs. 8 and 9) when absorbing particles are coated with non-absorbing substances. Clarke et al. (2007) also reported a large number of $\alpha_{\text {ap }}(470 / 660 \mathrm{~nm})$ values clustered between 0.7 and 1.1 for pollution plumes during extensive flights over North America as part the of the INTEX/ICARTT experiment in summer 2004.

Weekly and diurnal cycle amplitudes of $\sigma_{\mathrm{sp}}$ (Fig. 3) and nearly all intensive AOPs observed at the four sites are much smaller than the corresponding annual cycle amplitudes. Weekly and diurnal $\sigma_{\text {ap }}$ cycle amplitudes (Fig. 4) are larger than those of $\sigma_{\mathrm{sp}}$ at all sites and are largest in summer. Weekly $\sigma_{\text {ap }}$ cycles at all sites are marginally significant in fall with $\sigma_{\text {ap }}$ cycle amplitudes approximately twice the 
(a)

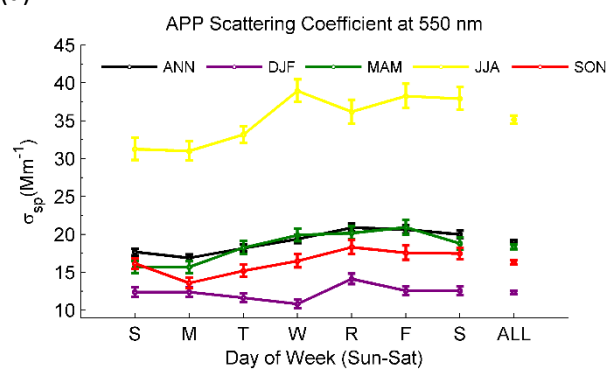

(c)

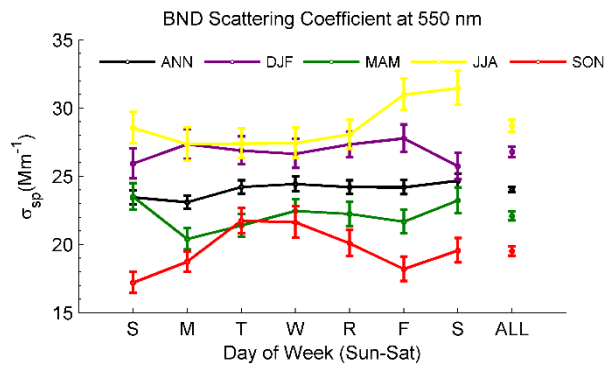

(e)

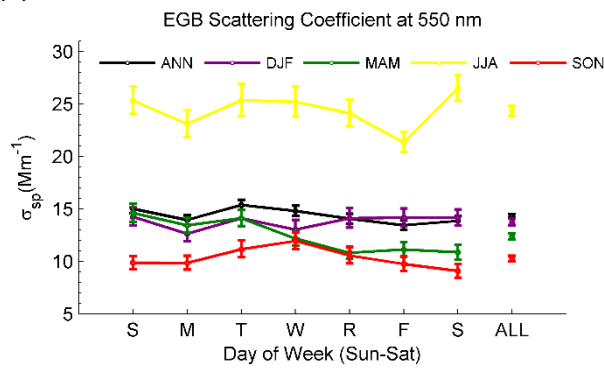

(g)

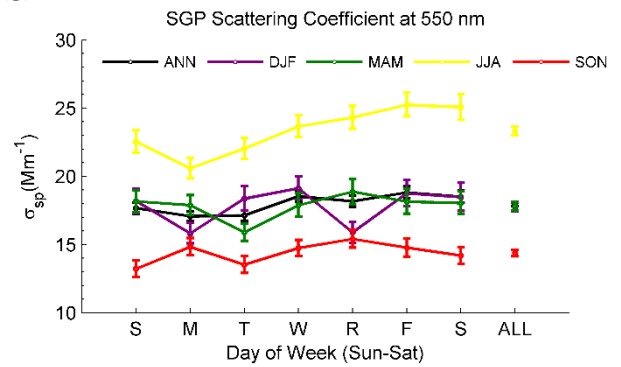

(b)

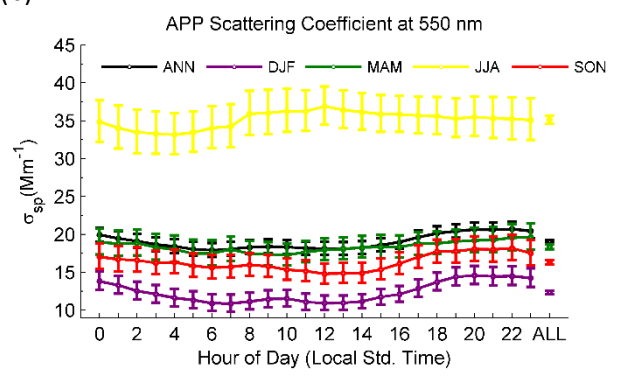

(d)

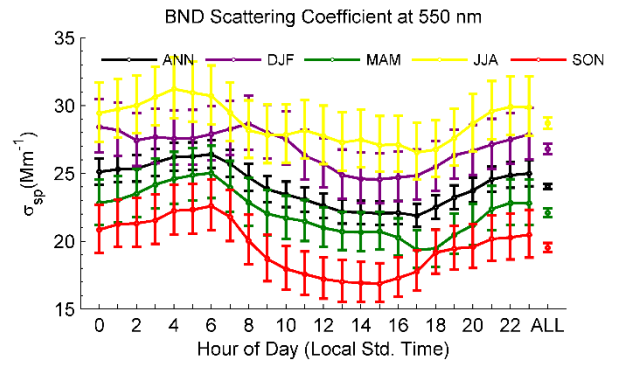

(f)

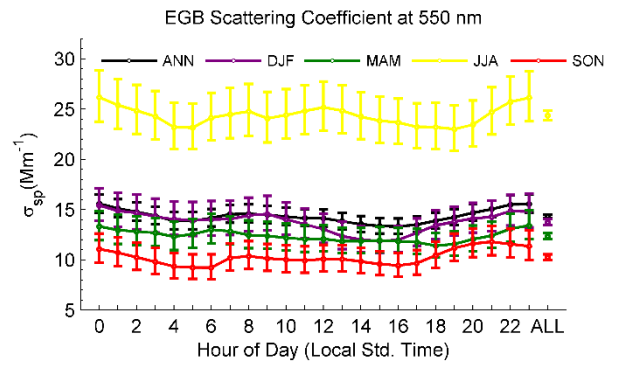

(h)

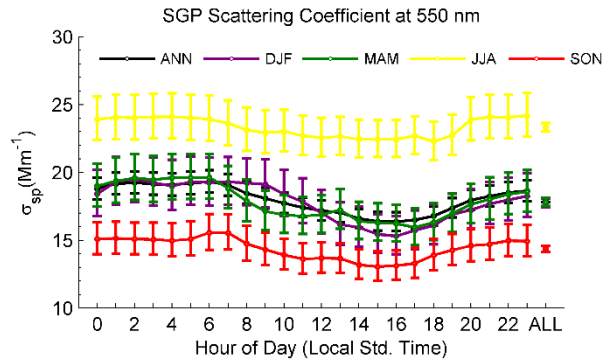

Figure 3. Weekly and diurnal cycles of geometric mean $\mathrm{PM}_{1} \sigma_{\mathrm{sp}}$ over full years (ANN traces) and for winter (DJF), spring (MAM), summer (JJA), and fall (SON) at APP, BND, EGB, and SGP over the 2010-2013 period. The value corresponding to the "ALL" data point of each trace is the mean value over all days of the week or over all hours of the day. Error bars represent $95 \%$ confidence intervals of mean $\sigma_{\mathrm{sp}}$ values.

$\sigma_{\text {ap }}$ measurement precision uncertainty (Table 3). All sites demonstrate small and/or insignificant weekly $\sigma_{\text {sp }}$ cycle amplitudes ( $\sim 20 \%$ or less) and a lack of weekly $\sigma_{\text {sp }}$ patterns across seasons (Fig. 3). This suggests that weekly $\sigma_{\text {sp }}$ cycles are driven by regional-scale phenomena, where any weekend effects are smoothed out by mixing. The weekly cycles of intensive AOPs are nearly always minimal at all sites (Figs. S9-S15).
Similar to the weekly $\sigma_{\text {ap }}$ cycles, the diurnal $\sigma_{\text {ap }}$ cycles are also much larger than diurnal $\sigma_{\mathrm{sp}}$ cycles at all sites. However, the diurnal $\sigma_{\text {ap }}$ variability is only significant during summer and (at all sites except APP) fall. Diurnal cycles of nearly all intensive AOPs are minimal and/or insignificant. Notable exceptions are $\omega_{0}$ and DRFE during summer and fall. The amplitudes of the diurnal $\omega_{0}$ cycles are $\sim 0.03-0.04$ during summer and fall at all sites (Fig. S12). In most of these cases, 
(a)

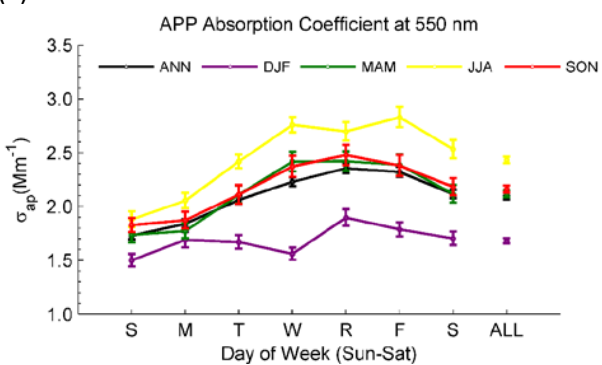

(c)

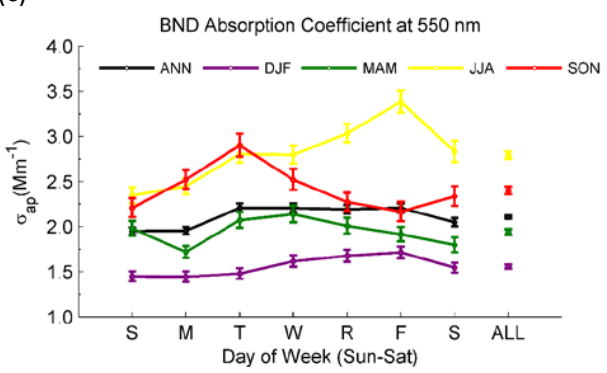

(e)

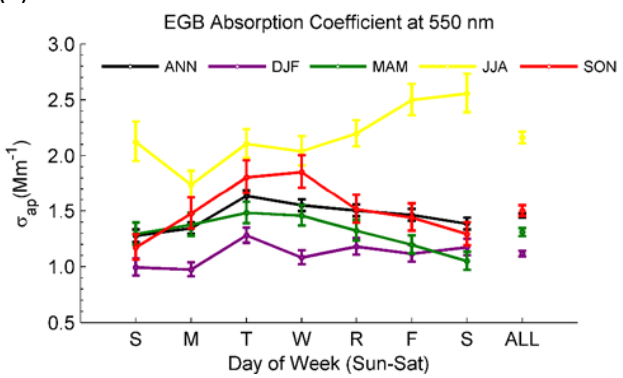

(g)

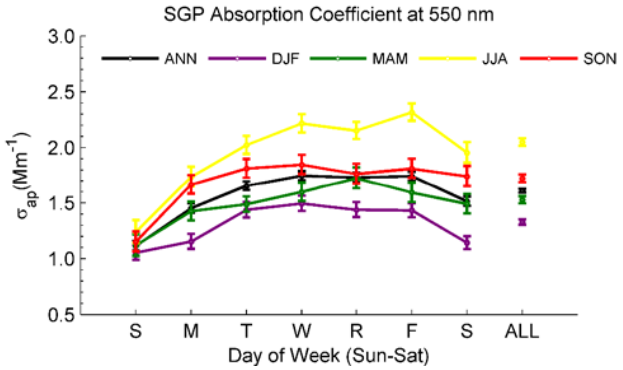

(b)

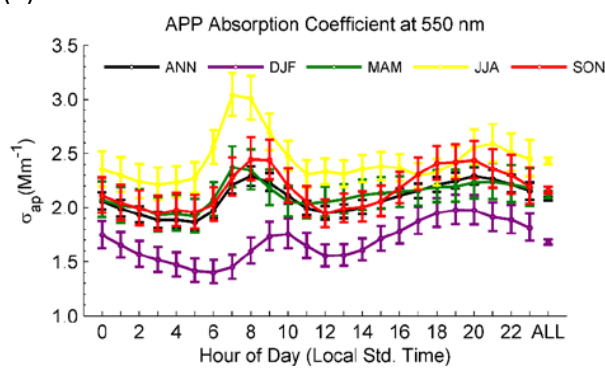

(d)

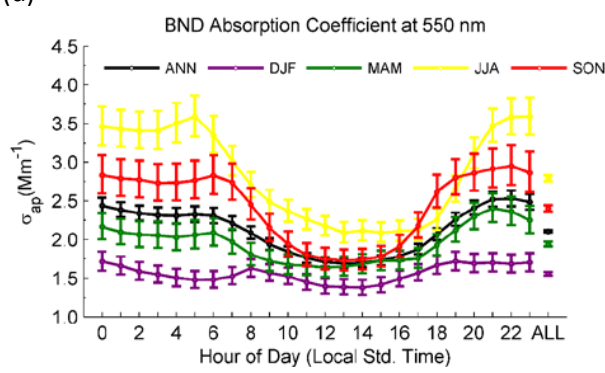

(f)

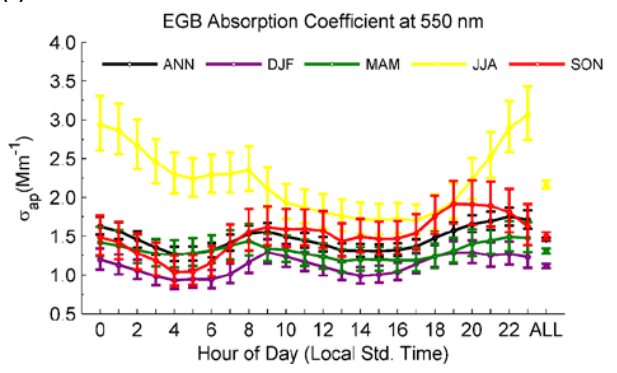

(h)

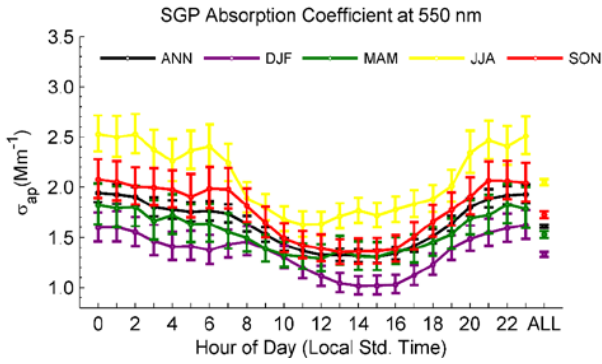

Figure 4. Weekly and diurnal cycles of geometric mean $\mathrm{PM}_{1} \sigma_{\mathrm{ap}}$ over full years (ANN traces) and for individual seasons at APP, BND, EGB, and SGP over the 2010-2013 period. The value corresponding to the "ALL" data point is the mean value over all days of the week or over all hours of the day. Error bars represent $95 \%$ confidence intervals of the mean values.

$\omega_{0}$ is lowest during late evening and/or early morning and highest during afternoon. At APP, the $\omega_{0}$ peak extends from around noon to the early morning hours. Diurnal DRFE cycles (Fig. S13) in turn follow the diurnal $\omega_{0}$ cycles, due to the lack of diurnal variability in b. Summer and fall DRFE is more negative by $\sim 3 \mathrm{~W} \mathrm{~m}^{-2} \mathrm{AOD}^{-1}$ during the afternoon than during the surrounding hours (Fig. S13). The lack of diurnal and weekly variability in mean $b, R_{\mathrm{sp}}$, and $\alpha_{\mathrm{sp}}$ indicates that particle size distributions at APP, BND, and SGP likely demonstrate little variability on weekly or daily timescales. D\&O2002 reported similar or slightly smaller $\omega_{0}$ and $b$ diurnal cycle amplitudes for BND and SGP, but they did not consider the diurnal cycles for individual seasons. 


\subsubsection{Temporal variability at APP}

Aerosol light scattering and absorption coefficients at APP are dominated by $\mathrm{PM}_{1}$ for all seasons and the relative influence of $\mathrm{PM}_{1}$ varies little with season, as seen by $R_{\mathrm{sp}}$ values of $0.80-0.88$ (Fig. 2c), $\alpha_{\mathrm{sp}}$ values of 1.9-2.2 (Fig. 2g), and $R_{\text {ap }}$ values of $0.90-0.95$ (Fig. S8c). Both $\sigma_{\text {sp }}$ and $\sigma_{\text {ap }}$ are moderately elevated for NE wind sectors, with $0-90^{\circ}$ wind directions (Fig. 5). Median $\sigma_{\text {ap }}$ is $\sim 20-30 \%$ higher for NE wind sectors than for the prevalent westerly wind sectors for all seasons except winter, when $\sigma_{\text {ap }}$ for the NE wind sectors is $\sim 2$ times higher than $\sigma_{\text {ap }}$ for westerly wind sectors (not shown). Median $\sigma_{\mathrm{sp}}$ is less elevated for the NE wind sectors (typically $\sim 10-15 \%$ ). Wind sector does not strongly influence median or mean values of most intensive AOPs, although low $\omega_{0}(<0.80)$ is more frequently associated with NE wind sectors (Fig. S17a). It should be noted that the prevalent westerly wind sectors represent the confluence of 3-4 (seasonally dependent) different average air mass backtrajectories, which all typically arrive at APP from the west. Link et al. (2015) reported that aerosol and gas phase chemistry measured at APP displayed a generally homogeneous distribution across source regions. One exception was elevated levels of urban, oil and natural gas, combustion tracers, and OA mass concentrations associated with air mass backtrajectories passing over the polluted Ohio River valley and Appalachian mountain region before arriving at APP with $\sim 0-90^{\circ}$ wind directions (Link et al., 2015).

$\mathrm{PM}_{1} \sigma_{\mathrm{sp}}$ at APP and its seasonality (Fig. 2a) are largely influenced by regional background SOA and sulfate. Biogenic SOA and sulfate both exhibit summer maxima and winter minima in the SE US (Goldstein et al., 2009; Hidy et al., 2014) and both summer and winter non-refractory $\mathrm{PM}_{1}$ aerosol mass at APP are dominated by SOA and sulfate (Supplement of Link et al., 2015). Summer $\sigma_{\text {sp }}$ at APP is correlated with both $\mathrm{OA}$ and sulfate mass concentrations $(r=0.60$ and $r=0.62$, respectively). The temperature dependence of $\mathrm{PM}_{1} \sigma_{\mathrm{sp}}$ at APP during April-October (Fig. S7) also agrees well with the expected temperature dependence of biogenic emissions (Guenther et al., 2006) and with the temperature dependence of AOD over the SE US (Goldstein et al., 2009). The summer $\sigma_{\text {sp }}$ peak coincides with a distinct minima in $b$ (30-40\% lower than all other seasons) and maxima in $\omega_{0}$ ( $\sim 0.07$ higher than during winter). Aerosol number concentrations measured at APP are also lower in summer than during spring and fall (unpublished result). The confluence of lower concentrations of larger, highly reflective $\mathrm{PM}_{1}$ particles during months with high regional temperatures, solar irradiance, and $\mathrm{RH}$ is consistent with gas-to-particle conversion onto existing particles.

The annual $\sigma_{\text {ap }}$ cycle at APP (Fig. 2b) is out of phase with the annual cycle of EC concentrations reported for rural eastern US IMPROVE sites (Hand et al., 2012b). Hand et al. (2012b) cited sources such as residential heating for the fall and winter EC concentration maxima. Absorption

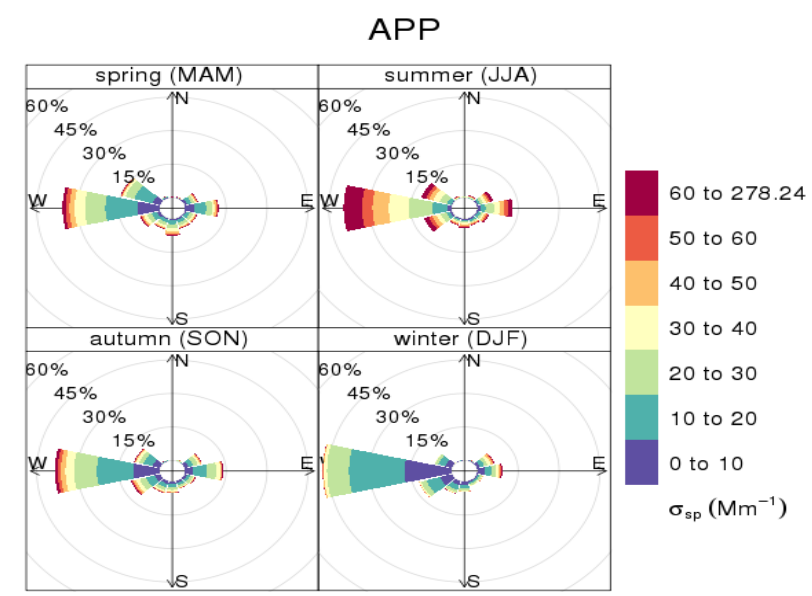

(b)

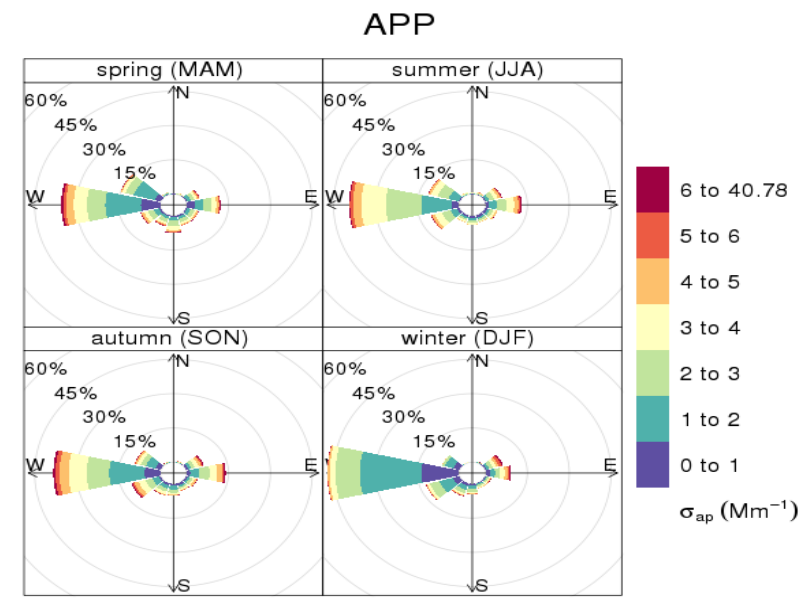

Figure 5. Pollution rose diagrams of $\mathrm{PM}_{1} \sigma_{\mathrm{sp}}$ and $\sigma_{\text {ap }}$ for individual seasons at APP over the 2010-2013 period. The percentages at a given radius represent the percentage of hourly profiles for a given wind sector.

coefficient at APP exhibits a summer maximum and a winter minimum, though the summer $\sigma_{\text {ap }}$ maximum is not significantly different from early fall and spring $\sigma_{\text {ap }}$ (to $95 \%$ confidence). Absorption Ångström exponents of 1.3-1.4 (Fig. 2h) and $\alpha_{\mathrm{sp}}>2$ during colder months (Fig. 2h) suggest a mixture of EC and light-absorbing OC (Fig. 2 of Cazorla et al., 2013). A contribution to $\sigma_{\text {ap }}$ from OC is also consistent with a biomass-burning OA factor in the winter aerosol mass spectra measured at APP (Fig. S2 of Link et al., 2015) and may result from winter residential wood-burning (US Census Bureau, 2010; Zhang et al., 2010). However, the diurnal $\sigma_{\text {ap }}$ cycles (Fig. 4b) suggest an influence from local traffic during all seasons and $\alpha_{\text {ap }}$ values of 1 or less for non-winter months suggest that $\mathrm{BC}$ is the major contributor to $\sigma_{\mathrm{ap}}$ during these months. 
APP is the only site to demonstrate consistent weekly $\sigma_{\mathrm{sp}}$ and $\sigma_{\text {ap }}$ cycles across seasons, with the exception of winter. Local commuter traffic likely exerts the largest influence on the diurnal $\sigma_{\text {ap }}$ cycles (Fig. 4b) and possibly the weekly $\sigma_{\text {ap }}$ cycles (Fig. 4a). Diurnal $\sigma_{\text {ap }}$ cycles are only significant at $95 \%$ confidence during summer, but a similar bi-modal structure is seen for all seasons (Fig. 4b), with morning and late afternoon/early evening commuter peaks. The only sign of weekend local traffic influence is an insignificant Saturday morning peak $\Delta \sigma_{\text {ap }} \sim 0.1-0.2 \mathrm{Mm}^{-1}$ present during most seasons (unpublished result), confirming the primary influence of local commuter traffic. The absence of any influence of diurnal PBL height variation on the diurnal $\sigma_{\mathrm{ap}}$ cycles at APP is consistent with the relatively small afternoon/morning PBL height differences measured at the heavily forested APP site (unpublished result). PBL height is often poorly defined at APP and may be related to the fact that the APP site is situated on a ridge. The PBL and free troposphere do not fully decouple during the evening. As a result, pronounced late-evening through early morning $\sigma_{\mathrm{sp}}$ and $\sigma_{\mathrm{ap}}$ maxima that are characteristic of a PBL height influence are not a regular feature of the diurnal cycles at APP (Figs. 3b and $4 \mathrm{~b}$ ). Diurnal variability of $\sigma_{\mathrm{sp}}$ and intensive AOPs is insignificant and/or minimal for all seasons (Figs. S9-S15), with the exceptions of (1) morning $\omega_{0}$ decreases (by $\sim 0.02$ 0.03) DRFE increases (by $2-3 \mathrm{~W} \mathrm{~m}^{-2} \mathrm{AOD}^{-1}$ ) during all seasons, coinciding with the commuter traffic; and (2) a small summer daytime decrease ( 0.6 to 0.4 ) in $\alpha_{\text {ap }}$, possibly due to coating of absorbing particles (Gyawali et al., 2009) or an artifact associated with filter-based $\sigma_{\text {ap }}$ measurements (Lack et al., 2008, 2009).

The spring, summer, and fall weekly $\sigma_{\mathrm{sp}}$ and $\sigma_{\mathrm{ap}}$ cycles at APP (Figs. 3a and 4a) are characterized by early week increases leading to broad Wednesday-Friday maxima. Both $\sigma_{\text {sp }}$ and $\sigma_{\text {ap }}$ begin to increase near the time of the Monday morning traffic peak (unpublished result) and decrease over the weekend, coinciding with less weekend traffic. The weekly $\sigma_{\mathrm{sp}}$ and $\sigma_{\mathrm{ap}}$ cycles are likely the result of a build-up of scattering and absorbing aerosols in the PBL during the first half of the week. Sunday $\sigma_{\text {ap }}$ minima and weekly cycle amplitudes of $\sim 25-35 \%$ during spring and fall are consistent with the timing and amplitudes of weekly EC concentration cycles reported for the rural US (Murphy et al., 2008) and with weekday-weekend EC concentration differences in the urban US (Bae et al., 2004; Blanchard et al., 2008). Smaller but significant weekly $\sigma_{\mathrm{sp}}$ cycle amplitudes of $\sim 15-20 \%$ during spring, summer, and fall are larger than weekly cycles in OC and sulfate reported by Murphy et al. (2008). Absorption coefficient exhibits a larger summer weekly cycle amplitude of $\sim 50 \%$ (Fig. 4a) than $\sigma_{\text {sp }}$ (Fig. 3a). Local traffic is less during summer, but construction activity and road repairs on the Appalachian State University campus and in town are higher so a larger influence from diesel emissions could be a source for the larger $\sigma_{\text {ap }}$ cycle during summer. Local traffic influences on the weekly and diurnal $\sigma_{\text {ap }}$ cy- cles during winter may be masked by other sources of EC, such as wood-burning. Small weekly cycles in several intensive AOPs are consistent with the above-discussed local traffic influence. Single-scattering albedo decreases by $\sim 0.02$ from Sunday to Wednesday during fall/winter (Fig. S12) with smaller decreases during spring/summer. DRFE increases by $\sim 2 \mathrm{~W} \mathrm{~m}^{-2} \mathrm{AOD}^{-1}$ from Sunday to Wednesday during fall/winter, with smaller insignificant increases in spring/summer (Fig. S13). Absorption Ångström exponent increases during the week by $\sim 0.2(0.4$ to 0.6$)$ during summer, with smaller, insignificant increases $(\sim 0.1)$ during fall and winter (Fig. S15).

\subsubsection{Temporal variability at BND}

$\mathrm{PM}_{1}$ particles contribute $\sim 76 \%(72 \%)$ to the summer (winter) $\mathrm{PM}_{10} \sigma_{\mathrm{sp}}$ and $88 \%(\sim 80 \%)$ to the summer (winter) $\mathrm{PM}_{10} \sigma_{\text {ap }}$ at BND (Figs. 2c and S8c). The annual $\mathrm{PM}_{1}$ and $\mathrm{PM}_{10} \sigma_{\mathrm{ap}}$ and $\sigma_{\mathrm{sp}}$ cycles are similar for all seasons (Figs. 2 and S8) so the $\mathrm{PM}_{1}$ AOP cycles at BND are representative of the $\mathrm{PM}_{10}$ aerosol. Many of the same general features of the $\sigma_{\mathrm{sp}}$ annual cycle at BND (Fig. 2a) have been reported by others (D\&O2002; Koloutsou-Vakakis et al., 2001), including the July-August $\sigma_{\mathrm{sp}}$ maximum and early autumn $\sigma_{\mathrm{sp}}$ minimum. D\&O2002 reported similar summer-autumn and summer-spring $\sigma_{\mathrm{sp}}$ differences, with median $\sigma_{\mathrm{sp}}$ values in July approximately 2 times larger than $\sigma_{\mathrm{sp}}$ in OctoberNovember and $\sim 1.5$ times larger than $\sigma_{\mathrm{sp}}$ in April-May. The $\sigma_{\text {ap }}$ annual cycle reported by $\mathrm{D} \& \mathrm{O} 2002$ was also very similar to that shown in Fig. 2b, except for an October $\sigma_{\text {ap }}$ maxima in their study. Planetary boundary layer heights reported for nearby Joliet, IL by Holzworth (1964) were approximately 3 times higher in summer than in winter, suggesting that summer aerosol production must be much higher (and/or sinks be much lower) to maintain the observed higher summer aerosol loading in the mixed layer.

Regional aerosol transport associated with southerly wind sectors (SE to SW wind directions) exerts a large influence on $\sigma_{\mathrm{sp}}$ during all seasons (Fig. 6a). Northerly wind sectors (NW to NE wind directions) exert a comparable or larger influence on $\sigma_{\mathrm{sp}}$ during winter months. Much of the light-scattering aerosol arriving from the south is likely secondary sulfate associated with the high-density of coalburning power plants in southern Illinois and the Ohio River valley region (Buzcu-Guven et al., 2007). Summer $\sigma_{\mathrm{sp}}$ may also be influenced by biogenic SOA. Median summer temperatures are $\sim 3^{\circ} \mathrm{C}$ higher for $\mathrm{SW}$ winds at $\mathrm{BND}$ than for $\mathrm{SE}$ winds and the forests over SW Illinois and SE Missouri emit high amounts of isoprene during summer (Fig. 3 of Parworth et al., 2015). Scattering coefficient for SW wind directions exhibits a sharp July peak and the temperature dependence of $\sigma_{\mathrm{sp}}$ at BND during April-October demonstrates modest agreement ( $r=0.47$, as shown in Fig. S7) with the exponential temperature dependence of biogenic volatile organic compound emissions (Guenther et al., 2006). The secondary 
(a)

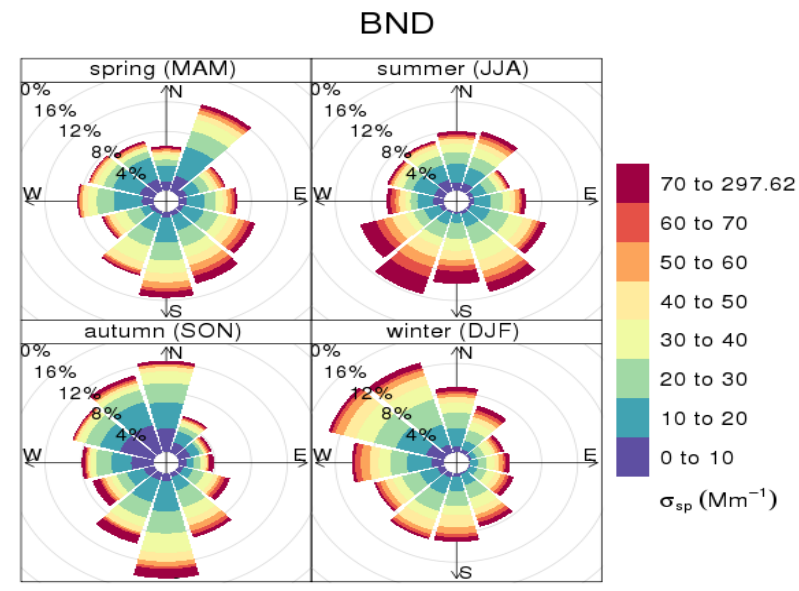

(b)

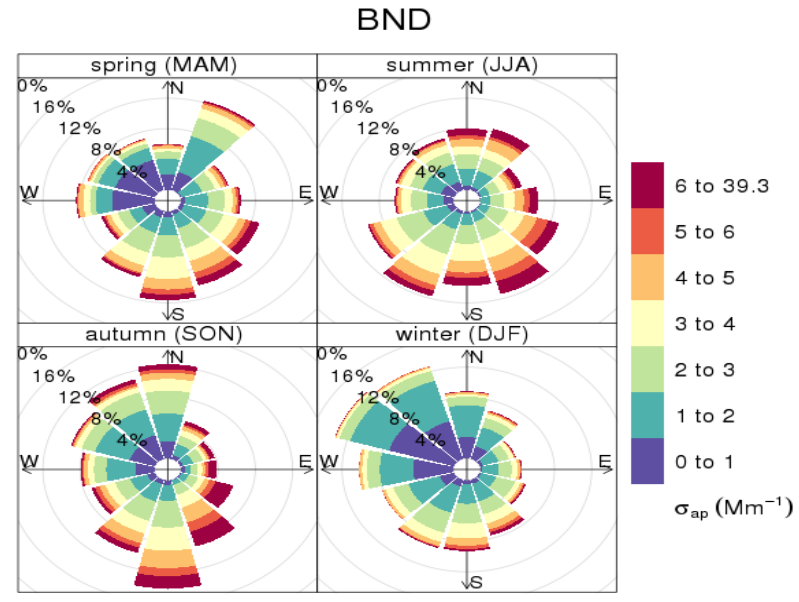

Figure 6. Pollution rose diagrams of $\mathrm{PM}_{1} \sigma_{\mathrm{sp}}$ and $\sigma_{\mathrm{ap}}$ for individual seasons at BND over the 2010-2013 period. The percentages at a given radius represent the percentage of hourly profiles for a given wind sector.

$\mathrm{PM}_{1} \sigma_{\text {sp }}$ peak during winter months at BND (Fig. 2a) may be influenced by temperature dependent gas-to-particle partitioning of regional ammonia and nitric acid into ammonium nitrate. Rupakheti et al. (2005) reported that gas-phase ammonia correlated positively with particulate ammonium and nitrate mass concentrations for temperatures below $12^{\circ} \mathrm{C}$ and that more ammonia remained in the gas phase for $T>12^{\circ} \mathrm{C}$. The temperature dependence of median $\mathrm{PM}_{1} \sigma_{\mathrm{sp}}$ at $\mathrm{BND}$ changes sign (positive to negative) for temperatures less than $\sim 10^{\circ} \mathrm{C}$, nearly doubling as temperature decreases from $\sim 10$ to $\sim-5^{\circ} \mathrm{C}$ (Fig. S5). The $\sigma_{\mathrm{sp}}$ increase is accompanied by an increase in median $\omega_{0}$ from 0.89 to 0.96 (Fig. S6); and a decrease in median $b$ from 0.15 to 0.13 . Addition of large, highly scattering $\mathrm{PM}_{1}$ particles at low temperatures is consistent with high winter ammonium nitrate concentrations reported for BND (Buzcu-Guven et al., 2007). Much of the winter $\sigma_{\mathrm{sp}}$ increase is likely due to regional transport from the north. Winter $\sigma_{\mathrm{sp}}$ exhibits the largest increase for northerly wind sectors (Fig. 6a) with winter $\sigma_{\text {sp }}$ a factor of $\sim 1.5-3$ larger than spring and fall $\sigma_{\mathrm{sp}}$. Winter $\omega_{0}$ and $b$ are highest for the northerly wind directions, with $\omega_{0} \geq 0.93$ and $b<0.15$ for a majority of the arriving air masses (Fig. S19). Northerly wind sectors are typically associated with colder air mass traveling over regions with high concentrations of ammonium and nitrate precursor gases (Hand et al., 2012b). Temperature-dependent ammonium nitrate production is also consistent with the highly variable timing and magnitude of the winter $\sigma_{\text {sp }}$ peak for individual years (Fig. S2). Lower winter PBL heights during winter (Holzworth, 1964) likely also contribute to elevated winter $\sigma_{\mathrm{sp}}$. Variability in winter PBL heights could conceivably contribute to winter $\sigma_{\mathrm{sp}}$ variability.

Diurnal $\sigma_{\mathrm{sp}}$ cycles are insignificant for all seasons except for a marginally significant fall amplitude of $\sim 25 \%$ (Fig. 3d). Diurnal $\sigma_{\text {ap }}$ cycle amplitudes (Fig. 4d) are much larger than those of $\sigma_{\mathrm{sp}}$ during all seasons except winter. Differences between $\sigma_{\mathrm{ap}}$ and $\sigma_{\mathrm{sp}}$ diurnal cycle amplitudes are largest in summer ( $\sim 60$ vs. $10 \%)$ and are also non-negligible in fall $(\sim 50$ vs. $\sim 25 \%)$ and spring $(\sim 40$ vs. $\sim 20 \%$ ). Diurnal $\sigma_{\text {ap }}$ and $\sigma_{\text {sp }}$ cycles are both smallest during winter, with cycle amplitudes of $\sim 10 \%$. The influence of diurnal PBL height cycle is clearly seen in the diurnal $\sigma_{\text {ap }}$ cycles (Fig. 4d) and a smaller PBL height influence is seen in the $\sigma_{\mathrm{sp}}$ cycles. The differences between $\sigma_{\mathrm{ap}}$ and $\sigma_{\mathrm{sp}}$ cycle amplitudes during summer and (to a lesser degree) fall and spring suggests a large additional source of scattering aerosols during summer daytime hours. Photochemical aerosol processing is the only source of scattering particles whose diurnal and seasonal dependence can explain the seasonality of differences between the $\sigma_{\mathrm{ap}}$ and $\sigma_{\mathrm{sp}}$ cycle amplitudes. It is also consistent with the seasonality of sulfate mass concentrations reported for BND (Buzcu-Guven et al., 2007). Weekly $\sigma_{\text {sp }}$ cycles are statistically significant for all seasons, but the cycle amplitudes are less than $15 \%$ for all seasons except fall. Our weekly $\sigma_{\mathrm{sp}}$ cycle amplitude for the entire year (Fig. 3c) is similar to that of Murphy et al. (2008).

Regional pollution transport associated with southerly wind sectors also influences the annual $\sigma_{\text {ap }}$ cycle at BND over all seasons (Fig. 6b). Highest $\sigma_{\mathrm{ap}}$ for the southerly wind sectors occurs during summer and fall and southerly winds are most common in summer (Fig. 6a), leading to the summer $\sigma_{\text {ap }}$ maxima (Fig. 2b). Lowest $\sigma_{\text {ap }}$ for the southerly wind sectors occurs during winter and air masses from the less anthropogenically perturbed W/NW reach the site most frequently in winter (Fig. 6b), leading to the winter $\sigma_{\text {ap }}$ minima. The difference between the month of maximum $\sigma_{\mathrm{ap}}$ (August) and that reported by D\&O2002 (October) could be due to differences in the seasonality of wind directions between the two periods. It could also arise due to differences in the seasonality of removal mechanisms such as precipitation between the 
periods, but this would have likely also shifted the month of maximum $\sigma_{\mathrm{sp}}$.

The weekly and diurnal $\sigma_{\text {ap }}$ cycles during summer and autumn (Fig. 4c, d) are consistent with a large influence from regional diesel emissions during these seasons and possibly during other seasons, although the weekly and diurnal $\sigma_{\mathrm{ap}}$ cycles are only significant in summer and autumn. Maximum $\sigma_{\mathrm{ap}}$ extends from sunset to sunrise for all seasons (Fig. 4d), with a broad minimum extending from just after sunrise to just before sunset. Large seasonality of PBL heights is obvious in the diurnal $\sigma_{\text {ap }}$ cycles (Fig. 4d), consistent with large (factor of 3) summer-to-winter PBL height differences reported for the region by Holzworth (1964). The absence of early morning and late afternoon local commuter peaks at BND is not surprising, since emissions from interstate highway traffic and agricultural activity represent the largest local sources of absorbing aerosols. Long-distance trucking comprises a large portion of interstate highway traffic in the region and both this and farming activities typically persist throughout the day. The diurnal $\sigma_{\text {ap }}$ cycles for individual days of the week show the same broad features as the corresponding weekly integrated diurnal $\sigma_{\text {ap }}$ cycles (Fig. 4d) for all seasons, with the exception of differences between post-dusk and pre-dawn $\sigma_{\mathrm{ap}}$ for individual days of the week (unpublished result). During summer, post-dusk $\sigma_{\mathrm{ap}}$ is slightly larger than pre-dawn $\sigma_{\text {ap }}$ for each day during Monday-Friday, leading to a gradual build-up of absorbing aerosols in the PBL. Post-dusk $\sigma_{\mathrm{ap}}$ is less than pre-dawn $\sigma_{\mathrm{ap}}$ on Saturday and Sunday. The resulting weekly $\sigma_{\text {ap }}$ cycle (Fig. $4 \mathrm{c}$ ) and the $\sigma_{\text {ap }}$ cycles for individual days suggest a nearly constant source of absorbing aerosols from sunrise to sunset, with the largest emissions from Monday to Friday. Both interstate truck traffic and farming activities are consistent with the observed diurnal and weekly patterns during summer, but truck traffic is likely the source more capable of contributing to the large summer diurnal and weekly $\sigma_{\text {ap }}$ cycle amplitudes (60 and $40 \%$, respectively), given the higher summer PBL heights in the region. The fall weekly $\sigma_{\text {ap }}$ cycle (Fig. $4 \mathrm{c}$ ) also exhibits a build-up of absorbing aerosols from Monday to Tuesday, followed by lower aerosol loading during the remainder of the week. This cycle is not consistent with known weekly cycles in truck traffic or agricultural practices near the site. Scattering coefficient exhibits a similar weekly cycle as $\sigma_{\text {ap }}$ during autumn (Fig. 3c) and the weekly $\sigma_{\mathrm{ap}}$ and $\sigma_{\mathrm{sp}}$ cycle amplitudes are similar $(\sim 25 \%)$ during fall. Similarities in the autumn weekly $\sigma_{\mathrm{ap}}$ and $\sigma_{\mathrm{sp}}$ cycles could simply be the result of a smaller compensating effect on $\sigma_{\mathrm{sp}}$ from daytime secondary aerosol production during autumn (e.g., less photochemistry) or it could be due to sources of scattering and absorbing aerosols that are more similar in autumn than in summer. Diesel emissions from agricultural activity would seem more capable of contributing to the weekly $\sigma_{\text {ap }}$ cycle during autumn, when PBL heights are lower. Biomass burning is a less likely source, even though Buzcu-Guven et al. (2007) reported a significant biomass-burning influence (a)

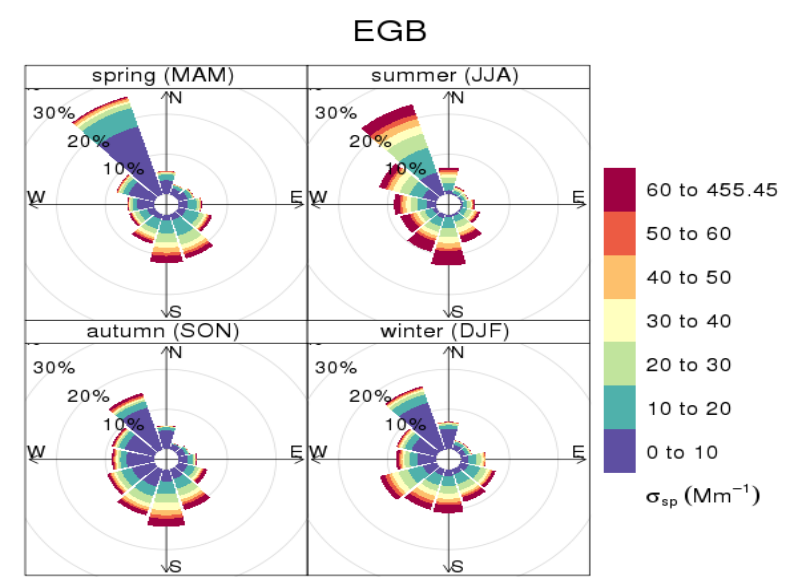

(b)

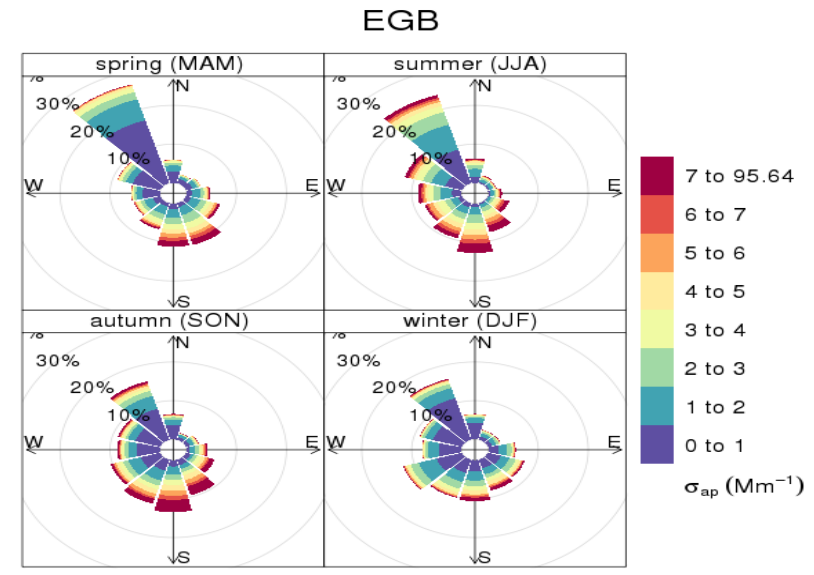

Figure 7. Pollution rose diagrams of $\mathrm{PM}_{1} \sigma_{\mathrm{sp}}$ and $\sigma_{\mathrm{ap}}$ for individual seasons at EGB over the 2010-2013 period. The percentages at a given radius represent the percentage of hourly profiles for a given wind sector.

on OM mass (38\%) at BND. Absorption Ångström exponent demonstrates minimal day of week variability during autumn (Fig. S15) and $\alpha_{\text {ap }}$ values of 1.1-1.2 are not statistically different from the theoretical value of 1 for $\mathrm{BC}$ (Bergstrom et al., 2002).

\subsubsection{Temporal variability at EGB}

Annual $\mathrm{PM}_{1} \sigma_{\mathrm{sp}}$ and $\sigma_{\mathrm{ap}}$ cycles at EGB (Fig. 2a and b) are influenced by more polluted southerly air masses (120$240^{\circ}$ wind directions) during all seasons, along with comparable contributions from less anthropogenically perturbed W/NW wind sectors during summer months (Fig. 7). Liggio et al. (2010) reported that S/SE wind directions were generally associated with transport from the greater Toronto area and that SW wind directions were often associated with more 
aged aerosol transported from the Ohio River valley region or other urban areas. Wind speeds are lower in May-October and polluted air masses from the south are typically associated with stagnant air masses ahead of fronts (Yang et al., 2011).

Scattering coefficient is elevated for all wind sectors during summer (Fig. 7a). Warm-season aerosol chemistry at EGB is influenced by temperature-dependent biogenic SOA from forests to the north (Leaitch et al., 2011; Slowik et al., 2010) and by photo-oxidation of anthropogenic pollutants from the south (Chan et al., 2010; Liggio et al., 2010). Scattering coefficients exhibit larger summer increases for the less anthropogenically perturbed wind sectors (all except $120-240^{\circ}$ wind directions) than for the southerly wind sectors (Fig. 7a). Monthly median $\sigma_{\text {sp }}$ for the southerly wind sectors are $\sim 1.5$ times higher in summer than in spring and autumn, with larger summer $\sigma_{\mathrm{sp}}$ increases (factor of 2-5) for the other wind sectors (unpublished result). The largest summer $\sigma_{\text {sp }}$ increases are for NW wind sectors (Fig. 7a). In addition to biogenic SOA, the NW wind sectors are influenced in summer by regional tourist traffic and by episodic longrange transport of smoke during peak fire season in northwest Canada. However, it is not possible to distinguish the effects of aged smoke from biogenic SOA from forests, based on the available aerosol optical measurements during the 2010 2013 period at EGB. The secondary $\sigma_{\mathrm{sp}}$ peak in winter is influenced by higher $\sigma_{\mathrm{sp}}$ associated with air masses from the S/SW (Fig. 7a), relative to spring and autumn. Winter $\sigma_{\mathrm{sp}}$ for wind directions $150-240^{\circ}$ is $\sim 2$ times higher than $\sigma_{\mathrm{sp}}$ from other wind sectors (not shown). Single-scattering albedo is also highest for the $150-240^{\circ}$ wind sectors in winter, with values often 0.95 or above (Fig. S20a). Rupakheti et al. (2007) reported episodic high nitrate concentrations associated with air masses transported from urban areas south of EGB, mostly occurring during cold, humid conditions. Scattering coefficient does not exhibit a noticeable increase with decreasing winter temperatures at EGB during the 20102013 period (Fig. S5). Meteorology likely plays a role in the elevated winter $\sigma_{\mathrm{sp}}$, as PBL heights in the region are lowest in winter at EGB (Horzworth, 1964).

The annual $\sigma_{\text {ap }}$ cycle (Fig. 2b) is qualitatively similar to annual EC mass concentration cycles reported for EGB (Yang et al., 2011) and for rural IMPROVE sites in the Great Lakes region (Spak and Holloway, 2009). Yang et al. (2011) reported mean EC concentrations (in units of $\mu \mathrm{g} \mathrm{m}^{-3}$ ) at EGB of 0.83 for summer, 0.71 for fall, 0.49 for winter, and 0.36 for spring. Spak and Holloway (2009) reported highest regional EC mass concentrations in summer and lowest in winter, with the June EC maxima $\sim 2.2$ times higher than the February EC minima. Our reported summer $\sigma_{\text {ap }}$ maxima in August is 2-2.5 times larger than the broad November-April minima (Fig. 2b).

Urban-influenced SE/S wind sectors are associated with highest $\sigma_{\mathrm{ap}}$ and lowest $\omega_{0}$ for all seasons (Figs. 7b and S20a). Chan et al. (2010) attributed higher $\sigma_{\mathrm{ap}}$, higher EC concen- trations, and lower OC / EC ratios in air masses arriving at EGB from the south to diesel emissions. Absorption coefficients are lowest in winter for all wind sectors and are largest for southerly wind sectors during summer and autumn (Fig. 7b), with monthly median $\sigma_{\text {ap }} \sim 1.5$ times higher in summer/autumn than in spring for these wind sectors. Much larger summer $\sigma_{\mathrm{ap}}$ increases (factors of $\sim 3-7$ ) are seen for westerly and northwesterly wind sectors (wind directions $\sim 240-360^{\circ}$ ). Episodic long-distance NW transport during the Canadian wildfire season may contribute to summer $\sigma_{\mathrm{ap}}$, but local/regional tourism traffic is more consistent with the observed summer weekly and diurnal $\sigma_{\text {ap }}$ cycles.

Weekly and diurnal $\sigma_{\text {ap }}$ cycles at EGB are significant in summer, marginally significant in autumn, and insignificant in winter and spring (Fig. 4e and f). Summer and autumn diurnal $\sigma_{\text {ap }}$ cycle amplitudes are $\sim 50 \%$ and summer and autumn weakly $\sigma_{\text {ap }}$ cycle amplitudes are $\sim 40 \%$. The diurnal and weekly cycles in $\sigma_{\text {ap }}$ during summer and autumn at EGB are more complicated than those at the other sites and are likely influenced to varying degrees by several sources, including (1) high volume of regional traffic during summer, largest on weekends; (2) transport of urban-influenced aerosol from the south; (3) diurnal PBL height evolution; and (4) local commuter traffic. Diurnal $\sigma_{\mathrm{ap}}$ cycles for individual days of the week reveal morning commuter peaks from Monday to Friday (unpublished result). Daytime $\sigma_{\mathrm{ap}}$ decreases due to lifting of the PBL height are dampened on each of these days by a large source of absorbing aerosol. Larger summer increases in $\sigma_{\text {ap }}$ for westerly wind sectors suggests a source in addition to transport from the south. The large additional source is likely regional tourism traffic. Differences between post-dusk and pre-dawn $\sigma_{\text {ap }}$ are small on Monday-Thursday (not shown) but are much larger on Friday $\left(\sim 1 \mathrm{Mm}^{-1}\right)$ and Saturday $\left(\sim 2 \mathrm{Mm}^{-1}\right)$ due to high volumes of weekend traffic. Post-dusk $\sigma_{\mathrm{ap}}$ on Sunday is $\sim 3 \mathrm{Mm}^{-1}$ lower than pre-dawn $\sigma_{\mathrm{ap}}$. The composite effect of these sources is the weekend $\sigma_{\mathrm{ap}}$ maxima and Monday minima during summer (Fig. 4e). The weekend $\sigma_{\text {ap }}$ increase gives rise to a small decrease $(0.02$ to 0.03$)$ in $\omega_{0}$ and a small increase $\left(\sim 2 \mathrm{~W} \mathrm{~m}^{-2} \mathrm{AOD}^{-1}\right)$ in DRFE (Figs. S12, S13) Diurnal $\sigma_{\mathrm{sp}}$ cycles for individual days of the week during summer reveal some of the same features as $\sigma_{\mathrm{ap}}$ (unpublished result) but are further complicated by an additional large source of daytime scattering aerosol, likely photochemical production and transport of SOA.

The autumn diurnal $\sigma_{\text {ap }}$ cycle (Fig. 4e) appears to be more influenced by frequent transport from the south (Fig. 7b), along with less regional traffic than during summer. Monthly averaged $\sigma_{\text {ap }}$ during September-October (Fig. 2b) remains near summer levels (except for August), but $\sigma_{\text {ap }}$ is much lower for all wind sectors except the urban-influenced southerly wind sectors, for which $\sigma_{\text {ap }}$ was similar in value to summer (Fig. 7b). The diurnal $\sigma_{\text {ap }}$ and $\sigma_{\text {sp }}$ cycles exhibit very little structure during fall so lower fall PBL heights may be partially offset by lower production of scattering 
and absorbing aerosol and/or more efficient removal mechanisms. Some additional source may be responsible for the early week increase in $\sigma_{\mathrm{ap}}$, similar to that observed during autumn at BND (Fig. 4c). The source of absorbing aerosol persists throughout the day and into the evening (not shown) and may be local agricultural activities.

\subsubsection{Temporal variability at SGP}

$\mathrm{PM}_{1}$ particles contribute $\sim 66 \%(78 \%$ ) to the summer (winter) $\mathrm{PM}_{10} \sigma_{\mathrm{sp}}$ and $\sim 85 \%$ to both summer and winter $\mathrm{PM}_{10}$ $\sigma_{\text {ap }}$ at SGP (Figs. 2c and S8c). The annual $\mathrm{PM}_{1}$ and $\mathrm{PM}_{10}$ $\sigma_{\mathrm{ap}}$ and $\sigma_{\mathrm{sp}}$ cycles are similar (Figs. $2 \mathrm{a}$ and $\mathrm{S} 8 \mathrm{a}$ ) so the $\mathrm{PM}_{1}$ AOP cycles at SGP are representative of the $\mathrm{PM}_{10}$ aerosol. The annual $\mathrm{PM}_{1} \sigma_{\text {ap }}$ cycle (Fig. 2b) demonstrates good overall agreement with the annual $\mathrm{PM}_{10} \sigma_{\text {ap }}$ cycle reported by D\&O2002 for 1997-2000, with the exception that their winter $\sigma_{\text {ap }}$ minima extends from November to February, while our $\sigma_{\mathrm{ap}}$ minima extends from January to February. The annual $\mathrm{PM}_{1} \sigma_{\mathrm{sp}}$ cycle during 2010-2013 (Fig. 2a) also agrees well with that reported by $\mathrm{D} \& \mathrm{O} 2002$ for most non-winter months. D\&O2002 reported a broad summer maxima, with monthly median $\sigma_{\mathrm{sp}}$ values lying $\sim 30-40 \%$ above spring and autumn months. Our $\sigma_{\mathrm{sp}}$ cycle during non-winter months differs only by a larger summer-to-autumn $\sigma_{\mathrm{sp}}$ decrease of close to factor of 2. Agreement is worse for winter months. Both D\&O2002 and Sheridan et al. (2001) reported minimum $\sigma_{\mathrm{sp}}$ in December and maximum in February, with median February $\sigma_{\mathrm{sp}}$ a factor of $\sim 4$ higher than December. Box plots of monthly binned $\sigma_{\mathrm{sp}}$ for individual 2010-2013 years (Fig. S4) show that median February $\sigma_{\mathrm{sp}}$ at SGP varies by up to a factor of 4 for different years, with somewhat smaller differences between individual January months (factor of $\sim 2$ ) and between individual March months (factor of $\sim 2-3$ ). Much of the inter-annual variability is smoothed out in the monthly binned $\sigma_{\mathrm{sp}}$ box plot for the entire period (Fig. S3), giving rise to relatively constant monthly mean $\sigma_{\mathrm{sp}}$ during winter for the current period (Fig. 2a). Lower December $\sigma_{\mathrm{sp}}$ and much higher February $\sigma_{\mathrm{sp}}$ occurred during the period reported by D\&O2002 and Sheridan et al. (2001), compared to the period reported here.

Pollution transport from the S/SE impacts $\mathrm{PM}_{1} \sigma_{\mathrm{ap}}$ and $\sigma_{\mathrm{sp}}$ throughout the year (Fig. 8). Wind directions are primarily from the S/SE for non-winter months (especially summer). Air mass back-trajectories show that air masses arriving at SGP from the S/SE often travel over or near large regional populations centers, including Oklahoma City, Tulsa, and (in summer) Dallas/Fort Worth (Parworth et al., 2015). Singlescattering albedo is generally lower for S/SE wind sectors than for the less anthropogenically influenced westerly and northerly wind sectors, except during summer (Fig. S22a). A large fraction of non-refractory $\mathrm{PM}_{1}$ aerosol mass $(\sim 70 \%)$ is aged SOA during April-October (Parworth et al., 2015). Many SE trajectories pass over regions of high summer isoprene emissions (Parworth et al., 2015), but the temperature (a)

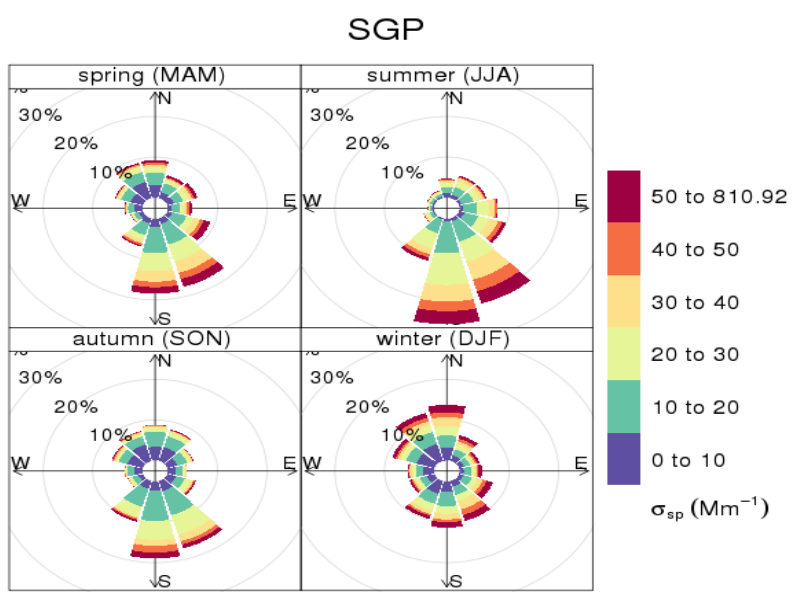

(b)

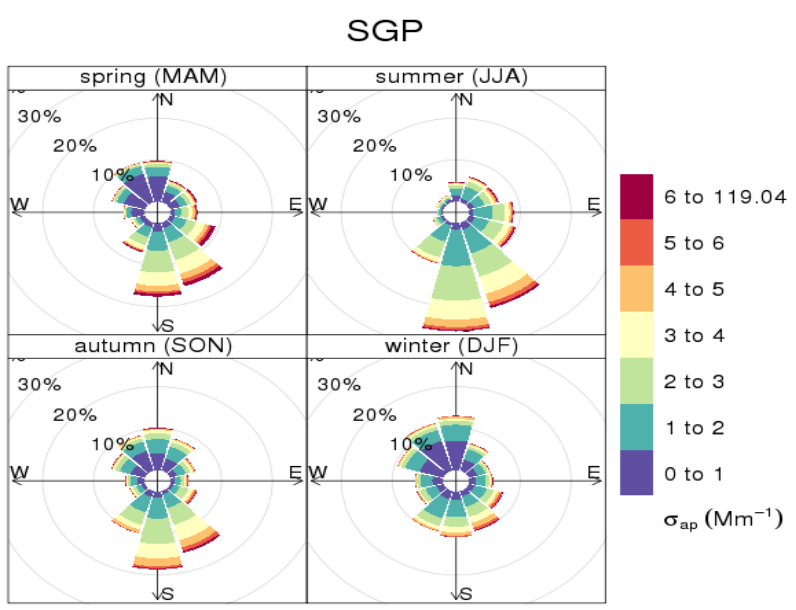

Figure 8. Pollution rose diagrams of $\mathrm{PM}_{1} \sigma_{\mathrm{sp}}$ and $\sigma_{\mathrm{ap}}$ for individual seasons at SGP over the 2010-2013 period. The percentages at a given radius represent the percentage of hourly profiles for a given wind sector.

dependence of $\sigma_{\mathrm{sp}}$ (Figs. S5 and S7) is less than for the sites with known biogenic SOA influence (EGB and APP). Absorption Ångström exponent values close to 1 for all seasons (Fig. 2h) suggest that despite high organic composition, light-absorbing OC exerts a minimal influence on the annual $\sigma_{\text {ap }}$ cycle and that most of the absorbing aerosol is BC. Daily averages of $\alpha_{\mathrm{ap}}$ can have values that extend to as high as 2.5 (unpublished result), which is consistent with observed plumes of biomass-burning aerosol reported by Parworth et al. (2015). Other than lower $\sigma_{\mathrm{sp}}$ during autumn, $\sigma_{\mathrm{sp}}$ and $\sigma_{\mathrm{ap}}$ for the S/SE wind sectors do not demonstrate much seasonality (Fig. 8). The lack of seasonal variability in mean $\sigma_{\mathrm{ap}}$ and $\sigma_{\mathrm{sp}}$ during non-winter months (relative to the other sites) may be due to a longer distance from the population centers (increased aerosol dispersion) and higher PBL heights at 
SGP during spring, summer, and autumn. Removal processes may also be more efficient in late spring and summer, when monthly averaged rainfall at SGP is highest.

The frequency of episodic transport of ammonium nitrate to SGP likely exerts some influence on winter $\sigma_{\mathrm{sp}}$ and its variability. Parworth et al. (2015) reported that ammonium nitrate comprised approximately half of the non-refractory $\mathrm{PM}_{1}$ mass at SGP during the 2010-2011 and 2011-2012 winters and early springs (e.g., March) (their Figs. 2 and 6). Ammonia and $\mathrm{NO}_{x}$ concentrations near SGP are relatively small and high nitrate episodes (mass concentrations $>3 \mu \mathrm{g} \mathrm{m}^{-3}$ ) were nearly always associated with temperatures $<3{ }^{\circ} \mathrm{C}$ and long-distance transport from agricultural states in the central Great Plains region. Colder temperatures and more frequent long-distance transport passing over these states likely contributed to nearly a factor of 2 higher average ammonium nitrate concentrations during the 2010-2011 winter than the 2011-2012 winter (Parworth et al., 2015). Average OA concentrations were similar between the two winters so variability in ammonium nitrate likely exerted an influence on the $\sim 50 \%$ higher average $\mathrm{PM}_{1}$ mass concentration during the 2010-2011 winter. Lower relative humidity during the 2010-2011 winter indicates that less wet deposition could also have contributed to higher $\mathrm{PM}_{1}$ aerosol mass during that winter (Parworth et al., 2015). The frequency of episodically transported biomassburning aerosol also influences $\sigma_{\mathrm{sp}}$ and $\sigma_{\mathrm{sp}}$ at SGP. Biomassburning aerosol is most prevalent in the spring, when prescribed crop burning in preparation of planting is more common. Parworth et.al. (2015) reported a much larger biomassburning aerosol influence in spring 2011 than spring 2012, primarily in March-April. Differences are observed in the mean $\sigma \mathrm{s}_{p}$ and $\sigma_{\mathrm{ap}}$ between the two springs, in addition to differences in the 50th, 75th, and 95th percentiles between the two springs (Fig. S4). Differences between the 2 years are more noticeable for $\sigma_{\mathrm{ap}}$ than for $\sigma_{\mathrm{sp}}$.

Diurnal $\sigma_{\text {ap }}$ cycle amplitudes (Fig. $4 \mathrm{~h}$ ) are near $40 \%$ for all seasons except spring $(25 \%)$. Only the summer and autumn cycles are statistically significant. Diurnal PBL height effects are clearly visible in the diurnal $\sigma_{\text {ap }}$ cycles (Fig. $4 \mathrm{~h}$ ), as is a lack of commuter influence. Similar to BND, there is no local commuter traffic that would be expected to influence AOP cycles at SGP. No obvious features are seen in the individual day of week $\sigma_{\mathrm{ap}}$ cycles (unpublished result) to indicate a possible role of interstate traffic or agricultural influences in the weekly or diurnal $\sigma_{\text {ap }}$ cycles (Fig. $4 \mathrm{~g}, \mathrm{~h}$ ). This is complicated by biased SGP $\sigma_{\text {ap }}$ observations during the weekends. The diurnal $\sigma_{\mathrm{sp}}$ cycle is insignificant for all seasons (Fig. 3h), which may reflect increased daytime photochemical processing that is somewhat less in the winter months. Larger mid-day decreases in $\sigma_{\text {ap }}$ than $\sigma_{\text {sp }}$ lead to increases in $\omega_{0}$ of $\sim 0.03$. The hemispheric backscatter fraction varies negligibly during the day. The midday increase in $\omega_{0}$ leads to more negative midday DRFE, by $\sim 3 \mathrm{~W} \mathrm{~m}^{-2} \mathrm{AOD}^{-1}$ in all and $2 \mathrm{~W} \mathrm{~m}^{-2} \mathrm{AOD}^{-1}$ in summer. The aerosol parameters related to size show contrasting trends. No visible diurnal or weekly trend is apparent in $b$ while $\alpha_{\text {sp }}$ shows a decline with larger aerosol in the early evening. The trend in declining afternoon $\alpha_{\mathrm{sp}}$ values starts earlier in the day during the winter and is weakest during the summer and spring.

\subsection{Regional variability of aerosol optical properties}

Regional differences in some annually averaged AOPs (Fig. 2; Table S5) are unbiased by single months or seasons. $\mathrm{PM}_{1} \sigma_{\mathrm{sp}}$ is highest at BND and lowest at EGB, with annual-mean $\sigma_{\mathrm{sp}} 70 \%$ higher at BND than at EGB (Fig. 2a). The regional differences in $\sigma_{\mathrm{sp}}$ reflect the fact that the upper midwestern US is more anthropogenically influenced than the other three regions, with more large population centers, high concentrations of coal-burning power plants, higher volumes of traffic, and more agricultural activity. Spak and Holloway (2009) concluded that " $\mathrm{PM}_{2.5}$ is a year-round air quality problem in the upper midwestern US and southern Canada, driven by nitrate in the winter, sulfate in the summer, and ammonium, OA, EC, and other components yearround". The largest winter $\sigma_{\mathrm{sp}}$ peak at BND may be due to higher levels of regional ammonium nitrate precursors and cold, humid winter conditions favorable for ammonium nitrate production in the upper midwestern US, where winter ammonium nitrate concentrations are higher than almost all other regions in the US (Hand et al., 2012b). The annual $\sigma_{\mathrm{sp}}$ cycle at APP (Fig. 2a) is driven almost completely by the seasonality of regional SOA and sulfate production (Goldstein et al., 2009; Hidy et al., 2014) due to the lack of urban influence on AOPs at APP. Both SGP and EGB are located downwind at times from large urban centers, but both sites receive only a small anthropogenic contribution from all but southerly wind sectors. More frequent polluted air masses from the south may be the reason for higher $\sigma_{\mathrm{sp}}$ at SGP than at EGB for all but summer months (Figs. 7a and 8a).

$\mathrm{PM}_{1}$ aerosol contributes a larger fraction to $\mathrm{PM}_{10} \sigma_{\mathrm{sp}}$ and $\sigma_{\text {ap }}$ at APP than at BND and SGP, as evidenced by higher $R_{\text {sp }}$ (Fig. 2c) and higher $R_{\mathrm{ap}}$ (Fig. S8c). Both $R_{\mathrm{sp}}$ and $R_{\mathrm{ap}}$ are the highest at APP for all months. The regional differences in $R_{\text {sp }}$ are significant for all months (Fig. 2c). Differences in $R_{\text {ap }}$ between APP and BND are only significant for NovemberMarch (Fig. S8c). The regional differences in $R_{\mathrm{sp}}$ and $R_{\mathrm{ap}}$ are likely due to a larger influence of soil dust to $\mathrm{PM}_{10}$ AOPs at SGP and BND. Sea salt concentrations are minimal in all three regions, and soil dust concentrations are higher in the agriculturally influenced midwestern US and southern Great Plains than in the Appalachian mountain region (Hand et al., $2012 b)$. Given the higher density of forests near EGB than near BND and SGP, it is likely that $R_{\mathrm{sp}}$ and $R_{\mathrm{ap}}$ would be higher at EGB (if measured there) than at SGP and BND. A larger regional agricultural influence near EGB than near APP may give rise to $R_{\mathrm{sp}}$ and $R_{\mathrm{ap}}$ that are slightly lower than those at APP. Other indicators of aerosol size distribution $\left(\mathrm{PM}_{1} b\right.$ and $\left.\mathrm{PM}_{10} \alpha_{\mathrm{sp}}\right)$ also follow similar seasonal cycles 
at BND and SGP (Fig. 2d and g). One notable difference is lower $\alpha_{\text {sp }}$ at SGP (by $\sim 0.3$ ) for nearly all months. Similar $R_{\mathrm{sp}}$ and $b$ values but different $\alpha_{\mathrm{sp}}$ could be indicative of differences in the larger part of the accumulation mode (particle diameters close to $1 \mu \mathrm{m})$. APP and EGB have very similar $b$ values for warm-season months (May-October), which is likely due to large biogenic SOA influences during the warm season in both regions (Goldstein et al., 2009; Link et al., 2015; Leaitch et al., 2011; Slowik et al., 2010). The highest annually averaged $b$ at APP amongst the sites (Fig. 2d) is influenced by cold-season months (November-April). EGB is influenced by large, highly scattering $\mathrm{PM}_{1}$ particles from the south during winter months (Fig. S20). Winter $\mathrm{PM}_{1}$ aerosol at APP is largely regional SOA and sulfate, with some influence from biomass-burning aerosol (Supplement to Link et al., 2015). Higher $b$ at APP during winter and the surrounding months could be due to less particle growth (photochemistry).

The differences between annually averaged $\sigma_{\text {ap }}$ among the sites is insignificant (Fig. 2b), based on $\sigma_{\text {ap }}$ precision measurement uncertainties (Table 3). Differences in monthly mean $\sigma_{\text {ap }}$ among the sites are insignificant for most months. The only exceptions are that (1) EGB $\sigma_{\text {ap }}$ is lower than APP in April and lower than APP and BND in November and (2) that SGP $\sigma_{\mathrm{ap}}$ is lower than BND in August. The annual $\sigma_{\text {ap }}$ cycle amplitudes are larger at BND and EGB than at APP and SGP. Larger $\sigma_{\text {ap }}$ increases during summer and the surrounding months at BND and EGB are consistent with higher levels of regional traffic during these months. The smaller annual $\sigma_{\text {ap }}$ cycle amplitudes at APP and SGP may be influenced by their further proximity from large urban centers. Biomass-burning aerosols also influence $\sigma_{\text {ap }}$ to some degree at APP during winter (Supplement to Link et al., 2015) and at SGP during winter and spring (Parworth et al., 2015) and may also dampen the $\sigma_{\text {ap }}$ cycles at APP and SGP. Absorption Ångström exponents (Fig. 2h) support the assertion that biomass-burning aerosol may influence winter monthly mean $\sigma_{\text {ap }}$ at APP in November-February (Cazorla et al., 2013). Monthly mean $\alpha_{\text {ap }}$, however, is not significantly greater than 1 during any other months at SGP, BND, and APP, given the $\alpha_{\text {ap }}$ measurement precision uncertainty (Table 3 ).

Annually averaged $\mathrm{PM}_{1} \omega_{0}$ and DRFE are statistically similar for APP, BND, and SGP. Lower annually averaged $\omega_{0}$ (Fig. 2e) and higher (less-negative) annually averaged DRFE (Fig. 2f) at EGB are marginally significant (at $95 \%$ confidence), and these differences are heavily biased by September and October. The simple use of annually averaged values to discuss regional $\omega_{0}$ variability (Fig. 2e) is a bit misleading, given the large seasonal $\omega_{0}$ variability at BND and EGB (and to a lesser degree-APP and SGP). Monthly averaged $\omega_{0}$ at EGB is close to 0.10 lower than that at APP and SGP during September-October and is also 0.08 lower than annually averaged $\omega_{0}$ at EGB. Single-scattering albedo differences between APP and BND are nearly this large in
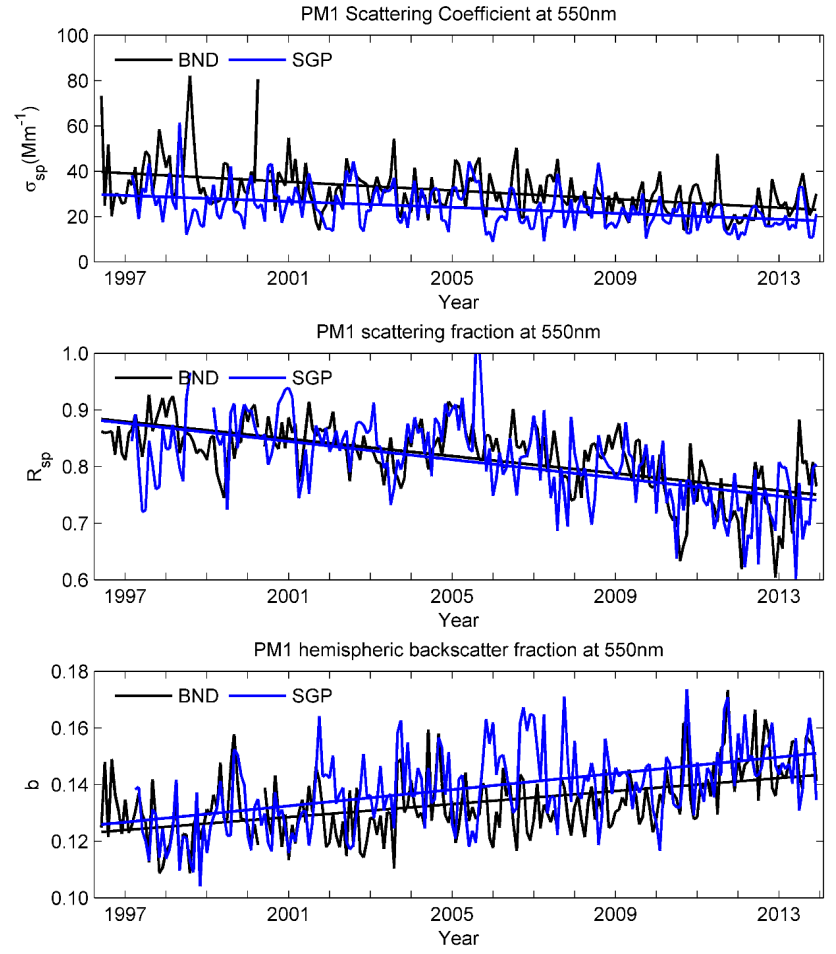

Figure 9. Time series of monthly averaged $\mathrm{PM}_{1} \sigma_{\mathrm{sp}}, R_{\mathrm{sp}}$, and $b$ at $550 \mathrm{~nm}$ for BND (1996-2013) and SGP (1997-2013). Trend lines, representing least-squared fits of the data, are also shown.

winter, despite the fact that annually averaged $\omega_{0}$ is statistically indistinguishable at the two sites. The regional $\omega_{0}$ differences are at least as large as reported $\omega_{0}$ differences among BND, SGP, and two North American coastal sites Barrow, Alaska and Sable Island, Nova Scotia (D\&O2002). In spite of the high seasonality in $\omega_{0}$ and $b$, the co-variation of these two intensive properties lead to insignificant annual DRFE cycles at APP and SGP. Larger DRFE cycle amplitudes are observed at EGB $\left(\sim 9 \mathrm{~W} \mathrm{~m}^{-2} \mathrm{AOD}^{-1}\right)$ and BND $\left(\sim 6 \mathrm{~W} \mathrm{~m}^{-2} \mathrm{AOD}^{-1}\right)$, with September-October DRFE maxima (least negative DRFE) at both sites (Fig. 2f).

\subsection{Long-term aerosol optical property trends at BND and SGP}

Trends in AOPs are calculated for the $\mathrm{PM}_{10}$ and $\mathrm{PM}_{1}$ size cuts at BND and SGP. In general, the sign of the AOP trends are the same for both size cuts, although the magnitudes of the trends differ. With the exception of $\alpha_{\mathrm{sp}}$, where the $\mathrm{PM}_{10}$ value is more meaningful, we focus on the $\mathrm{PM}_{1}$ AOP trends for consistency with the rest of the paper. Statistically significant trends in $\mathrm{PM}_{1} \sigma_{\mathrm{sp}}$ (decreasing), $R_{\mathrm{sp}}$ (decreasing), and $\mathrm{PM}_{1} b$ (increasing) are found at BND from 1996 to 2013 and at SGP from 1997 to 2013 (Table 4). Visual examination of Fig. 9 reveals that the trends in these AOPs since $\sim 2009$ are somewhat more pronounced than in earlier years, pointing 
Table 4. Mann-Kendall slopes (\%/decade) and trend significance* for long-term trends in several $\mathrm{PM}_{10}$ and $\mathrm{PM}_{1}$ aerosol optical properties measured at BND and SGP. Monthly averaged data are used for the calculations. BND data for the time period 1996-2013 are used; SGP data for the time period 1997-2013 are used. Trends that are significant at or above the $p<0.05$ level are in bold.

\begin{tabular}{|c|c|c|}
\hline & BND slope (\%/10 yr), significance & SGP Slope (\%/10 yr), significance \\
\hline$\sigma_{\mathrm{sp}, 10}$ & $-16.3, p<0.01$ & $-19.6, p<0.001$ \\
\hline$\sigma_{\mathrm{sp}, 1}$ & $-23.1, p<0.001$ & $-24.0, p<0.001$ \\
\hline$\sigma_{\mathrm{ap}, 10}$ & -15.2 , not significant & N/A \\
\hline$\sigma_{\mathrm{ap}, 1}$ & $-10.5, p<0.1$ & N/A \\
\hline$\alpha_{\mathrm{sp}, 10}$ & 1.9 , not significant & $-5.3, p<0.05$ \\
\hline$b_{10}$ & $7.6, p<0.001$ & $11.2, p<0.001$ \\
\hline$b_{1}$ & $11.8, p<0.001$ & $15.1, p<0.001$ \\
\hline$R_{\mathrm{sp}}$ & $-8.1, p<0.001$ & $-9.1, p<0.001$ \\
\hline$\omega_{0,10}$ & -0.5 , not significant & N/A \\
\hline$\omega_{0,1}$ & $-1.55, p<0.01$ & N/A \\
\hline
\end{tabular}

* Slopes and significance were obtained using the function "TheilSen" in the R package "openair" (Carslaw and Ropkins, 2012, Carslaw, 2015). Data were de-seasonalized and autocorrelation was accounted for using options supplied with the TheilSen function. Decadal slopes (\%/10 year) were calculated by multiplying the yearly slope by 10 , i.e., $10 \times \% /$ year.

out the pitfalls associated with trend analysis on short-term time series. Additionally, there is a statistically significant decreasing trend in $\mathrm{PM}_{10} \alpha_{\mathrm{sp}}$ at SGP (Table 4; Fig. S24); the BND trend in $\sigma_{\mathrm{ap}}$ is negative but not statistically significant. BND also demonstrates a slight, but statistically significant negative trend in $\omega_{0}$ (Table 4; Fig. S25). The significant decrease in $\sigma_{\mathrm{sp}}$ at both sites is consistent with other studies (CC2013; Hand et al., 2014) that reported large decreases in near-surface aerosol light scattering and light extinction coefficients in North America during the past decade. The concurrent decreasing trend in $R_{\mathrm{sp}}$ implies that scattering by $\mathrm{PM}_{1}$ is decreasing at a faster rate than scattering by super$1 \mu \mathrm{m}$ particles (which may or may not be decreasing) at both $\mathrm{BND}$ and SGP. One possible source for reductions in $\mathrm{PM}_{1}$ $\sigma_{\mathrm{sp}}$ at $\mathrm{BND}$ and $\mathrm{SGP}$ could be decreasing $\mathrm{SO}_{2}$ emissions by regional power plants. Annual $\mathrm{US} \mathrm{SO}_{2}$ emissions from power plants decreased at a rate of $\sim 6 \%$ per year from 2001 to 2010 , with similar reductions in sulfate concentrations at rural US sites (Hand et al., 2012a).

CC2013, performed trend analyses on $\sigma_{\mathrm{sp}}, \sigma_{\mathrm{ap}}, \alpha_{\mathrm{sp}}$, and $b$ at BND and SGP as part of a larger study looking at long term changes in in situ aerosol properties measured around the globe. There are several key differences between our analysis and that of CC2013 so the magnitudes of the trends should not be directly compared, but the signs of the trends (positive/negative) can be compared. Differences between the two studies include the following: (1) monthly data are used in our analysis (CC2013 used daily); (2) our trend analysis extends the data sets 3 more years past that of CC2013; (3) we report trends for both $\mathrm{PM}_{10}$ and $\mathrm{PM}_{1}$ AOPs (CC2013 used $\mathrm{PM}_{10} \mathrm{AOPs}$ ); and (4) we reference the percent slope to the first year value, while CC2013 referenced their slope to the median value of the parameter for the entire data set.

For $\sigma_{\mathrm{sp}}$ and $\sigma_{\mathrm{ap}}$, the direction (positive/negative) of the trends in CC2013 and this study are the same. CC2013 re- ported larger trends for $\sigma_{\mathrm{ap}}$ and $\sigma_{\mathrm{sp}}$ than are found here, likely due to a combination of the differences between the two analyses noted above. One noticeable difference between CC2013 and this study is that CC2013 found a statistically significant decrease in BND $\mathrm{PM}_{10} \sigma_{\mathrm{ap}}$ at the $p<0.05$ level, while the decreasing trend for $\mathrm{PM}_{10} \sigma_{\text {ap }}$ calculated here is not statistically significant. CC2013's analysis also included $b$ and $\alpha_{\mathrm{sp}}$ trends at BND and SGP. Unlike the analysis performed here, they found no statistically significant trends in either $b$ or $\alpha_{\mathrm{sp}}$ when using the Mann-Kendall test with Sen's slope (MK), although the signs of their MK slopes match what is reported in Table 4 for this study. CC2013 found significant positive trends in $b$ at both sites and a negative trend in $\alpha_{\mathrm{sp}}$ at SGP when they applied the generalized least square trend test with autoregressive bootstrap confidence intervals (GLS/ARB). CC2013 hypothesized that this discrepancy could be the result of lower sensitivity of the MK method for trends in normally distributed data. Most intensive AOPs are closer to normally distributed than are $\sigma_{\mathrm{sp}}$ and $\sigma_{\text {ap }}$, a point noted by $\mathrm{C} 2013$ and confirmed by the authors using data at the four sites reported in our study. CC2013's trend slope in $b$ using the GLS/ARB method was nearly identical in magnitude $(7.7 \% / 10$ year) to our slope for BND (Table 4), while their trend slope in $b$ at SGP was smaller (7.8\%/10 year) than our slope. The trend slope in $\alpha_{\mathrm{sp}}$ reported by CC2013 for SGP ( $-4.2 \%$ at SGP) is very similar to our trend slope (Table 4). CC2013 did not analyze trends in $\omega_{0}$.

\subsection{Systematic relationships among aerosol optical properties}

Most systematic relationships amongst AOPs are qualitatively similar for all seasons at each site and are suitably represented by the annual relationships. Several of these annual 
relationships have also been reported for BND and SGP by others (D\&O2002; Andrews et al., 2011) and most are similar to the relationships reported here for BND and SGP. We briefly summarize these relationships (Sect. 4.4.1) and highlight any differences in the BND and SGP relationships for our study period (compared to D\&O2002 and Andrews et al., 2011), in addition to any differences in the relationships at BND and SGP and those at APP and EGB, which have not been studied. Relationships involving $\alpha_{\text {ap }}$ are seasonally dependent (especially at APP) and are hence presented for individual seasons at APP, BND, and SGP in Sect. 4.4.2.

\subsubsection{Annual systematic relationships among AOPs}

Single scattering albedo increases and $b$ decreases with increasing $\sigma_{\mathrm{sp}}$ at all sites (Fig. 10a, b). Hemispheric backscatter fraction demonstrates an inverse relationship with $\omega_{0}$ over the entire $\omega_{0}$ range at EGB and for $\omega_{0}>0.85$ at the other sites (Fig. 10c), a condition representative of all months (Fig. 2d, e). The co-variability of $\omega_{0}$ and $b$ leads to a DRFE dependence on $\sigma_{\mathrm{sp}}$ that is statistically insignificant for all sites, with the exception of the lowest $\sigma_{\mathrm{sp}}$ conditions at APP (Fig. 10d). Greater influences by smaller, darker particles under lowloading conditions and by larger, brighter particles under high-loading conditions are seen in the annual $\sigma_{\mathrm{sp}}, b$, and $\omega_{0}$ cycles for the four sites in this paper (Fig. 2a, d, and e) and have been reported for SGP and BND by D\&O2002. The tendency toward lower $\omega$ o and higher $b$ for low-loading conditions is consistent with preferential removal of large, less-absorbing particles by cloud scavenging and/or wet deposition. It can also be the result of new particle formation with growth by condensation and/or coagulation to optically active sizes (Andrews et al., 2011). Scattering Ångström exponent and $R_{\mathrm{sp}}$ are both relatively insensitive to changes in $\sigma_{\mathrm{sp}}$ at APP over the entire $\sigma_{\mathrm{sp}}$ range (Fig. 10e, f). Scattering Ångström exponent is insensitive to changes in $\sigma_{\text {sp }}$ for all but the lowest aerosol loading levels at BND and SGP (Fig. 10e). $\mathrm{PM}_{1}$ scattering fraction shows a modest decrease with increasing $\sigma_{\mathrm{sp}}$ for $\sigma_{\mathrm{sp}}>20 \mathrm{Mm}^{-1}$ at BND and SGP (Fig. 10f). A similar lack of sensitivity of $\alpha_{\mathrm{sp}}$ to changes in $\sigma_{\mathrm{sp}}$ at SGP and BND was reported by D\&O2002. $\mathrm{PM}_{1}$ scattering fraction increases proportionally with $\alpha_{\mathrm{sp}}$ at APP, BND, and SGP (Fig. 10g). D\&O2002 reported similar $R_{\mathrm{sp}}$ vs. $\alpha_{\mathrm{sp}}$ relationships for SGP and BND. The fact that the $R_{\mathrm{sp}}$ vs $\alpha_{\mathrm{sp}}$ relationship is much stronger than either of their relationships with $\sigma_{\mathrm{sp}}$ suggests that $\alpha_{\mathrm{sp}}$ is a better indicator of the relative contributions of coarse and fine mode aerosol to $\mathrm{PM}_{10} \sigma_{\mathrm{sp}}$ than an indicator of average particle size-at least for APP, BND, and SGP. Based on the range of $R_{\mathrm{sp}}$ values measured at SGP, BND, and APP (Fig. 2c), the aerosol size distributions are on average bi-modal (with higher coarse mode fractions at SGP and BND than at APP) and care must be exercised when using $\alpha_{\mathrm{sp}}$ to infer average particle size or aerosol type. The $R_{\mathrm{sp}}$ vs $\alpha_{\text {sp }}$ relationship (Fig. $10 \mathrm{~g}$ ) is consistent with decreasing trends in both $R_{\mathrm{sp}}$ and $\alpha_{\mathrm{sp}}$ at SGP (Table 4) but seems in- consistent with the lack of change in $\alpha_{\mathrm{sp}}$ at BND, despite reductions in $R_{\text {sp }}$ similar in magnitude to those at SGP.

AOPs at the rural continental sites reported here have similar relationships (Fig. 10) as those at a majority of mountain sites reported on by Andrews et al. (2011). Andrews et al. (2011) also reported relationships amongst AOPs based on long-term aircraft measurements made over BND and SGP, although their free tropospheric AOP relationships for BND and SGP only extended up to $\sigma_{\mathrm{sp}} \sim 25 \mathrm{Mm}^{-1}$. Most of the free troposphere AOP relationships reported for SGP (Andrews et al., 2011) are similar to the corresponding nearsurface AOP relationships (Fig. 10), but there are some noticeable differences for BND. Andrews et al. (2011) reported the following AOP relationships as $\sigma_{\mathrm{sp}}$ increased from zero to $25 \mathrm{Mm}^{-1}$ at BND: (1) $b$ increased slightly (0.12 to 0.13 ); (2) $\omega_{o}$ remained nearly constant (less than 0.01 increase); and (3) $\alpha_{\text {sp }}$ increased by a larger amount ( $\sim 0.12$ to 0.17$)$ than in our study (Fig. 10e). The differences between these relationships and those in Fig. 10a, b, and e could be due to smaller particles that undergo less atmospheric processing (particle growth, cloud scavenging, and deposition) in the free troposphere above BND, relative to particles near the surface.

\subsubsection{Seasonal relationships involving absorption Ångström exponent}

The relationships between $\alpha_{\mathrm{ap}}$ and $\sigma_{\mathrm{sp}}$ for individual seasons and the annual relationship are most different at APP (Fig. 11a) and least different at BND (Fig. 11b). Absorption Angström exponent at APP is statistically higher than 1 $\left(\alpha_{\text {ap }} \geq 1.2\right)$ for all $\sigma_{\mathrm{sp}}$ bins during winter and is statistically lower than $1\left(\alpha_{\mathrm{ap}} \leq 0.8\right)$ for all $\sigma_{\mathrm{sp}}$ bins during summer and for higher-loading conditions $\left(\sigma_{\mathrm{sp}} \geq 50 \mathrm{Mm}^{-1}\right)$ during spring and autumn (Fig. 11a). Absorption Ångström exponent at BND (Fig. 11b) and SGP (Fig. 11c) is not statistically different from 1 for any $\sigma_{\mathrm{sp}}$ bins except for (1) summer loading $\sigma_{\mathrm{sp}} \geq 30 \mathrm{Mm}^{-1}$; and (2) spring and autumn loading $\sigma_{\mathrm{sp}} \geq 80 \mathrm{Mm}^{-1}$ (SGP only). Relationships among $\alpha_{\text {ap }}$ and intensive AOPs $\left(\alpha_{\mathrm{sp}}\right.$ and $\left.\omega_{0}\right)$ can be used to identify contributions to $\sigma_{\text {ap }}$ by sources other than BC, such as dust, OC, and coated BC (Cazorla, et al., 2013; Costabile et al., 2013; Gyawali et al., 2009). Absorption Ångström exponent exhibits a systematic decrease with increasing $\alpha_{\mathrm{sp}}$ for all seasons at SGP (Fig. 11f) and $\alpha_{\text {sp }}$ decreases in a step-wise manner for all seasons except summer at BND (Fig. 11e). The $\alpha_{\text {ap }}-\alpha_{\text {sp }}$ relationship is more complicated at APP (Fig. 11d), where $\alpha_{\text {ap }}$ demonstrates a similar decrease with increasing $\alpha_{\text {sp }}$ during summer to that observed at BND but a marginally significant increase with increasing $\alpha_{\mathrm{sp}}$ during winter. Values of $\alpha_{\text {ap }}$ that are statistically higher than $1\left(\alpha_{\mathrm{sp}} \geq 1.2\right)$ tend to be associated with $\alpha_{\mathrm{sp}} \geq 1.5$ at APP (Fig. 11d), suggesting a mix of EC and OC (Fig. 2 of Cazorla, et al., 2013). Values of $\alpha_{\mathrm{sp}} \geq 1.2$ at BND and SGP are most often associated with $\alpha_{\mathrm{sp}}<1$ (Fig. 11e, f), suggesting a mix of EC and dust (Fig. 2 of Cazorla et al., 2013). Dust influences $\sigma_{\text {ap }}$ at SGP during 
(a)

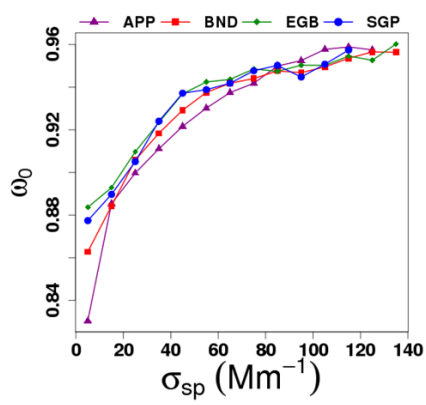

(d)

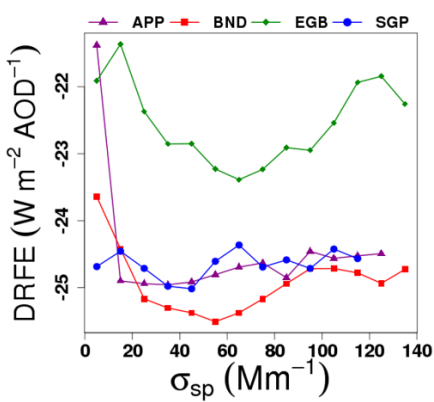

(f)

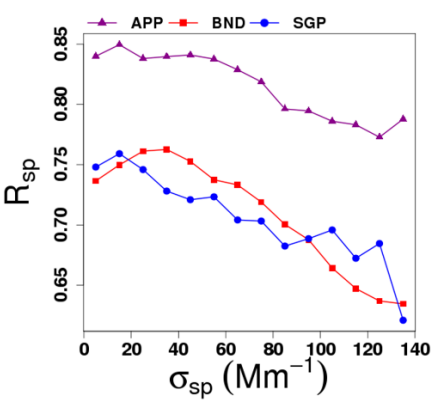

(b)

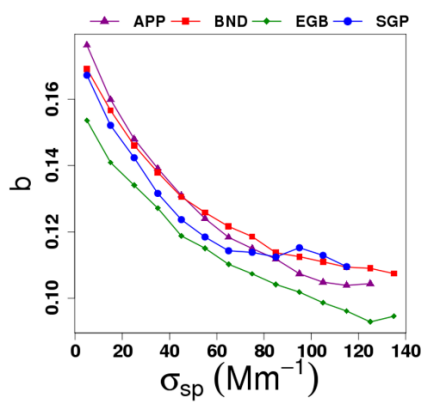

(e)

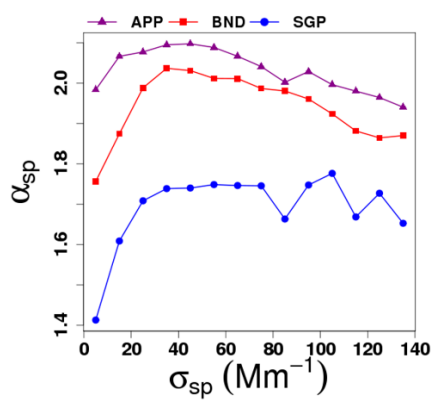

(g)

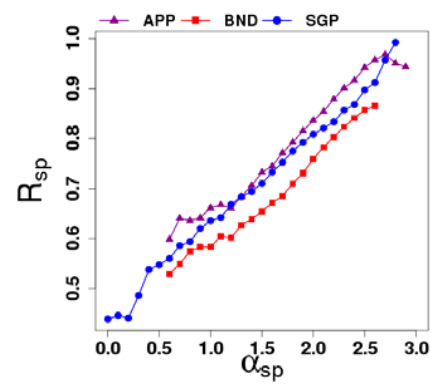

(c)

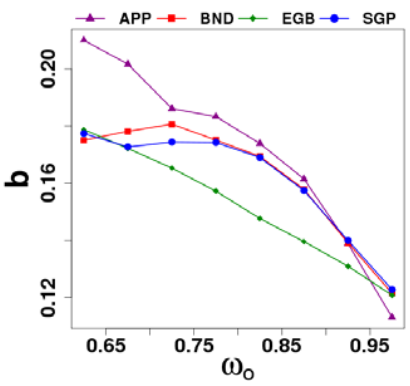

Figure 10. Systematic relationships among mean AOPs over full annual cycles of the 2010-2013 period at APP, BND, EGB, and SGP: (a) $\mathrm{PM}_{1} \omega_{0}$ vs. $\mathrm{PM}_{1} \sigma_{\mathrm{sp}}$; (b) $\mathrm{PM}_{1} b$ vs. $\mathrm{PM}_{1} \sigma_{\mathrm{sp}}$; (c) $\mathrm{PM}_{1} b$ vs. $\mathrm{PM}_{1} \omega_{0} ;$ (d) $\mathrm{PM}_{1}$ DRFE vs. $\mathrm{PM}_{1} \sigma_{\mathrm{sp}} ;\left(\right.$ e) $\mathrm{PM}_{10} \alpha_{\mathrm{sp}}$ vs. $\mathrm{PM} 1 \sigma_{\mathrm{sp}} ;$ (f) $R_{\mathrm{sp}}$ vs. $\mathrm{PM}_{1} \sigma_{\mathrm{sp}} ;$ and $(\mathrm{g}) R_{\mathrm{sp}}$ vs. $\mathrm{PM}_{10} \alpha_{\mathrm{sp}}$.

all seasons and also influences BND $\sigma_{\text {ap }}$ during autumn, as seen by the number of data points with $\alpha_{\mathrm{sp}} \geq 1.2$ and $\alpha_{\mathrm{sp}}<1$ in Fig. 11e, f. Episodic biomass burning that impacts SGP during spring (Parworth et al., 2015) also contributes to high $\alpha_{\text {ap }}$ values, which can reach $\sim 2.5$ for individual days (unpublished result). Summer values of $\alpha_{\text {ap }}$ are lower than those of other seasons for all $\alpha_{\mathrm{sp}}$ bins at BND and APP and for all but the lowest $\alpha_{\mathrm{sp}}$ bins at SGP (where dust likely influenced absorption). The slopes of the $\alpha_{\text {ap }}$ vs $\alpha_{\text {sp }}$ curves indicates that $\alpha_{\text {ap }}$ values significantly lower than 1 during summer coincide with higher fractions of fine-mode aerosol (higher $\alpha_{\mathrm{sp}}$ ).

The annual $\alpha_{\mathrm{ap}}-\omega_{0}$ relationships for all individual seasons are also most similar at BND (Fig. 11h) and least similar at
APP (Fig. 11g), where the summer and winter $\alpha_{\mathrm{ap}}-\omega_{0}$ relationships are noticeably different. Absorption Ångström exponent is lowest over the entire $\omega_{0}$ range during summer at all sites. All of the individual season $\alpha_{\text {ap }}-\omega_{0}$ curves are similar in that $\alpha_{\text {ap }}$ remains constant or slightly increasing with increasing $\omega_{0}$ until $\omega_{0}$ approaches 0.90 (specifically the $\omega_{0}$ bin centered at 0.875 ). This is followed by sharp decreases in $\alpha_{\text {ap }}$ with further increases in $\omega_{0}$. Absorption Angström exponents significantly less than $1\left(\alpha_{\mathrm{ap}} \leq 0.8\right)$ during summer months coincide with $\omega_{0} \geq 0.85$ at APP, $\omega_{0} \geq 0.90$ at BND, and $\omega_{0} \geq 0.95$ at SGP. Absorption Ångström exponent at APP is also significantly less than 1 for $\omega_{0} \geq 0.95$ during autumn. From the $b$ vs. $\omega_{0}$ relationships (Fig. 10c), 
(a)

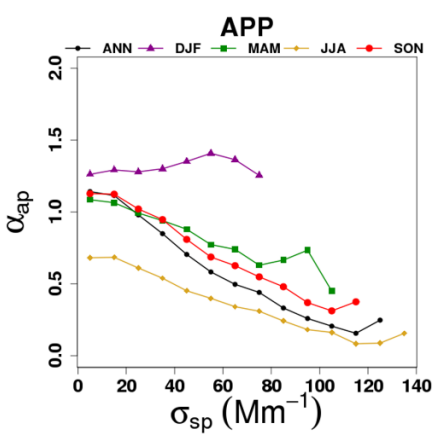

(d)

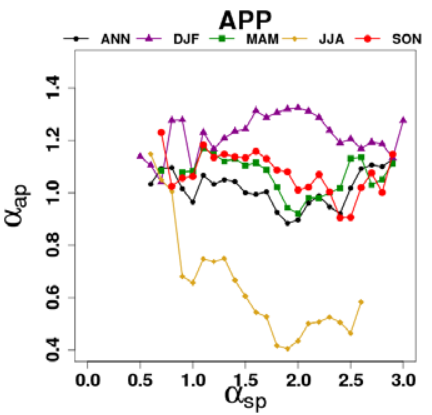

(f)

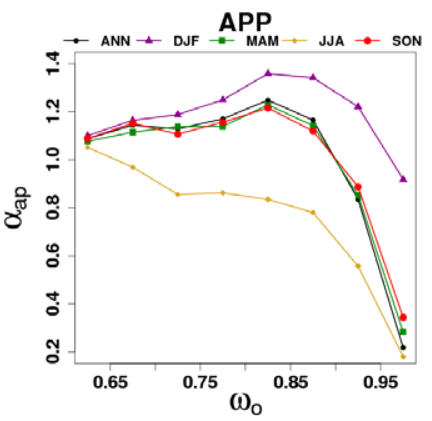

(b)

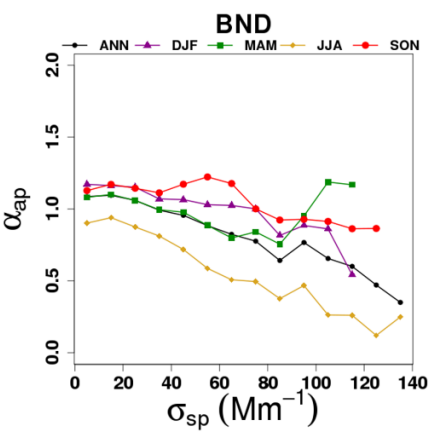

(e)

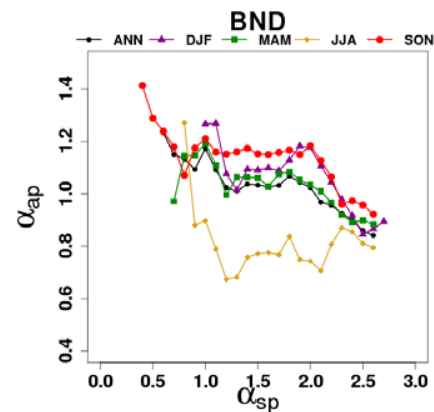

(g)

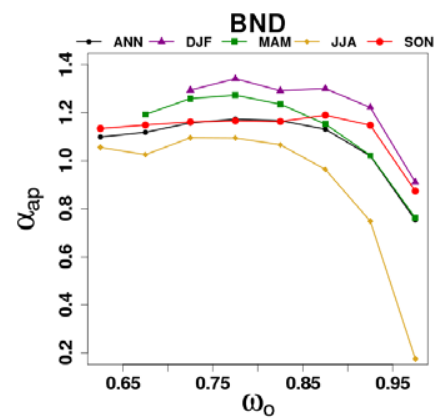

(c)

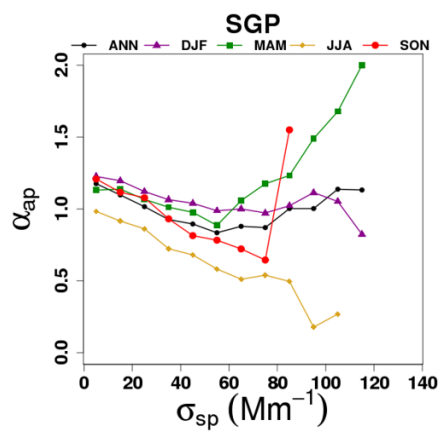

(f)

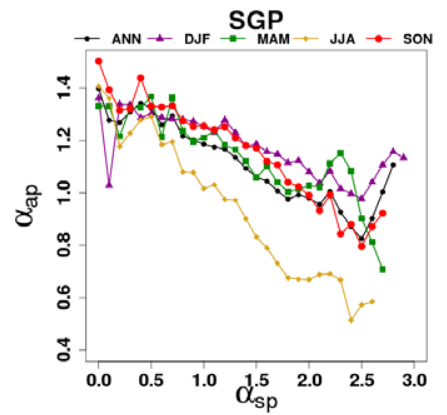

(i)

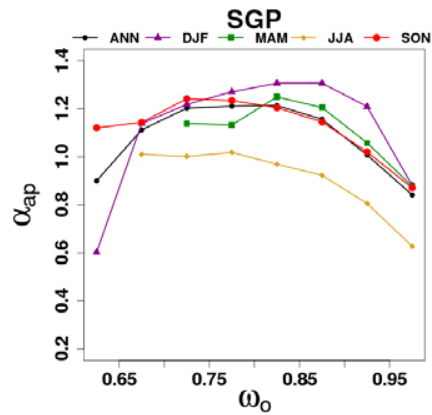

Figure 11. Systematic relationships among mean AOPs involving $\mathrm{PM}_{1}$ absorption Ångström exponent ( $\left.\alpha_{\text {ap }}\right)$ for individual seasons of the 2010-2013 period at APP, BND, and SGP: (a) $\alpha_{\text {ap }}$ vs. $\sigma_{\mathrm{sp}}$ at APP; (b) $\alpha_{\text {ap }}$ vs. $\sigma_{\mathrm{sp}}$ at BND; (c) $\alpha_{\mathrm{ap}}$ vs. $\sigma_{\mathrm{sp}}$ at SGP; (d) $\alpha_{\mathrm{ap}}$ vs. $\alpha_{\mathrm{sp}}$ at APP; (e) $\alpha_{\text {ap }}$ vs. $\alpha_{\text {sp }}$ at BND; (f) $\alpha_{\text {ap }}$ vs. $\alpha_{\text {sp }}$ at SGP; (g) $\alpha_{\text {ap }}$ vs. $\omega_{0}$ at APP; (h) $\alpha_{\text {ap }}$ vs. $\omega_{0}$ at BND; (i) $\alpha_{\text {ap }}$ vs. $\omega_{0}$ at SGP.

the lower mean $\alpha_{\text {ap }}$ values at all sites during summer also coincide with lower mean $b$ values. When combined, these relationships indicate that lower $\alpha_{\text {ap }}$ values are associated with larger, less-absorbing, fine-mode particles. Gyawali et al. (2009) reported a similar $\alpha_{\mathrm{ap}}-\omega_{0}$ relationship for summer months with no biomass-burning influence in Reno, NV. Single-scattering albedo was near constant $\left(\alpha_{\text {ap }} \sim 1.1-1.2\right)$ up to $\omega_{0} \sim 0.90$, followed by $\alpha_{\text {ap }}$ values mostly below one for higher $\omega_{0}$. Gyawali et al. (2009) attributed this wavelength dependence of absorption to EC particles coated with nonabsorbing organic and inorganic matter. It should be noted that Gyawali et al. (2009) used a photo-acoustic spectrometer, as compared to the filter-based techniques that are em- ployed at the sites in this study. Gyawali et al. (2009) also used different wavelengths (405 and $870 \mathrm{~nm}$ ) so the results are not directly comparable. The summer values of $\alpha_{\text {ap }}$ at APP are also much lower for all $\omega_{0}$ than those reported by Gyawali et al. (2009). Possible biases in filter-based absorption measurements made in high-OA environments could in principle contribute to this result (e.g., Lack et al., 2008, 2009). A detailed analysis of the effects, both real and artifact, of absorbing and non-absorbing coatings on the wavelength dependence of light absorption by black carbon is beyond the scope of this paper. 


\section{Summary and conclusions}

Seasonal variability of nearly all $\mathrm{PM}_{1}$ AOPs is generally much larger than weekly and diurnal AOP variability at the APP, BND, EGB, and SGP surface aerosol monitoring stations. All sites exhibit summer $\sigma_{\mathrm{sp}}$ maxima (Fig. 2a) and broader summer $\sigma_{\text {ap }}$ maxima (Fig. 2b). Secondary winter peaks in $\sigma_{\mathrm{sp}}$ are observed at all sites except APP and coincide with minimum $\sigma_{\mathrm{ap}}$. Scattering coefficient is lowest at all sites except APP during autumn. Low autumn $\sigma_{\mathrm{sp}}$ coincides with $\omega_{0}$ minima (Fig. 2e) and $b$ maxima (Fig. 2d) at all sites. In spite of the high seasonality in $\omega_{0}$ and $b$, the co-variation of these two intensive properties lead to insignificant annual DRFE cycles at APP and SGP. Larger DRFE cycle amplitudes are observed at EGB $(\sim 40 \%)$ and BND $(\sim 25 \%)$, with September-October DRFE maxima (least negative DRFE) at both sites (Fig. 2f). Regional differences in annual mean AOPs are in general much less than their seasonal variability at individual sites (Fig. 2), requiring that studies of regional AOP variability be conducted on a seasonal basis. Amplitudes of diurnal and weekly cycles in $\sigma_{\mathrm{ap}}$ at the sites (Fig. 4) are larger for all seasons than those of $\sigma_{\mathrm{sp}}$ (Fig. 3), with the largest differences occurring in summer. The weekly and diurnal cycle amplitudes of most intensive AOPs are minimal in most cases, especially those related to parameterizations of aerosol size distribution. Statistically significant trends in $\sigma_{\mathrm{sp}}$ (decreasing), $R_{\mathrm{sp}}$ (decreasing), and $b$ (increasing) are found at BND from 1996 from 2013 and at SGP from 1997 to 2013 (Table 4). A statistically significant decreasing trend in $\alpha_{\mathrm{sp}}$ is also observed for SGP but not BND.

Systematic relationships among $\omega_{0}, \sigma_{\mathrm{sp}}$ and $b$ (Fig. 10a-d) show that high aerosol loading conditions are associated with larger, less-absorbing particles and that low aerosol loading conditions are associated with smaller, more-absorbing particles for all sites and seasons. These relationships are consistent with other studies (D\&O2002; Andrews et al., 2011) and suggest the influences of particle growth, wet deposition, and cloud/fog scavenging of larger, less-absorbing particles on $\sigma_{\mathrm{sp}}$ and $b$ (Andrews et al., 2011). Systematic relationships among $\alpha_{\mathrm{ap}}, \sigma_{\mathrm{sp}}$, and $\alpha_{\mathrm{sp}}$ (Fig. 11a-f) suggest that aerosol light absorption is largely due to EC for all sites and seasons, with the exception of a mixture of EC and light-absorbing OC during winter at APP. Dust and OC likely influence $\sigma_{\mathrm{ap}}$ episodically at SGP (Fig. 11c and f). The $\alpha_{\mathrm{ap}}-\alpha_{\mathrm{sp}}$ relationships for SGP (Fig. 11f) and BND (Fig. 11e) are consistent with a mixture of EC and dust for the majority of higher $\alpha_{\mathrm{ap}}$ values $\left(\alpha_{\mathrm{sp}} \geq 1.2\right)$ at SGP during all seasons and BND during autumn. The relationships between $\alpha_{\mathrm{ap}}$ and $\omega_{0}$ indicate that values of $\alpha_{\text {ap }}$ significantly less than 1 are associated with weakly absorbing particles. When combined with the $\omega_{0}-b$ relationships (Fig. 10c), the confluence of low $\alpha_{\text {ap }}$, high $\omega_{0}$, and low $b$ may suggest an influence of coated EC on low $\sigma_{\text {ap }}$ during summer (Gyawali et al., 2009). More detailed studies involving aerosol chemistry and size distributions are clearly needed to state this more definitively.
Many general features of the annual $\sigma_{\mathrm{sp}}$ and $\sigma_{\mathrm{ap}}$ cycles and the weekly and diurnal $\sigma_{\mathrm{ap}}$ cycles at the sites are explained (Sect. 4.1.1-4.1.5) in a self-consistent manner using the following: (1) pollution-rose diagrams showing the seasonality of pollution transport (Figs. 5-8); (2) published aerosol chemistry at the sites (Link et al., 2015; Parworth et al., 2015; Yang et al., 2011 and references therein; Buzcu-Guven et al., 2007); (3) temperature dependence of some known regional $\sigma_{\mathrm{sp}}$ sources; and (4) reported seasonality of PBL heights for the regions. One exception deals with the $\sigma_{\text {ap }}$ cycles at APP. The influence of local traffic is seen in the APP diurnal $\sigma_{\text {ap }}$ cycles (Fig. 4b) and possibly the weekly $\sigma_{\text {ap }}$ cycles (Fig. 4a). Local and regional wood-burning influence during winter is also consistent with reported aerosol chemistry at APP (Supplement to Link et al., 2015) and with winter-month $\alpha_{\text {ap }}$ values (Fig. 2h) and their relationship with $\alpha_{\mathrm{sp}}$ (Fig. 11d). However, neither of these sources nor the seasonality of transport of moderately elevated $\sigma_{\text {ap }}$ from the northeast (Fig. 5b) adequately explain the annual $\sigma_{\text {ap }}$ cycle at APP. More studies are also needed to better understand the differences in $\sigma_{\mathrm{ap}}$ and $\sigma_{\mathrm{sp}}$ cycle amplitudes on weekly and diurnal timescales, especially in summer. The potential influence of photochemistry on the annual $\sigma_{\mathrm{sp}}$ cycles is consistent with published aerosol chemistry at the sites. We hypothesize that local photochemical aerosol production could also provide the large daytime source of scattering aerosols during summer and surrounding months that counteracts diurnal PBL height variation, leading to much smaller diurnal cycles in $\sigma_{\mathrm{sp}}$ than $\sigma_{\mathrm{ap}}$. However, the available data sets in this study are not sufficient to test this hypothesis. Relationships between AOPs and meteorology are also necessary to better understand the effects of atmospheric processing on AOPs at the four sites and their annual and diurnal cycles.

\section{The Supplement related to this article is available online at doi:10.5194/acp-15-12487-2015-supplement.}

Acknowledgements. Funding for obtaining and evaluating the data came from the DOE ARM program, NOAA Climate Program Office, Appalachian State University College of Arts and Sciences, and Environment Canada, Atmospheric Science and Technology Directorate. We thank the technicians, students, and support staff at all the sites for the dedication and diligence, 24/7/365, required to produce the data sets reported here. The authors also thank the two anonymous reviewers for their many helpful suggestions for improving the manuscript.

Edited by: P. Laj 


\section{References}

Anderson, T. L. and Ogren, J. A.: Determining aerosol radiative properties using the TSI 35631400 integrating nephelometer, Aerosol Sci. Technol., 29, 57-69, 1998.

Anderson, T. L., Covert, D. S., Wheeler, J. D., Harris, J. M., Perry, K. D., Trost, B. E., Jaffe, D. J., and Ogren, J. A.: Aerosol backscatter fraction and single-scattering albedo: Measured values and uncertainties at a coastal station in the Pacific Northwest, J. Geophys. Res., 104, 26793-26807, doi:10.1029/1999JD900172, 1999.

Anderson, T. L., Masonis, S. J. Covert, D. S., Ahlquist, N. C., Howell, S. G., Clarke, A. D., and McNaughton, C. S.: Variability of aerosol optical properties derived from in situ aircraft measurements during ACE-Asia, J. Geophys. Res., 108, 8647, doi:10.1029/2002JD003247, 2003.

Andreae, M. O., Jones, C. D., and Cox, P. M.: Strong present-day aerosol cooling implies a hot future, Nature, 435, 1187-1190, 2005.

Andrews, E., Sheridan, P. J., Ogren, J. A., and Ferrare, R.: In situ aerosol profiles over the Southern Great Plains cloud and radiation test bed site: 1. Aerosol optical properties, J. Geophys. Res. 109, D06208, doi:10.1029/2003JD004025, 2004.

Andrews, E., Ogren, J. A., Bonasoni, P., Marinoni, A., Cuevas, E., Rodriguez, S., Sun, J. Y., Jaffe, D. A., Fischer, E. V., Baltensperger, U., Weingartner, E., Collaud Coen, M., Sharma, S., Macdonald, A. M., Leaitch, W. R., Lin, N.-H., Laj, P., Arsov, T., Kalapov, I., Jefferson, A., and Sheridan, P.: Climatology of aerosol radiative properties in the free troposphere, Atmos. Res., 102, 365-393, 2011.

Bae, M., Schaur, J. J., DeMinter J. T., and Turner, J. R.: Hourly and daily patterns of particulate- phase organic and elemental carbon concentrations in the urban atmosphere, J. Air Waste Manage., 54, 823-833, doi:10.1080/10473289.2004.10470957, 2004.

Bergstrom, R. W., Russell, P. B., and Hignett, P. B.: The Wavelength Dependence of Black Carbon Particles: Predictions and Results from the TARFOX experiment and Implications forthe Aerosol Single Scattering Albedo, J. Atmos. Sci., 59, 567-577, 2002.

Bergstrom, R. W., Pilewskie, P., Russell, P. B., Redemann, J., Bond, T. C., Quinn, P. K., and Sierau, B.: Spectral absorption properties of atmospheric aerosols, Atmos. Chem. Phys., 7, 5937-5943, doi:10.5194/acp-7-5937-2007, 2007.

Blanchard, C. L., Tanenbaum, S., and Lawson, D. R.: Differences between weekday and weekend air pollution levels in Atlanta, Baltimore, Chicago, Dallas-Fort Worth, Denver, Houston, New York, Phoenix, Washington, DC, and surrounding areas, J. Air Waste Manage., 58, 1598-1615, doi:10.3155/10473289.58.12.1598, 2008.

Bond, T. C., Anderson, T. L., and Campbell, D.: Calibration and inter-comparison of filter- based measurements of visible light absorption by aerosols, Aerosol Sci. Technol., 30, 582-600, doi:10.1080/027868299304435, 1999.

Buzcu-Guven, B., Brown, S. G., Frankel, A., Hafner, H. J., and Roberts P. T.: Analysis and apportionment of organic carbon and fine particulate matter sources at multiple sites in the midwestern United States, J. Air Waste Manage., 57, 606-619, 2007.

Carslaw, D. C.: The openair manual - open-source tools for analysing air pollution data, Manual version 1.1-4, King's College London, UK, 2015.
Carslaw, D. C. and Ropkins, K.: openair - an R package for air quality data analysis, Environ. Modell. Softw., 27-28, 52-61, 2012.

Cazorla, A., Bahadur, R., Suski, K. J., Cahill, J. F., Chand, D., Schmid, B., Ramanathan, V., and Prather, K. A.: Relating aerosol absorption due to soot, organic carbon, and dust to emission sources determined from in-situ chemical measurements, Atmos. Chem. Phys., 13, 9337-9350, doi:10.5194/acp-13-9337-2013, 2013.

Chan, T. W., Huang, L., Leaitch, W. R., Sharma, S., Brook, J. R., Slowik, J. G., Abbatt, J. P. D., Brickell, P. C., Liggio, J., Li, S.M., and Moosmüller, H.: Observations of OM / OC and specific attenuation coefficients (SAC) in ambient fine PM at a rural site in central Ontario, Canada, Atmos. Chem. Phys., 10, 2393-2411, doi:10.5194/acp-10-2393-2010, 2010.

Clarke, A., McNaughton C., Kapustin,V., Shinozuka,V., Howell, S., Dibb, J., Zhou, J., Anderson, B., Brekhovskikh, V., Turner, H., and Pinkerton, M.: Biomass burning and pollution aerosol over North America: Organic components and their influence on spectral optical properties and humidification response, J. Geophys. Res., 112, D12S18, doi:10.1029/2006JD007777, 2007.

Collaud Coen, M., Weingartner, E., Nyeki, S., Cozic, J., Henning, S., Verheggen, B., Gehrig, R., and Baltensperger, U. Long-term trend analysis of aerosol variables at the highalpine site Jungfraujoch, J. Geophys. Res., 112, D13213, doi:10.1029/2006JD007995, 2007.

Collaud Coen, M., Andrews, E., Asmi, A., Baltensperger, U., Bukowiecki, N., Day, D., Fiebig, M., Fjaeraa, A. M., Flentje, H., Hyvärinen, A., Jefferson, A., Jennings, S. G., Kouvarakis, G., Lihavainen, H., Lund Myhre, C., Malm, W. C., Mihapopoulos, N., Molenar, J. V., O’Dowd, C., Ogren, J. A., Schichtel, B. A., Sheridan, P., Virkkula, A., Weingartner, E., Weller, R., and Laj, P.: Aerosol decadal trends - Part 1: In-situ optical measurements at GAW and IMPROVE stations, Atmos. Chem. Phys., 13, 869894, doi:10.5194/acp-13-869-2013, 2013.

Costabile, F., Barnaba, F., Angelini, F., and Gobbi, G. P.: Identification of key aerosol populations through their size and composition resolved spectral scattering and absorption, Atmos. Chem. Phys., 13, 2455-2470, doi:10.5194/acp-13-2455-2013, 2013.

Delene, D. J. and Ogren, J. A.: Variability of aerosol optical properties at four North American surface monitoring sites, J. Atmos. Sci., 59, 1135-1150, 2002.

Delle Monache, L., Perry, K. D., Cederwall, R. T., and Ogren, J. A.: In Situ Aerosol Profiles Over the Southern Great Plains Cloud and Radiation Test Bed Site: 2. Effects of Mixing Height on Aerosol Properties, J. Geophys. Res., 109, D06209, doi:10.1029/2003JD004024, 2004.

Dubovik, O., Smirnov, A., Holben, B. N., King, M. D., Kaufman, Y. J., Eck, T. F., and Slutsker, I.: Accuracy assessments of aerosol optical properties retrieved from Aerosol Robotic Network (AERONET) Sun and sky radiance measurements, J. Geophys. Res., 105, 9791-9806, 2000.

Dubovik, O., Holben, B., Eck, T. F., Smirnov, A., Kaufman, Y. J., King, M. D., Tanre, D., and Slutsker, I.: Variability of absorption and optical properties of key aerosol types observed in worldwide locations, J. Atmos. Sci., 59, 590-607, 2005.

Goldstein, A. H., Koven, C. D., Heald, C. L., and Fung, I. Y.: Biogenic carbon and anthropogenic pollutants combine to form a cooling haze over the southeastern United States, P. Natl. Acad. 
Sci. USA, 106, 8835-8840, doi:10.1073/pnas.0904128106, 2009.

Guenther, A., Karl, T., Harley, P., Wiedinmyer, C., Palmer, P. I., and Geron, C.: Estimates of global terrestrial isoprene emissions using MEGAN (Model of Emissions of Gases and Aerosols from Nature), Atmos. Chem. Phys., 6, 3181-3210, doi:10.5194/acp-63181-2006, 2006.

Gyawali, M., Arnott, W. P., Lewis, K., and Moosmüller, H.: In situ aerosol optics in Reno, NV, USA during and after the summer 2008 California wildfires and the influence of absorbing and non-absorbing organic coatings on spectral light absorption, Atmos. Chem. Phys., 9, 8007-8015, doi:10.5194/acp-9-8007-2009, 2009.

Hand, J. L., Schichtel, B. A., Malm, W. C., and Pitchford, M. L.: Particulate sulfate ion concentration and $\mathrm{SO}_{2}$ emission trends in the United States from the early 1990s through 2010, Atmos. Chem. Phys., 12, 10353-10365, doi:10.5194/acp-1210353-2012, 2012a.

Hand, J. L., Schichtel, B. A., Pitchford, M. L., Malm, W. C., and Frank, N. H.: Seasonal composition of remote and urban fine particulate matter in the United States, J. Geophys. Res., 117, D05209, doi:10.1029/2011JD017122, 2012b.

Hand, J. L., Schichtel, B. A., Pitchford, M. L., Malm, W. C., and Frank, N. H.: Spatial and temporal trends in $\mathrm{PM}_{2.5}$ organic and elemental carbon across the United States, Advances in Meteorology, 2003, 367674, doi:10.1155/2013/367674, 2013.

Hand, J. L., Schichtel, B. A., Malm, W. C., Copeland, S., Molenar, J. V., Frank, N., and Pitchford, M.: Widespread reductions in haze across the United States from the early 1990s through 2011, Atmos. Environ., 94, 671-679, doi:10.1016/j.atmosenv.2014.05.062, 2014.

Haywood, J. M. and Shine, K. P.: The effect of anthropogenic sulfate and soot aerosol on the clear sky planetary radiation budget, Geophys. Res. Lett., 22, 603-606, doi:10.1029/95GL00075, 1995.

Hidy, G. M., Blanchard, C. L., Baumann, K., Edgerton, E., Tanenbaum, S., Shaw, S., Knipping, E., Tombach, I., Jansen, J., and Walters, J.: Chemical climatology of the southeastern United States, 1999-2013, Atmos. Chem. Phys., 14, 11893-11914, doi:10.5194/acp-14-11893-2014, 2014.

Holzworth, G. C.: Estimates of mean maximum mixing depths in the contiguous United States, Mon. Weather. Rev., 92 235-242, 1964.

Kahn, R. A., Yu, H., Schwartz, S. E., Chin, M., Feingold, G., Remer, L. A., Rind, D., Halthore, R., and DeCola, P.: Introduction, in: Atmospheric Aerosol Properties and Climate Impacts, A Report by the US Climate Change Science Program and the Subcommittee on Global Change Research, edited by: Chin, M., Kahn, R. A., and Schwartz, S. E., National Aeronautics and Space Administration, Washington, D.C., USA, 2009.

Koloutsou-Vakakis, S., Carrico, C. M., Kus, P., Rood, M. J., Li, Z., Shrestha, R., Ogren, J. A., Chow, J. C., and Watson, J. G.: Aerosol properties at a midlatitude Northern Hemisphere continental site, J. Geophys. Res., 106, 3019-3032, doi:10.1029/2000JD900126, 2001.

Lack, D. A., Cappa, C. D., Covert, D. S., Baynard, T., Massoli, P., Sierau, B., Bates, T. S., Quinn, P. K., Lovejoy, E. R., and Ravishankara, A. R.: Bias in Filter-Based Aerosol Light Absorption Measurements Due to Organic Aerosol Loading: Evidence from
Ambient Measurements, Aerosol Sci. Technol, 42, 1033-1041, doi:10.1080/02786820802389277, 2008.

Lack, D. A., Cappa, C. D., Cross, E. S., Massoli, P., Ahern, A. T., Davidovits, P., and Onasch, T. B.: Absorption Enhancement of Coated Absorbing Aerosols: Validation of the Photo-Acoustic Technique for Measuring the Enhancement, Aerosol Sci. Technol, 43, 1006-1012, doi:10.1080/02786820903117932, 2009.

Leaitch, W. R., Macdonald, A. M., Brickell, P. C., Liggio, J., Siostedt, S. L., Vlasenko, A., Bottenheim, J. W., Huang, L., Li, S., Liu, S. K., Toom-Sauntry, D., Hayden, K. A., Sharma, S., Shantz, N. C., Wiebe, H. A., Zhang, W., Abbatt, J., Slowik, J. G., Chang, R., Russell, L. M., Schwartz, R. E., Takahama, S., Jayne, J. T., and $\mathrm{Ng}, \mathrm{N}$.: Temperature response of the submicron organic aerosol from temperate forests, Atmos. Environ., 45, 6696-6704, 2011.

Levy, R. C., Remer, L. A., Kleidman, R. G., Mattoo, S., Ichoku, C., Kahn, R., and Eck, T. F.: Global evaluation of the Collection 5 MODIS dark-target aerosol products over land, Atmos. Chem. Phys., 10, 10399-10420, doi:10.5194/acp-10-10399-2010, 2010.

Li, J., Carlson, B. E., Dubovik, O., and Lacis, A. A.: Recent trends in aerosol optical properties derived from AERONET measurements, Atmos. Chem. Phys., 14, 12271-12289, doi:10.5194/acp14-12271-2014, 2014.

Liggio, J., Li, S.,Vlasenko, A., Siostedt, S. L.,Chang, R., Shantz, N., Abbatt, J., Slowik, J. G., Bottenheim, J. W., Brickell, P. C., Stroud, C., and Leaitch, R. R.: Primary and secondary organic aerosols in urban air masses intercepted at a rural site, J. Geophys. Res., 115, D21305, doi:12010JD0144260.1029, 2010.

Link, M. F., Zhou, Y., Taubman, B. F., Sherman, J. P., Sive, B. C., Morrow, H., Krintz, I., Robertson, L., Cook, R., Stocks, J., and West, M.: A characterization of volatile organic compounds and secondary organic aerosol at a mountain site in the southeastern United States Estimating background secondary organic aerosol in the southeastern United States from a regionally representative site, J. Atmos. Chem, 72, 81-104, doi:10.1007/s10874-0159305-5, 2015.

Malm, W. C., Schichtel, B. A., Pitchford, M. L., Ashbaugh, L. L., and Eldred, R. A.: Spatial and monthly trends in speciated fine particle concentration in the United States, J. Geophys. Res, 109, D03306, doi:10.1029/2003JD003739, 2004.

Müller, T., Henzing, J. S., de Leeuw, G., Wiedensohler, A., Alastuey, A., Angelov, H., Bizjak, M., Collaud Coen, M., Engström, J. E., Gruening, C., Hillamo, R., Hoffer, A., Imre, K., Ivanow, P., Jennings, G., Sun, J. Y., Kalivitis, N., Karlsson, H., Komppula, M., Laj, P., Li, S.-M., Lunder, C., Marinoni, A., Martins dos Santos, S., Moerman, M., Nowak, A., Ogren, J. A., Petzold, A., Pichon, J. M., Rodriquez, S., Sharma, S., Sheridan, P. J., Teinilä, K., Tuch, T., Viana, M., Virkkula, A., Weingartner, E., Wilhelm, R., and Wang, Y. Q.: Characterization and intercomparison of aerosol absorption photometers: result of two intercomparison workshops, Atmos. Meas. Tech., 4, 245-268, doi:10.5194/amt-4-245-2011, 2011.

Murphy, D. M., Capps, S. L., Daniel, J. S., Frost, G. J., and White, W. H.: Weekly patterns of aerosol in the United States, Atmos. Chem. Phys., 8, 2729-2739, doi:10.5194/acp-8-2729-2008, 2008.

Murphy, D. M., Chow, J. C., Leibensperger, E. M., Malm, W. C., Pitchford, M., Schichtel, B. A., Watson, J. G., and White, W. H.: Decreases in elemental carbon and fine particle mass 
in the United States, Atmos. Chem. Phys., 11, 4679-4686, doi:10.5194/acp-11-4679-2011, 2011.

Ogren, J. A.: Comment on "Calibration and Intercomparison of Filter-Based Measurements of Visible Light Absorption by Aerosols", Aerosol Sci. Technol., 44, 589-591, doi:10.1080/02786826.2010.482111, 2010.

Ogren, J. A., Wendell, J. Sheridan, P. J., Hageman, D., and Jefferson, A.: Continuous light absorption photometer performance, ASR Science Team Meeting, Potomac, Md, USA, 18-21 March 2013, available at: http://asr.science.energy.gov/meetings/stm/ posters/view?id=781 (last access: 26 October 2014), 2013.

Parworth C., Fast, J, Mei, F., Shippert, T., Sivaraman, C., Tilp, A., Watson, T., and Zhang, Q.: Long-term measurements of submicrometer aerosol chemistry at the Southern Great Plains (SGP) using an aerosol chemical speciation monitor (ACSM), Atmos. Environ., 106, 43-55, 2015.

Rupakheti, M., Leaitch, R., Lohmann, U., Hayden, K., Brickell, P., Lu, G., Li, S., Toom-Sauntry, D., Bottenheim, J. W., Brook, J. R., Vet, R., Jayne, J. T., and Worsnop, D. R.: An Intensive Study of the Size and Composition of Submicron Atmospheric Aerosols at a Rural Site in Ontario, Canada, Aerosol Sci. Tech., 39, 722736, doi:10.1080/02786820500182420, 2005.

Schuster, G. L., Dubovik, O., and Holben, B. N.: Angstrom exponent and bimodal aerosol size distributions, J. Geophys. Res., 111, D07207, doi:10.1029/2005JD006328, 2006.

Seinfeld, J. H. and Pandis, S. N.: Atmospheric chemistry and physics: from air pollution to climate change, 2nd edition, John Wiley \& Sons, New York, USA, 1998.

Sheridan, P. J. and Ogren, J. A.: Observations of the vertical and regional variability of aerosol optical properties over central and eastern North America, J. Geophys. Res., 104, 16793-16805, doi:10.1029/1999JD900241, 1999.

Sheridan, P. J., Delene, D. J., and Ogren, J. A.: Four years of continuous surface aerosol measurements from the Department of Energy's Atmospheric Radiation Measurement Program Southern Great Plains Cloud and Radiation Testbed site, J. Geophys. Res., 106, 20735-20747, doi:10.1029/2001JD000785, 2001.

Sheridan, P. J., Jefferson, A., and Ogren, J. A.: Spatial variability of submicrometer aerosol radiative properties over the Indian Ocean during INDOEX, J. Geophys. Res., 107, 8011, doi:10.1029/2000JD000166, 2002.

Sheridan, P. J., Andrews, E., Ogren, J. A., Tackett, J. L., and Winker, D. M.: Vertical profiles of aerosol optical properties over central Illinois and comparison with surface and satellite measurements, Atmos. Chem. Phys., 12, 11695-11721, doi:10.5194/acp12-11695-2012, 2012.

Slowik, J. G., Stroud, C., Bottenheim, J. W., Brickell, P. C., Chang, R. Y.-W., Liggio, J., Makar, P. A., Martin, R. V., Moran, M. D., Shantz, N. C., Sjostedt, S. J., van Donkelaar, A., Vlasenko, A., Wiebe, H. A., Xia, A. G., Zhang, J., Leaitch, W. R., and Abbatt, J. P. D.: Characterization of a large biogenic secondary organic aerosol event from eastern Canadian forests, Atmos. Chem. Phys., 10, 2825-2845, doi:10.5194/acp-10-2825-2010, 2010.
Spak, S. N. and Holloway, T.: Seasonality of speciated aerosol transport over the Great Lakes region, J. Geophys. Res., 114, D08302, doi:10.1029/2008JD010598, 2009.

US Census Bureau: 2006-2010 American Community Survey, available at: http://www.census.gov/acs/www/ (last access: 3 January 2012), 2010.

van de Hulst, H. C.: Light scattering by small particles, John Wiley and Sons, New York, USA, 1957.

Wiscombe, W. J. and Grams, G. W.: The backscattered fraction in two-stream approximations, J. Atmos. Sciences, 33, 2440-2451, 1976.

WMO: WMO/GAW Aerosol Measurement procedures guidelines and recommendations, World Meteorological Organization, Technical Document No. 1178, GAW Report No. 153, Geneva, Switzerland, 2003.

Yang, F., Huang, L., Sharma, S., Brook, J. R., Zhang, W., Li, S., and Tan, J.: Two-year observations of fine carbonaceous particles in variable sampling intervals, Atmos. Environ., 45, 2418-2426, 2011.

Yoon, J., von Hoyningen-Huene, W., Kokhanovsky, A. A., Vountas, M., and Burrows, J. P.: Trend analysis of aerosol optical thickness and Ångström exponent derived from the global AERONET spectral observations, Atmos. Meas. Tech., 5, 12711299, doi:10.5194/amt-5-1271-2012, 2012.

Yu, H., Kaufman, Y. J., Chin, M., Feingold, G., Remer, L. A., Anderson, T. L., Balkanski, Y., Bellouin, N., Boucher, O., Christopher, S., DeCola, P., Kahn, R., Koch, D., Loeb, N., Reddy, M. S., Schulz, M., Takemura, T., and Zhou, M.: A review of measurement-based assessments of the aerosol direct radiative effect and forcing, Atmos. Chem. Phys., 6, 613-666, doi:10.5194/acp-6-613-2006, 2006.

Yu, H., Quinn, P. K., Feingold, G., Remer, L. A., Kahn, R. A., Chin, M., and Schwartz, S. E.: Remote Sensing and In Situ Measurements of Aerosol Properties, Burdens, and Radiative Forcing, in Atmospheric Aerosol Properties and Climate Impacts, A Report by the US Climate Change Science Program and the Subcommittee on Global Change Research, edited by: Chin, M., Kahn, R. A., and Schwartz, S. E., National Aeronautics and Space Administration, Washington, D.C., USA, 2009.

Zhang, X., Hecobian, A., Zheng, M., Frank, N. H., and Weber, R. J.: Biomass burning impact on $\mathrm{PM}_{2.5}$ over the southeastern US during 2007: integrating chemically speciated FRM filter measurements, MODIS fire counts and PMF analysis, Atmos. Chem. Phys., 10, 6839-6853, doi:10.5194/acp-10-6839-2010, 2010. 